Zweiter Beratungsgegenstand:

\title{
Das Verfassungsrecht vor den Herausforderungen der Globalisierung
}

1. Bericht von Professor Dr. Georg Nolte, München*

Inhalt

I. Aspekte der Globalisierung . . . . . . . . . . . . . . 130

II. Herausforderungen im Recht der Sicherheit . . . . . . . 132

1. Die gezielten Sanktionen des VN-Sicherheitsrates ... 132

2. Reaktionsmuster bei der Terrorbekämpfung außerhalb der VN .................. 139

3. Widersprüchliche Tendenzen? . . . . . . . . . . 142

4. Wirkkraft der Grundrechte bei Sachverhalten mit erheblicher Auslandsberührung . . . . . . . . . . 143

III. Allgemeine Herausforderungen für das Verfassungsrecht und seine Wissenschaft . . . . . . . . . . . . . 145

1. Globalisierung als Katalysator für historisierende und vergleichende Selbstreflexion . . . . . . . . . . 146

2. Anstöße für Differenzierungen im materiellen Verfassungsrecht . . . . . . . . . . . . . 149

3. Auslöser veränderter Rollenverständnisse von Gerichten

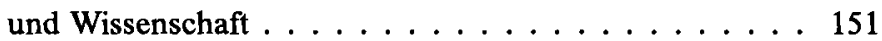

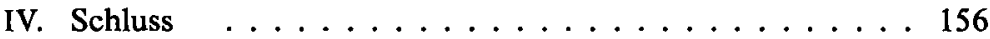

* Ich danke dem Wissenschaftskolleg zu Berlin und seinen Mitarbeitern für die schönen Bedingungen bei der Einarbeitung, sowie meinen Münchener Mitarbeitern, insbesondere Helmut Aust, Carla Thies und Nina Naske, für Nachforschungen und andere technische Hilfe. 


\section{Aspekte der Globalisierung}

„Das“ Verfassungsrecht vor den Herausforderungen „der“ Globalisierung! Das Thema ist wahrlich weitgespannt. Dies selbst dann, wenn man den Begriff „des" Verfassungsrechts auf den des deutschen Verfassungsrechts begrenzen wollte und "die" Globalisierung als bloß faktisches Phänomen begreifen würde. Aber das Verfassungsrecht anderer Staaten sollte ebenso wenig ausgeblendet werden wie mögliches überstaatliches Verfassungsrecht. Und „die“ Globalisierung würde verkürzt, wenn man nicht auch ihre subjektive Seite $^{1}$ und ihren normativen Niederschlag berücksichtigen würde. ${ }^{2}$

"Die“ Globalisierung hat auch materiell viele Aspekte. ${ }^{3}$ Man kann drei Dimensionen unterscheiden: das Grundphänomen der wirtschaftlich-technisch-kommunikativen Verflechtungsprozesse mit ihrer Relativierung der Rolle des Staates und dem Aufstieg anderer Akteure; die mehr oder weniger "normale“ Verarbeitung dieser Verflechtungsprozesse auf politischer, sozialer und kultureller Ebene; sowie schließlich die Pathologien dieser Prozesse, etwa Staatszerfall, globaler Terrorismus, wirtschaftlich-soziale Notlagen und Umweltzerstörung.

Welche dieser Dimensionen „der“ Globalisierung am wichtigsten ist, weiß ich nicht. ${ }^{4}$ Ich weiß nur, dass bei der Beantwortung dieser Frage Akzentverschiebungen stattgefunden haben. $\mathrm{Zu}$ Beginn der neunziger Jahre stand der wirtschaftlich-technisch-kommunikative Aspekt im Vordergrund. Es herrschte nicht nur im Westen ein liberaler Optimismus

\footnotetext{
1 C. Möllers Globalisierte Jurisprudenz, ARSP Beiheft Nr. 79, 2001, 41 (48) spricht von "Selbstwahrnehmungsphänomen".

${ }^{2} A$. von Bogdandy Demokratie, Globalisierung, Zukunft des Völkerrechts - eine Bestandsaufnahme, ZaöRV 63 (2003), 853 (854 ff); M. Ruffert Die Globalisierung als Herausforderung an das Öffentliche Recht, 2004, 12, 20 und 30f.

${ }^{3}$ Bericht des VN-Generalsekretärs, General Globalization and Interdependence, UN Doc. A/62/150, http://www.un.org/esa/coordination/GlobalizationReport\%202007. FINAL.website.pdf (zuletzt aufgerufen am 26. 09. 2007); $U$. Beck Was ist Globalisierung?, 1997, 17 ff., $42 \mathrm{ff}$.; $R$. Dahrendorf Anmerkungen zur Globalisierung, in: U. Beck (Hrsg.) Perspektiven der Weltgesellschaft, 1998, 41 (43 ff.), 53; A. Peters Global Constitutionalism in a Nutshell, FS Delbrück, 2005, 535 (537).

${ }^{4}$ C. Möllers Globalisierte Jurisprudenz (Fn. 1), 46 und 48 verzichtet bewußt auf eine Definition; die Vielschichtigkeit des Prozesses betonen auch $A$. von Bogdandy Demokratie (Fn. 2), 854; R. Michaels Welche Globalisierung für das Recht? Welches Recht für die Globalisierung?, RabelsZ 69 (2005) 526; kritisch gegenüber der Neigung zu „unterkomplexen Prophetien“ $R$. Wahl Der einzelne in der Welt jenseits des Staates, Der Staat 40 (2001), 45 (55).
} 
vor. ${ }^{5}$ Die Dialektik von Globalisierung und Fragmentierung war allerdings schon damals in Bürgerkriegen schmerzhaft erkennbar geworden. ${ }^{6} \mathrm{Ab}$ Mitte der neunziger Jahre wurden politische, soziale und kulturelle Rückwirkungen der Globalisierung stärker empfunden. Es regte sich Widerstand gegen bestimmte wirtschaftlich-soziale Konsequenzen, die ihr zugeschrieben wurden. ${ }^{7}$ Seit Beginn unseres Jahrzehnts drängt der Sicherheitsaspekt auch in den westlichen Staaten in den Vordergrund und droht sich mit dem kulturellen zu vermischen. ${ }^{8}$ Jüngst hat die Bundeskanzlerin erklärt, Deutschland habe die Globalisierung bewältigt. ${ }^{9}$ Damit hat sie aber wohl nur einen begrenzten wirtschaftlichen Anpassungsprozeß politisch überhöht.

Wer das komplexe Verhältnis von Globalisierung und Verfassungsrecht so breit vermessen möchte, wie es Aspekte der Globalisierung gibt, wird sich schnell in Einzelheiten, Allgemeinplätzen oder weltanschaulichen Bekenntnissen verlieren. Deshalb möchte ich zunächst einige Problemkonstellationen aus einem bestimmten Rechtsgebiet erörtern und erst in deren Licht allgemeinere Überlegungen anstellen. Als Referenzgebiet ziehe ich das Recht der Sicherheit heran. In den letzten Jahren ist deutlich geworden, dass sich typische Herausforderungen der Globalisierung für das Verfassungsrecht zugespitzt und in größtmöglicher juristischer Schärfe im Recht der Sicherheit manifestieren..$^{10}$ Ich werde mich auf Fragen der Grundrechte und ihre judikative

s U. Beck, Globalisierung (Fn. 3), 35; F. Fukuyama Das Ende der Geschichte, 1992, $75 \mathrm{ff} ., 383 \mathrm{ff}$.

6 Bericht des VN-Generalsekretärs, An Agenda for Peace, UN Doc. A/47/277 S/24111, 11, 17, 19, 50, abrufbar unter http://www.un.org/Docs/SG/agpeace.html (zuletzt aufgerufen am 26. 09. 2007).

7 J. Gray False Dawn: The Delusions of Modern Capitalism, 1998; J. Guéhenno Das Ende der Demokratie, 1994; U. Beck Globalisierung (Fn. 3), 33 ff.; O. Höffe Demokratie im Zeitalter der Globalisierung, 2002, 15.

8 Vgl. World Summit Outcome, UN Doc. A/RES/60/1, 7-9, 14, 16, 69-72, abrufbar unter http://daccessdds.un.org/doc/UNDOC/GEN/N05/487/60/PDF/N0548760.pdf? OpenElement (zuletzt aufgerufen am 26. 09. 2007).

9 Vgl. die Vorab-Veröffentlichung des Plenarprotokolls der 111. Sitzung des Deutschen Bundestages vom 12. 9. 2007, TOP 2, abrufbar unter http://www.bundestag.de/ bic/plenarprotokolle/plenarprotokolle/16111.html (zuletzt aufgerufen am 15. 10. 2007); nur angedeutet werden können die Fragen, ob die bisherige Globalisierung als Amerikanisierung begriffen werden kann, dazu S. Sur The State between Fragmentation and Globalization, EJIL 3 (1997), 421; C. Möllers Globalisierte Jurisprudenz (Fn. 1), 52, und ob sich angesichts des Aufstiegs wichtiger nicht-westlicher Staaten und Regionen ein neuartiger globaler Kontext entwickelt.

10 Dieser Aspekt des Rechts der Sicherheit hatte bei der Tagung der Vereinigung im Jahr 2003 und für die Referate von W. Brugger und C. Gusy zum Thema „Gewähr- 
Sicherung konzentrieren sowie auf die Rolle, die die Wissenschaft des Öffentlichen Rechts in diesem Zusammenhang spielt.

\section{Herausforderungen im Recht der Sicherheit}

Die Gewährleistung von Sicherheit ist die elementare Staatsfunktion. ${ }^{11}$ Der Verfassungsstaat hat die Aufgabe, Sicherheit in Freiheit zu gewährleisten. ${ }^{12}$ Nach den Weltkriegen hielten es die allermeisten Staaten für erforderlich, Sicherheit vor äußeren Bedrohungen auch durch das kollektive Sicherheitssystem der Vereinten Nationen gewährleisten zu lassen. Der moderne globale Terrorismus hat die Grenzen zwischen äußerer und innerer Sicherheit fließend werden lassen. ${ }^{13}$ Dieser Terrorismus und seine global koordinierte Bekämpfung fordern das Verfassungsrecht in seiner Kernfunktion heraus.

\section{Die gezielten Sanktionen des VN-Sicherheitsrates}

Am offensichtlichsten ist dies bei den sog. gezielten Sanktionen des VN-Sicherheitsrats. ${ }^{14}$ Kann es für die EU/EG und ihre Mitgliedstaaten zulässig sein, Vermögen bestimmter Terrorverdächtiger ohne Anhörung zum Zweck der Gefahrenabwehr zu beschlagnahmen, weil der Sicherheitsrat dies so bestimmt hat, und zwar aufgrund eines undurchsichtigen Verfahrens, ohne eine Begründung zu geben und ohne ein gerichtliches

leistung von Freiheit und Sicherheit im Lichte unterschiedlicher Staats- und Verfassungsverständnisse“, VVdStRL 63 (2003), 101 und 151 noch kaum eine Rolle gespielt.

11 BVerfGE 49, 24 (56f.); B. Greszick Staat und Terrorismus, in: J. Isensee (Hrsg.) Der Terror, der Staat und das Recht, 2004, 55 (68); $M$. Möstl Die staatliche Garantie für die öffentliche Sicherheit und Ordnung, 2002, 3; P.-T. Stoll Sicherheit als Aufgabe von Staat und Gesellschaft, 2003, 3 ff.; G. Hermes Das Grundrecht auf Schutz von Leben und Gesundheit, 1987, $148 \mathrm{ff}$; $J$. Isensee Das Grundrecht auf Sicherheit, 1983, $3 \mathrm{ff}$.

12 W. Brugger Gewährleistung von Freiheit und Sicherheit (Fn. 10); C. Gusy Gewährleistung von Freiheit und Sicherheit (Fn. 10); C. Calliess, Sicherheit im freiheitlichen Rechtsstaat, ZRP 2002, 1-7.

${ }^{13}$ H. Münkler Elemente einer neuen Sicherheitsarchitektur, IP 62 (2007), Heft 5, 6; C. Calliess Auswärtige Gewalt, HStR IV, 2006, $\$ 83$, Rn. 3 ff.; $M$. Möstl Die staatliche Garantie (Fn. 11), $277 \mathrm{ff}$.

14 Überblick bei $B$. Fassbender Targeted Sanctions Imposed by the UN Security Council and Due Process Rights, International Organizations Law Review 3 (2006), 437. 
Rechtsschutzverfahren zur Verfügung zu stellen ${ }^{15}$ Damit ist eine Variante der Identitätsfrage gestellt, die das deutsche Verfassungsrecht seit der ersten Solange-Entscheidung beschäftigt hat. ${ }^{16}$ Diese Variante dürfte auch das Bundesverfassungsgericht noch beschäftigen. Viele möchten die Grundsätze, die im deutschen Verfassungsrecht gegenüber der EU/EG entwickelt worden sind, auf das Verhältnis zu den VN übertragen. So wie das Bundesverfassungsgericht eine Sensibilisierung der europäischen Ebene für den Grundrechtsschutz herbeigeführt habe, so müsse nun auch bewirkt werden, dass die globale Ebene einen Grundrechtsschutz entwickelt, der dem nationalen oder europäischen Standard „im wesentlichen vergleichbar" ist. ${ }^{17}$

Die Herausforderung für das Verfassungsrecht - und seine Wissenschaft - besteht meines Erachtens nun aber gerade darin zu klären, ob der im europäischen Kontext erfolgreiche Lösungsansatz auch tatsächlich auf das Verhältnis zur globalen Ebene übertragen werden kann und sollte. ${ }^{18}$ Manche Unterschiede lassen da zögern: Auf der VNEbene gibt es - noch - keinen fachlichen Spruchkörper, mit dem ein europäisches oder mitgliedstaatliches Gericht ein „Kooperationsverhältnis“ aufbauen könnte. ${ }^{19}$ Der Sicherheitsrat selbst ist ein politisches

$15 \mathrm{Vgl}$. die Resolutionen des UN-Sicherheitsrates von S/RES/1267 (1999) bis S/RES/1730 (2006) sowie die Richtlinien für das Verfahren des Sanktionsausschusses: Guidelines of the Committee for the Conduct of its Work, abrufbar unter http://www.un.org/sc/committees/1267/pdf/1267_guidelines.pdf (zuletzt abgerufen am 21. 08. 2007).

16 BVerfGE 37,$271 ; 73,339 ; 89,155 ; 102,147$.

${ }^{17}$ So etwa $U$. Haltern Gemeinschaftsgrundrechte und Antiterrormaßnahmen der UNO, JZ 2007, 537 (545 und 547); G. Biehler Individuelle Sanktionen der Vereinten Nationen und Grundrechte, AVR 41 (2003), 169 (180f.); S. Schmahl Effektiver Rechtsschutz gegen „targeted sanctions“ des UN-Sicherheitsrats?, EuR 41 (2006) 566 (574); $V$. Röben Außenverfassungsrecht - Eine Untersuchung zur auswärtigen Gewalt des offenen Staates, 2007, 492f.; siehe auch A. von Arnauld UN-Sanktionen und gemeinschaftsrechtlicher Grundrechtsschutz, AVR 44 (2006), 201 (208) und C. Möllers Das EuG konstitutionalisiert die Vereinten Nationen, EuR 41 (2006), 426 (429).

${ }_{18} \mathrm{Vgl}$. $R$. Wahl Der einzelne in der Welt jenseits des Staates (Fn. 4), $51 \mathrm{ff}$; C. Walter Grundrechtsschutz gegen Hoheitsakte internationaler Organisationen, AöR 129 (2004), 39 (66ff.).

19 Der Internationale Gerichtshof, das Hauptrechtsprechungsorgan der VN (Art. 92 SVN), kommt hierfür aufgrund seiner begrenzten Zuständigkeiten nach Art. 36 des IGH-Statuts nicht in Frage. Es ist aber nicht ausgeschlossen, dass sich auf VN-Ebene ein wenigstens gerichtsähnliches Organ herausbildet, das für die Überprüfung der Listung von Individuen zuständig sein könnte: vgl. jetzt die Einrichtung des sog. „focal point ${ }^{\alpha}$, an den sich gelistete Individuen wenden können, um ein de-listing-Verfahren anzustrengen, UN Doc. S/RES/1730 (2006). Als Beispiel hierfür könnte die Einrichtung 
Organ. ${ }^{20}$ Jede Verweigerung der Umsetzung von Beschlüssen des Sicherheitsrates unter Berufung auf eigene staatliche oder europäische Maßstäbe muss deren mögliche Folgewirkungen für das VN-Sicherheitssystem insgesamt berücksichtigen. Hierzu gehört auch die Möglichkeit illegitimer Nachahmer, die aber gleiche Rechte beanspruchen. ${ }^{21}$ Das VN-Sicherheitssystem ist erheblich antagonistischer als die Europäische Union. Dies liegt nicht nur an der höheren Zahl und der größeren Unterschiedlichkeit seiner Mitglieder, sondern auch an der Besonderheit seines Gegenstandes: Sicherheit. Selektive Umsetzungen von Sicherheitsratsresolutionen sind auch deshalb systemgefährdender, weil sie besonders starke Staaten wie die USA veranlassen können, das Ziel der für erforderlich gehaltenen Maßnahmen einseitig und unter Missachtung der Rechte und Interessen schwächerer Staaten zu erreichen. ${ }^{22}$

Damit verschärft sich die Alternative, vor der die Gerichte in Europa stehen: Anders als im innereuropäischen Verhältnis besteht bei einer Umsetzungsverweigerung gegenüber den VN die Gefahr, dass ein hoher Preis gezahlt werden muss. Der Preis bestünde in der Beschädigung dieser bestmöglich legitimierten Form universeller kollektiver Sicherheitsgewährleistung und ihre Ersetzung durch hegemoniale Mechanismen und einseitige Maßnahmen. Die VN mögen nicht immer alle Erwartungen und Hoffnungen erfüllt haben. Dies ist aber kein ausreichender Grund, den einzigen globalen Mechanismus zu beschädigen, der in rechtlich strukturierten Verfahren zeitnah global verbindliche Entscheidungen bei Friedensbedrohungen treffen kann. Dies zu vermeiden und dennoch die Identität des maßgeblichen Verfassungsrechts zu bewahren, darin liegt eine zentrale Herausforderung.

eines Expertengremiums zur Überprüfung der UNMIK-Hoheitsakte im Kosovo dienen, hierzu G. Nolte Human Rights Protection against International Institutions in Kosovo, FS Tomuschat, 2006, 245; zu den Fragen der „Architektur“ siehe auch $M$. Nettesheim, U.N. Sanctions against Individuals - A Challenge to the Architecture of European Union Governance, CMLR 44 (2007) 567-600.

${ }^{20} \mathrm{IGH}$, Conditions to Admission of a State to Membership in the United Nations, Gutachten vom 28. Mai 1948, ICJ Reports 1948, 57 (64); IGH, Questions of Interpretation and Application of the 1971 Montreal Convention arising from Aerial Incident at Lockerbie (Libyan Arab Jamahiriya v. United Kingdom), Preliminary Objections, Judgment of 27 February 1998, ICJ Reports 1998, 115.

${ }^{21}$ Zum Grundsatz der souveränen Gleichheit (Art. 2 Nr. 1 UN-Charta) C. Tomuschat International Law: Ensuring the Survival of Mankind on the Eve of a New Century, $\operatorname{RdC} 281$ (1999), $161 \mathrm{ff}$.

22 N. Krisch, Amerikanische Hegemonie und liberale Revolution im Völkerrecht, Der Staat 43 (2004) 267 (289f.); für ein sachnahes Beispiel siehe FAZ vom 22. September 2007, 11 („Amerika hat den Bogen überspannt“). 
Eine Möglichkeit, diese Herausforderung zu meistern, liegt darin anzuerkennen, dass die eigene verfassungsrechtliche Identität gegenüber dem Sicherheitsrat auf die Einhaltung eines völkerrechtlichen Mindeststandards - also jedenfalls ius cogens ${ }^{23}$ - beschränkt ist. Diesen Ansatz hat das EuG für das Gemeinschaftsrecht gewählt ${ }^{24}$ und der britische Court of Appeals in Hinblick auf die EMRK erwogen. ${ }^{25}$ Der Ansatz widerspricht allerdings dem bekannten Maßstab des Bundesverfassungsgerichts, wonach Rechtsakte internationaler Organisationen „in Deutschland“ einen Grundrechtsstandard gewährleisten müssen, der dem „des Grundgesetzes im Wesentlichen gleich zu achten sei“.26 Der Europäische Gerichtshof für Menschenrechte hat einen ähnlichen Maßstab verwendet. ${ }^{27}$ Allerdings hat der EGMR diesen allgemeinen Maßstab jüngst im Behrami und Saramati-Fall spektakulär eingeschränkt: Danach gilt das Gebot vergleichbaren Grundrechtsschutzes jedenfalls dann nicht, wenn Mitgliedstaaten - wie im Kosovo - außerhalb ihres Staatsgebiets auf der Grundlage einer einigermaßen spezifizierten Ermächtigung des VN-Sicherheitsrates handeln. Diese Ausnahme hat der Gerichtshof wesentlich mit der rechtlichen Einzigartigkeit der VN und deren Bedeutung für die Aufrechterhaltung der internationalen Sicher-

${ }^{23}$ Vgl. Art. 53, 64 des Wiener Übereinkommens über das Recht der Verträge vom 23. Mai 1969, B GBl. 1985 II, 927; allgemein zum ius cogens: C. Tomuschat/J.-M. Thouvenin (Hrsg.) The Fundamental Rules of the International Legal Order, 2006; S. Kadelbach Zwingendes Völkerrecht, 1992; A. Paulus Jus Cogens in a Time of Hegemony and Fragmentation, Nordic Journal of International Law 74 (2005), 297; A. Orakhelashvili Peremptory Norms in International Law, 2006.

${ }^{24}$ EuG, Yusuf u.a. ./. Rat der EU und Kommission der EG, Rs T-306/01, Urteil vom 21. September 2005, Slg. 2005-II, 3533; EuG, Kadi ./. Rat der EU und Kommission der EG, Rs. T-315/01, Urteil vom 21. September 2005, Slg. 2005-II, 3569; dazu ua C. Tomuschat Case Note, CMLR 43 (2006), 537; M. Kotzur Eine Bewährungsprobe für die europäische Grundrechtsgemeinschaft, EuGRZ 2006, 19; M. Payandeh Rechtskontrolle des UN-Sicherheitsrates durch staatliche und überstaatliche Gerichte, ZaöRV 66 (2006), 41; H. Aust/N. Naske Rechtsschutz gegen den UN-Sicherheitsrat durch europäische Gerichte? ZöR 61 (2006), 587.

25 Court of Appeals, $R$ (on the application of Al-Jedda) v. Secretary of State for Defence, [2006] EWCA Civ 327, Nr. 71), abrufbar unter http://alpha.bailii.org/ew/cases/ EWCA/Civ/2006/327.rtf, zuletzt aufgerufen am 22. 09. 2007).

26 Vgl. zuletzt BVerfGE 102, 147 (161 ff.); anders $F$. SchorkopfGrundgesetz und Überstaatlichkeit, 2007, 161; siehe auch BVerfG, 1 BvR 2036/05, Kammerentscheidung vom 14. 5. 2007, Rn.8.

27 EGMR, Bosphorus Hava Yollari Turizm ve Ticaret Anonim Sirketi ./. Irland, Urteil der Großen Kammer vom 30. 06. 2005, NJW 2006, 197, Nr. 155; obwohl hier Resolutionen des VN-Sicherheitsrates im Raum standen, war der Gerichtshof erkennbar bemüht, sich nur zu dem Verhältnis von Gemeinschaftsrecht und EMRK zu äußern, vgl. F. Hoffmeister Case Note, AJIL 100 (2006), 442 (448). 
heit begründet. ${ }^{28}$ Welche Tragweite diese Entscheidung hat, ist noch nicht ganz klar.

Kann man sagen, dass auch nach deutschem Verfassungsrecht gegenüber Maßnahmen des VN-Sicherheitsrats ein Sondermaßstab gilt? Dies ist begründbar, wenn man das materielle Ziel der Präambel, wonach die Bundesrepublik „von dem Willen beseelt“ ist, „dem Frieden der Welt zu dienen“, mit der institutionellen Norm des Art. 24 Abs. 2 GG zusammenliest. ${ }^{29}$ Die Vereinten Nationen werden in Art. 24 Abs. 2 GG zwar nicht ausdrücklich genannt. Diese Vorschrift setzt die Vereinten Nationen jedoch als vorrangige Grundlage und als Maßstab für alle anderen kollektiven Sicherheitssysteme und sogar für alle anderen zwischenstaatlichen Einrichtungen voraus. ${ }^{30}$ Auch wenn die junge Bundesrepublik noch nicht VN-Mitglied war und die VN-Satzung Deutschland sogar als Feindstaat behandelte, konnte niemand im Jahr 1949 erwarten, dass die Bundesrepublik oder Deutschland als Ganzes einem kollektiven Sicherheitssystem beitreten würde, das nicht VN-kompatibel wäre. Das Grundgesetz drückt in der Normkombination aus Präambel und Art. 24 Abs. 2 GG aus, dass die loyale Mitwirkung bei der VN-Friedenssicherung für die Bundesrepublik höchsten verfassungsrechtlichen Rang genießt. ${ }^{31}$ Diese Verfassungsentscheidung mag zwar keine formelle Durchgriffswirkung von Sicherheitsratsresolutionen ermöglichen, sie bewirkt aber eine besondere materielle Legitimation von VN-Entscheidungen und damit verbundener Grundrechtseinschränkungen, in welcher Form sie auch immer umgesetzt werden. ${ }^{32}$ Diese verfassungsrechtliche Legitimation rechtfertigt es, gegenüber bindenden und ermächtigenden Maßnahmen der Vereinten Nationen nicht auf den gleichen

${ }^{28}$ EGMR, Agim Behrami and Bekir Behrami ./. Frankreich und Ruzhdi Saramati ./. Frankreich, Deutschland und Norwegen, Entscheidung der Großen Kammer vom 31. 05. 2007, Nrn. $149 \mathrm{ff}$. [noch nicht in offizieller Entscheidungssammlung aufgenommen].

$29 \mathrm{Vgl}$. schon $K$. Vogel Die Verfassungsentscheidung des Grundgesetzes für eine internationale Zusammenarbeit, 1964 (=Recht und Staat, Heft 292/293), 35.

${ }^{30} \mathrm{H}$. von Mangold $t$ sprach davon, dass mit System gegenseitiger kollektiver Sicherheit „das Weltsystem der Vereinten Nationen“ gemeint gewesen sei, JÖR N.F. 1 (1951) 225; siehe auch C. Hillgruber Der Nationalstaat in der überstaatlichen Verflechtung, HStR II, 2004, $\S 32$, Rn. 129 ff. und $134 \mathrm{ff}$.

${ }^{31}$ B. Fassbender Art. 19 Abs. 4 GG als Garantie innerstaatlichen Rechtsschutzes gegen Individualsanktionen des UN-Sicherheitsrates, AöR 132 (2007), 268 (275); vgl. auch Klaus Vogel (Fn. 29), $41 \mathrm{f}$.

32 Vgl. aber I. Pernice in: R. Dreier (Hrsg.) GG II, 2. Aufl. 2006, Art. 24, Rn. 66; A. Randelzhofer in: T. Maunz/G. Dürig u. a. (Hrsg.) GG, Art. 24 II, Rn. 42 und C. Tomuschat in R. Dolzer (Hrsg.) BK, Art. 24, Rn. 153 (Zweitbearbeitung 1985). 
Standards zu bestehen wie gegenüber allen partikularen zwischenstaatlichen Einrichtungen.

Der Schutz der Menschenwürde und damit verbundener elementarer rechtsstaatlicher Mindeststandards dürfen allerdings auch gegenüber dem Sicherheitsrat nicht preisgegeben werden. ${ }^{33}$ Wann die Menschenwürde verletzt ist, ist jedoch kontextabhängig. ${ }^{34}$ Relevante Elemente dieses Kontextes sind auch Legitimation und Verfahren einer Maßnahme. Eine Kontensperrung kann eine Missachtung des Eigenwerts des Menschen ausdrücken, wenn sie von einer untergeordneten Stelle verfügt wird, aber möglicherweise nicht, wenn sie aufgrund eines formalen $\mathrm{Ab}$ stimmungsprozesses zwischen fünfzehn Regierungen nach der VN-Satzung und global sichtbar erfolgt. Gezielte Sanktionen des Sicherheitsrates eröffnen auch einen Interpretationshorizont, der es nahelegt, den Begriff der Menschenwürde am völkerrechtlichen Mindeststandard orientiert auszulegen. Das Bundesverfassungsgericht sollte die VNverfügte Sperrung eines Kontos einer Person nicht mit der Begründung aufheben, dies verstoße gegen eine in Deutschland besonders anspruchsvoll verstandene Menschenwürde. ${ }^{35}$ Stattdessen sollte das Gericht methodisch - aber nicht notwendig in der Sache - der Rechtsprechung des israelischen Supreme Court folgen. Dieses Gericht füllt die Menschenwürde im sicherheitsrechtlichen Kontext wesentlich mit Hilfe von völkerrechtlichen Standards aus. ${ }^{36}$

\footnotetext{
${ }^{33}$ BVerfGE 115, 118 (152); 115, 320 (358); 112, 1 (46) (abw. Meinung Lübbe-Wolff); 109, 279 (310); B. Fassbender (Fn. 31), 275.

${ }^{34}$ BVerfGE 30, 1 (25); 109, 279 (311); 115, 118 (153); weitergehend $M$. Herdegen in: T. Maunz/G. Dürig u.a. (Hrsg.) GG, Art. 1, Rn. 43 ff.

${ }^{35}$ So ist das BVerfG aber ansatzweise in seinem Urteil zum Luftsicherheitsgesetz vorgegangen. Dort hat es eine weite absolute Regel formuliert, ohne international anerkannte Ausnahmen zu berücksichtigen, wie etwa den Fall, dass menschliche Schutzschilde gegen eine VN-Friedenstruppe zur Begehung eines Massakers an der Zivilbevölkerung verwendet werden, vgl. N. Naske/G. Nolte Case Note, AJIL 101 (2007), 466 (469f.); siehe auch O. Lepsius Was kann die deutsche Staatsrechtswissenschaft von der amerikanischen Rechtswissenschaft lernen?, in: H. Schulze-Fielitz (Hrsg.) Staatsrechtslehre als Wissenschaft, Die Verwaltung, Beiheft 7, 2007, 319 (350ff.); zum völkerrechtlichen Verständnis von Menschenwürde $J$. Abr. Frowein Human Dignity in International Law, in: D. Kretzmer/E. Klein (Hrsg.) The Concept of Human Dignity in Human Rights Discourse, 2002, 121; M. Herdegen Verfassungsinterpretation als methodische Disziplin, JZ 2004, 873 (878f.); rechtsvergleichende Betrachtungen zur Menschenwürde bei $\boldsymbol{H}$. Dreier in: ders. (Hrsg.) GG I, 2. Aufl. 2004, Art. 1, Rn. 34 ff.; G. Bognetti The Concept of Human Dignity in European and US Constitutionalism, in: G. Nolte (Hrsg.) European and US Constitutionalism, 2005, 85 (106f.).

${ }^{36}$ Exemplarisch ist das Urteil des israelischen Supreme Court zur Folter: Public Committee Against Torture in Israel v. The State of Israel, HCJ 5100/94, Urteil vom
} 
Diese Form der völkerrechtsfreundlichen Verfassungsauslegung mag weitreichend erscheinen. ${ }^{37}$ Es ist jedoch zu bedenken, dass sich Gerichten bei der Ermittlung des völkerrechtlichen Mindeststandards, an den auch der Sicherheitsrat gebunden ist, Interpretationsspielräume bieten. Dieser Mindeststandard könnte über das zwingende Völkerrecht, ius cogens, hinaus gehen. Er könnte etwa auch aus allgemeinen völkerrechtlichen Rechtsgrundsätzen abgeleitet werden. ${ }^{38}$ Nationale Gerichte könnten auch begründen, dass die nicht-derogierbaren Menschenrechte ${ }^{39}$ und der gewohnheitsrechtliche Kernbestand des humanitären Völkerrechts $^{40}$ grundsätzlich zu diesem Mindeststandard zählen. Die Unklarheit des Völkerrechts in diesem Zusammenhang sollte nicht als Problem, ${ }^{41}$ sondern als Vorteil gesehen werden. Sie ermöglicht es den Gerichten, unbestimmte, aber konstruktiv wirkende Drohungen mit Nichtumsetzung anzudeuten, die aber nur im Not- und Einzelfall verwirklicht werden müssten. Damit könnte der bereits angelaufene Prozeß der rechtsstaatlichen Verbesserung des VN-Sanktionensystems ${ }^{42}$ in eine verallgemeinerungsfähige Richtung gelenkt werden.

Die Konkretisierung des völkerrechtlichen Mindeststandards erfolgt im Wege eines Rechtsprechungsdialogs unter internationalen und nationalen Spruchkörpern. ${ }^{43}$ Ein Begriff wie die Menschenwürde, der einen

6. September 1999; dieses und weitere einschlägige Urteile bei: Judgments of the Israel Supreme Court: Fighting Terrorism within the Law, http://www.mfa.gov.il/NR/ rdonlyres/599F2190-F81C-4389-B978-7A6D4598AD8F/0/terrorirm_law.pdf (zuletzt aufgerufen am 24.09. 2007).

${ }^{37}$ B VerfGE 111, 307 (319ff.); vgl. auch die Entscheidung zur Wiener Konsularrechtskonvention: BVerfG, Beschluss vom 19. September 2006 in den Verfahren 2 BvR 2115/01, 2 BvR 2132/01 und 2 BvR 348/03, Abs. 57 ff., hierzu M. Payandeh Die verfassungsrechtliche Stärkung der internationalen Gerichtsbarkeit, AVR 45 (2007), 244.

${ }^{38} \mathrm{Vgl}$. A. Peters Privatisierung, Globalisierung und die Resistenz des Verfassungsstaates, ARSP Beiheft Nr. 105, 2007, 100 (131); S. Kadelbach/T. Kleinlein Überstaatliches Verfassungsrecht - Zur Konstitutionalisierung im Völkerrecht, AVR 44 (2006), 235 (255 ff.).

${ }^{39} \mathrm{~S}$. Kadelbach The Identification of Fundamental Norms, in C. Tomuschat/ J.-M. Thouvenin (Hrsg.) The Fundamental Rules (Fn. 23), 21 (30); sehr weitgehend bezüglich des Inhalts des menschenrechtlichen ius cogens A. Orakhelashvili Peremptory Norms (Fn. 23), $53 \mathrm{ff}$.

40 S. Kadelbach (Fn. 39), 30f.; R. Nieto-Navia International Peremptory Norms (Jus Cogens) and International Humanitarian Law, FS Cassese, 2003, 595 (627 ff.); $R$. Kolb Jus Cogens, Intangibilité, Intransgressibilité, Derogation positive et négative, RGDIP 109 (2005), 305 (313 ff.).

${ }^{41}$ So aber F. Schorkopf Grundgesetz und Überstaatlichkeit (Fn. 26), 172 und 205.

42 UN Doc. S/RES/1730 (2006).

${ }^{43} \mathrm{Vgl}$. B. $-O$. Bryde The Constitutional Judge and the International Constitutionalist Dialogue, Tulane Law Review 80 (2005), 203; A. Nußberger Wer zitiert wen?, JZ 2006, 
Anspruch auf universal gleiches Verständnis erhebt, sollte nicht offen oder unbewußt mit partikularen Identitätsvorstellungen gefüllt werden. Das Bundesverfassungsgericht sollte, wenn nötig, mit diesem Begriff Einfluss auf den internationalen Dialog nehmen. ${ }^{44}$ Solange der Sicherheitsrat keinen gerichtlichen Rechtsschutz gegen seine Maßnahmen zur Verfügung stellt, sollten international beachtete Verfassungsrechtskulturen wie die deutsche zur Frage des globalen Mindeststandards, den auch der Sicherheitsrat nicht unterschreiten darf, verallgemeinerungsfähig Stellung beziehen. Wenn sie sich dabei am völkerrechtlichen Mindeststandard orientieren, führen sie damit nicht einen veralteten Monismus durch die Hintertür ein. Vielmehr wird dadurch ein pluralistischer Rechtskonkretisierungsprozeß ermöglicht, der die Sonderstellung der Vereinten Nationen mit der Identität des jeweiligen Verfassungsrechts bestmöglich vereinbaren kann.

\section{Reaktionsmuster bei der Terrorbekämpfung außerhalb der $V N$}

Diese Orientierung des nationalen Verfassungsrechts an internationalen Maßstäben und Dialogen spielt auch außerhalb des Bereichs der VN-Sanktionen eine Rolle. ${ }^{45}$ Der globale Terrorismus hat viele Staaten zu besonderen Anti-Terror-Maßnahmen und Gesetzgebung veranlaßt. ${ }^{46}$ Hierbei stand immer auch die Frage im Raum, ob eine Neujustierung des Verhältnisses von Freiheit und Sicherheit erforderlich sei. ${ }^{47} \mathrm{Na}$ türlich können unterschiedliche politische Systeme unterschiedliche Einschätzungen dazu entwickeln, was sicherheitsrechtlich erforderlich ist. Bemerkenswerterweise hat sich jedoch nach den Anschlägen des 11. September 2001 in Verfassungsstaaten eine im Grundansatz ver-

763; A.-M. Slaughter A New World Order?, 2004, 69ff. (,constitutional cross-fertilization“); dies. A Global Community of Courts, Harvard International Law Journal 44 (2003), 191; V. C. Jackson Constitutional Dialogue (Fn. 35), $18 \mathrm{ff}$.

${ }^{44} \mathrm{Vgl}$. A. Tschentscher Dialektische Rechtsvergleichung, JZ 2007, 807 (814f.); A.-M. Slaughter A New World Order? (Fn.43), 68.

${ }^{45} \mathrm{Vgl}$. z.B. H. Krieger Limitations on Privacy, Freedom of Press, Opinion and Assembly as a Means of Fighting Terrorism, in: C. Walter u.a. (Hrsg.) Terrorism as a Challenge for National and International Law: Security versus Liberty?, 2004, 51.

${ }^{46} \mathrm{Vgl}$. die Länderberichte in C. Walter u. a. (Hrsg.) Terrorism as a Challenge (Fn. 45) und die vergleichende Untersuchung zur Terrorismusbekämpfung in den USA und in der EU von C. Fijnaut/J. Wouters/F. Naert (Hrsg.) Legal Instruments in the Fight against International Terrorism - A Transnational Dialogue, 2004.

47 Vgl. BVerfGE 115, 320 (360): „Die Balance zwischen Freiheit und Sicherheit darf vom Gesetzgeber neu justiert, die Gewichte dürfen jedoch von ihm nicht grundlegend verschoben werden." 
gleichbare Reaktion der jeweiligen Verfassungssysteme gezeigt: Während die Exekutiven die Legislativen zunächst vielfach ohne allzu große Schwierigkeiten überzeugen konnten, dass die terroristische Bedrohung neue scharfe Maßnahmen erforderlich mache ${ }^{48}$, haben die Gerichte den Übersteigerungen solcher Tendenzen nach anfänglichem Zögern ${ }^{49} \mathrm{Wi}$ derstand entgegengesetzt..$^{50}$

Manifestiert hat sich diese Reaktion insbesondere im Vereinigten Königreich und Kanada, aber auch in kontinentaleuropäischen Ländern und sogar in den USA. ${ }^{51}$ Das House of Lords hat eine besondere Präventivhaft für terrorverdächtige abzuschiebende Ausländer für gleichheitswidrig und unverhältnismäßig erklärt.52 Dasselbe Gericht hat die Verwertung von Aussagen, die im Ausland möglicherweise unter Folter gewonnen worden sind, für Abschiebungsverfahren von Terrorverdächtigen untersagt. ${ }^{53}$ Der kanadische Supreme Court hat bei der Prüfung eines besonderen Abschiebungsverfahrens für Terrorverdächtige entscheidend darauf abgestellt, dass ein milderes Mittel im Ausland praktiziert werde und funktioniere. ${ }^{54}$ Der US Supreme Court hat die rechtsschutzlose Präventivhaft von Gefangenen in Guantanamo für einen Verstoß gegen die IV. Genfer Konvention erklärt. ${ }^{55}$ Die Reaktion der Gerichte aus den englischsprachigen Staaten ist insofern bemerkenswert, als diese Gerichte der Exekutive - und a fortiori auch der Legisla-

48 S. Less Country Report on the USA, in: C. Walter u.a. (Hrsg.) Terrorism as a Challenge (Fn. 45), 633 (675f.); M. Wagner Country Report on Canada, ebd., 173-215 (175); $K$. Roach The post-9/11 migration of Britain's Terrorism Act 2000, in: S. Choudhry (Hrsg.) The Migration of Constitutional Ideas, 2007, $374 \mathrm{ff}$; D. Dyzenhaus The Constitution of Law, 2006, 1; F. Schoch Abschied vom Polizeirecht des liberalen Rechtsstaats?, Der Staat 43 (2004), 347 (350ff.).

$49 \mathrm{Vgl}$. House of Lords, Secretary of State for the Home Department v. Rehman, [2001] 3 W.L.R. 877, dort unter Nr. 50 (Lord Hoffmann).

so E. Benvenisti United We Stand: National Courts Reviewing Counterterrorism Measures, in: A. Bianchi/A. Keller (Hrsg.), Democracy, Separation of Powers and the Fights against Terrorism, 2007, i.E., abrufbar unter http://ssrn.com/abstract $=965638$ (zuletzt aufgerufen am 18. 10. 2007), $1 \mathrm{ff}$; $J$. Ip Comparative Perspectives on the Detention of Terrorist Suspects, Transnational Law \& Contemporary Problems 16 (2007), 773.

51 Nachweise bei E. Benvenisti United We Stand (Fn. 50), $7 \mathrm{ff}$.

52 House of Lords, A (FC) and others (FC) $v$. Secretary of State for the Home Department, [2004] UKHL 56, Urteil vom 16. Dezember 2004.

53 A (FC) and others (FC) (Appellants) v. Secretary of State for the Home Department (Respondent), [2005] UKHL 71, Urteil vom 8. Dezember 2005.

54 Supreme Court of Canada, Charkaoui v. Canada (Citizenship and Immigration), 2007 S.C.C. 9, Urteil vom 23. 02. 2007, Rn. 66ff.; siehe auch schon Suresh v. Canada (Citizenship and Immigration), [2002] 1 SCR 3, [2002] S.C.C. 1.

55 US Supreme Court, Hamdan v. Rumsfeld, 126 S.Ct. 2749 (2006). 
tive - bis dahin besonders weite Einschätzungsspielräume im Bereich der nationalen Sicherheit eingeräumt hatten..$^{56}$

Solche Entscheidungen sind Ausdruck eines Trends in Verfassungsstaaten, den Menschenrechtsschutz bei der globalen Terrorbekämpfung nicht zu reduzieren, sondern zum Teil sogar noch zu stärken. ${ }^{57} \mathrm{Zu}$ diesem Trend gehören auch die Entscheidungen des Bundesverfassungsgerichts zum Europäischen Haftbefeh ${ }^{58}$ und zum Luftsicherheitsgesetz..$^{59}$ Dieser Trend dürfte sich nicht nur durch den materiellen Gehalt der Grund- und Menschenrechte erklären. Durch eine informell koordinierte Rechtsprechung in Fragen der Terrorismusbekämpfung wird auch das gemeinsame Interesse der Gerichtsbarkeit in allen Verfassungsstaaten gewahrt, einen grundrechtlichen race to the bottom und Verschiebungen im Gewaltengefüge zu vermeiden. ${ }^{60}$ Wenn die Grundrechtsprechung in unterschiedlichen Staaten nämlich erheblich voneinander abwiche, könnten die freiheitlicher judizierenden Staaten attraktiver für Terrorgruppen erscheinen. ${ }^{61}$ Jedenfalls könnte die Verantwortung für eventuell eintretende Terroranschläge dieser besonders freiheitlich judizierenden Rechtsprechung zugeschrieben werden - mit entsprechenden Folgen für deren innerstaatliche Stellung. Wenn die Gerichte in unterschiedlichen Staaten dagegen eine einigermaßen harmonische Grundtendenz verfolgen, können sie Grundrechtsstandards leichter wahren. Die Gerichte können dann auch die eigenen nationalen Exekutiven und Legislativen besser vor internationalem Druck in Richtung auf eine unangemessene Verschärfung der Sicherheitsmaßnahmen schützen. Zumindest können die Gerichte die Verantwortung der jeweiligen Exekutiven und Legislativen zu eigenständiger Prüfung der Sicherheitsanforderungen einfordern. So können die Gerichte unter Berufung auf grund- und menschenrechtlich begründete Parlamentsvorbehalte auf gründlicher demokratischer Willensbildung im nationalen Rahmen bestehen. ${ }^{62}$

56 E. Benvenisti Judicial Misgivings Regarding the Application of International Law, EJIL 4 (1993), 159 (169 ff.); H. Krieger Die gerichtliche Kontrolle von militärischen Operationen, in: D. Fleck (Hrsg.) Rechtsfragen der Terrorismusbekämpfung durch Streitkräfte, 2004, 223 (228ff.).

57 A. Barak A Judge on Judging: The Role of a Supreme Court in a Democracy, Harvard Law Review 116 (2002), 16; E. Benvenisti Reclaiming Democracy: Why National Courts (Sometimes) Take Foreign and International Law Seriously, i.E., abrufbar unter http://ssrn.com/abstract=1007453 (zuletzt aufgerufen am 18. 10. 2007).

58 BVerfGE 113, 273.

\$9 BVerfGE 115, 118.

${ }^{60}$ E. Benvenisti Reclaiming Democracy (Fn. 57), 26.

${ }^{61}$ E. Benvenisti Reclaiming Democracy (Fn. 57), $9 \mathrm{ff}$.

${ }^{62}$ E. Benvenisti Reclaiming Democracy (Fn. 57), 25 ff. m.w.N. 


\section{Widersprüchliche Tendenzen?}

Ist diese - begrüßenswerte - internationale Entwicklung mit meiner These zu vereinbaren, dass die eigenen deutschen oder europäischen Identitätsvorstellungen bei der Frage des Rechtsschutzes gegenüber Maßnahmen des VN-Sicherheitsrats nicht vorschnell aus naheliegenden Mustern heraus übertragen werden sollten, sondern dass das reduzierte Schutzniveau eines völkerrechtlichen Mindeststandards gilt? Diese Frage kann man meines Erachtens bejahen, wenn man zwei Faktoren berücksichtigt: Der Sicherheitsrat ist von der VN-Satzung - und damit grundsätzlich auch verfassungsrechtlich legitimiert - als Notstandsinstanz konzipiert, die bei Friedensbedrohungen handelt. Soweit nationale Instanzen Notstandsbefugnisse gar nicht in Anspruch nehmen, wie dies bislang in Kanada und Deutschland der Fall gewesen ist, hat sich für sie von vornherein keine vergleichbare verfassungsrechtliche Frage gestellt. ${ }^{63}$ Soweit nationale Instanzen aber wohl Notstandsbefugnisse in Anspruch nehmen, können nationale und regionale Gerichte die Erforderlichkeit ihrer Ausübung besser prüfen, als sie Maßnahmen des VNSicherheitsrats prüfen können. ${ }^{64}$ Dem Sicherheitsrat müssen Einschätzungsspielräume gewährt werden.

Hinzu kommt, dass Entscheidungen des Sicherheitsrates in Hinblick auf breiter gestreute globale Bedrohungen weniger panikanfällig sein dürften als innerstaatliche politische Prozesse. ${ }^{65}$ Staatlich organisierte Gesellschaften lassen sich - unabhängig von ihrer Regierungsform durch neuartige Sicherheitsbedrohungen leichter zu exzessiven Reaktionen in Hinblick auf sich selbst hinreißen als fünfzehn Mitgliedstaaten des Sicherheitsrates in Hinblick auf den gesamten Globus. Die Gefahr, dass der Sicherheitsrat von den Exekutiven der beteiligten Staaten, insbesondere auf Druck der USA, missbraucht wird, um ihre jeweiligen Legislativen und Judikativen zu umgehen, halte ich demgegenüber für weniger groß. ${ }^{66}$ Dies verhindern die fortbestehende politische Konkur-

${ }^{63}$ H. Krieger in: R. Grote/Th. Marauhn (Hrsg.) EMRK/GG Konkordanzkommentar, 2006, Kapitel 8 - Notstand, Rn. 4; zur Rechtslage in Kanada $K$. Roach Terrorism, Globalization and the Rule of Law, Cardozo Law Review 27 (2006), 2151.

64 S. Chesterman The Spy Who Came in from the Cold War, Michigan Journal of International Law 27 (2006), 1071 (1109ff.).

${ }^{65}$ AA offenbar F. Schorkopf Grundgesetz und Überstaatlichkeit (Fn. 26), $253 \mathrm{f}$.

${ }^{66}$ Ein Sonderfall ist der Wunsch der Niederlande nach einer gegen sie selbst ergangenen Kapitel VII-Resolution im Kontext des Charles Taylor-Prozesses, vgl. hierzu den Brief des Ständigen Vertreters der Niederlande bei den Vereinten Nationen vom 31. März 2006 (UN Doc. S/2006/207, Annex II) und die Resolution 1688 (2006) des VN-Sicherheitsrates, dort Nrn. 7 und 8. 
renz und die typischerweise unterschiedlichen Gefahreinschätzungen der Exekutiven. Der Sicherheitsrat hat selbst unmittelbar nach den Anschlägen des 11 . September 2001, also als ein maximales internationales Verständnis für die USA und für die von ihnen für erforderlich gehaltenen Maßnahmen bei der Terrorbekämpfung bestand, keine konkreten exzessiven Maßnahmen getroffen.

\section{Wirkkraft der Grundrechte bei Sachverhalten mit erheblicher Auslandsberührung}

Unabhängig von internationaler Regelung oder Koordinierung stellt sich in vielen sicherheitsrelevanten Konstellationen die Frage nach der Wirkkraft von Grund- und Menschenrechten bei Sachverhalten mit erheblicher Auslandsberührung. ${ }^{67}$ Dies ist offensichtlich, wenn der Staat mit seinen Organen im Ausland handelt, es kann aber auch Situationen im Inland betreffen.

Die Bemühungen der Wissenschaft, für die Beurteilung solcher Konstellationen klare abstrakte Maßstäbe zu entwickeln, haben sich angesichts deren Vielfalt als vergeblich erwiesen. So ist es nicht plausibel, dass die Grundrechtswirkung immer von territorialen und personalen Anknüpfungspunkten oder von einer bestimmten Art des Unterworfenseins abhängig sein soll.68 Andererseits besteht aber Einigkeit darüber, dass die Grundrechte bei Sachverhalten mit erheblicher Auslandsberührung nicht immer so stark wirken wie bei inländisch geprägten Sachverhalten. Diese verfassungsrechtliche Grauzone ist nicht nur damit zu erklären, dass der deutsche Staat die Grundrechte außerhalb seines Hoheitsbereichs faktisch nicht vollständig durchsetzen kann, ${ }^{69}$ oder dass er hierbei völkerrechtlichen Grenzen unterliegt. ${ }^{70}$ Vielmehr kann es auch um Sachlagen gehen, die ein bestimmtes Grundrecht von seinem Sinn und Zweck her nicht oder nur begrenzt erfasst. ${ }^{71}$

${ }^{67} D$. Lorenz Der territoriale Anwendungsbereich der Grund- und Menschenrechte, 2005; H. Krieger Gerichtliche Kontrolle (Fn. 56), 223; H. Kronke Die Wirkungskraft der Grundrechte bei Fällen mit Auslandsbezug, BDGVR 38 (1998), 33; R. Hofmann Grundrechte und grenzüberschreitende Sachverhalte, 1993; G. Elbing Zur Anwendbarkeit der Grundrechte bei Sachverhalten mit Auslandsbezug, 1992.

$68 \mathrm{~J}$. Isensee Grundrechtsvoraussetzungen und Verfassungserwartungen an die Grundrechtsausübung, HStR V, 2000, $\$ 115$ Rn. $78 \mathrm{ff}$.; M. Heintzen Auswärtige Beziehungen privater Verbände, 1988, 97 ff.

69 BVerfGE 92, 26 (41f.).

70 BVerfGE 100, 313 (362); 66, 39 (57 ff.).

71 BVerfGE 100, 313 (362); 31, 58 (77); vgl. D. Lorenz Der territoriale Anwendungsbereich (Fn. 67), $175 \mathrm{f}$. 
Wenn die Bundeswehr also eine terrorverdächtige Person in Afghanistan verhaftet oder eine solche Person an die Streitkräfte oder Behörden anderer Staaten überstellt, muss die Prüfung zunächst am sachlich einschlägigen Grundrecht ansetzen. Die Freiheit der Person ändert ihren Sinn grundsätzlich nicht je nachdem, ob der Staat im Inland oder im Ausland handelt. Sie läßt aber Raum dafür, dass der Staat im Ausland gegebenenfalls auch nach Maßgabe des humanitären Völkerrechts handeln darf. Der Staat kann dann zwar höhere Standards einhalten, er muss dies aber etwa nicht tun, wenn ein operationeller Freiraum in einer multinationalen Operation völkerrechtlich vorausgesetzt wird. Dies hat auch Rückwirkungen auf die Reichweite des Parlamentsvorbehalts aus Gründen der Grundrechtsrelevanz. ${ }^{72}$

Ähnliche Kontextualisierungen ${ }^{73}$ kann es auch bei Konstellationen geben, deren Schwerpunkt im Inland liegt, etwa bei der Fernmeldeüberwachung von deutschem Boden aus in das Ausland. ${ }^{74}$ Soweit es um staatliches Handeln im Inland geht, unterliegt eine mögliche Relativierung des Grundrechtsschutzes bei Sachverhalten mit erheblicher Auslandsberührung höheren Begründungsanforderungen. Diese sind jedoch schwer in allgemeinen grundrechtsdogmatischen Kategorien auszudrücken. Sie hängen vom Sinn des einschlägigen Grundrechts ab. ${ }^{75}$

Auch wenn es in manchen Bereichen zur Fiktion wird, erscheint es grundsätzlich immer noch sinnvoll, bei Maßnahmen deutscher Staatsorgane auf deutschem Staatsgebiet von einem Inlandssachverhalt mit voller Grundrechtswirkung auszugehen. So mutet es zwar merkwürdig an, wenn sich die Verteidiger der globalisierungstypischsten Freiheit, der Freiheit zur Nutzung des Internet, gegenüber der Forderung nach Online-Durchsuchungen auch auf die traditionellsten räumlichen Katego-

72 Dies übersieht $K . U$. Voss Rechtsstaat ad hoc? - Anwendung von Gesetzesvorbehalt und Parlamentsvorbehalt bei Auslandseinsätzen der Bundeswehr, ZRP 2007, 78.

${ }^{73}$ Beispiele für eine differenzierte Herangehensweise im Kontext der extraterritorialen Grundrechtswirkung sind das Urteil des britischen Court of Appeal (Civil Division), The Queen (on the application of Hilal Abdul-Razzaq Ali Al-Jedda) ./. Secretary of State for Defence, [2006] EWCA Civ 327 und die Entscheidung des House of Lords, Al Skeini and others v. Secretary of State for Defence, [2007] UKHL 26, Urteil vom 13. Juni 2007.

74 BVerfGE 100, 313.

${ }^{75}$ Etwa bei der Frage, wieweit es für die Verwertbarkeit von Informationen einen relevanten Unterschied bedeutet, ob sie von inländischen oder von ausländischen Behörden möglicherweise unter Verstoß gegen das Folterverbot gewonnen worden sind, vgl. House of Lords, A (FC) and others (FC) (Appellants) v. Secretary of State for the Home Department (Respondent), [2005] UKHL 71, Urteil vom 8. Dezember 2005; $R$. Marx "Globaler Krieg gegen den Terrorismus“ und territorial gebrochene Menschenrechte, KJ 2006, 151 (174 ff). 
rien, Wohnung und - jedenfalls implizit - Staatsgebiet, berufen. ${ }^{76}$ Solange aber kein Staat offiziell den Anspruch erhebt, dass das Netz einschließlich der damit verbundenen Rechner - ein für alle Staaten gleichermaßen beobachtbarer Raum sei, ${ }^{77}$ kann das nationale Verfassungsrecht weiter davon ausgehen, dass die widerstreitenden Interessen „in einem Raum ausgetragen <werden>, der von der deutschen Rechtsordnung ... mit alleinigem Gültigkeitsanspruch beherrscht wird“.78

\section{Allgemeine Herausforderungen für das Verfassungsrecht und seine Wissenschaft}

Die Problemkonstellationen aus dem Recht der Sicherheit, die ich bis hier skizziert habe, illustrieren allgemeinere Herausforderungen der Globalisierung für das Verfassungsrecht und seine Wissenschaft. Ich möchte diese Beispiele allerdings nicht dazu benutzen, um alten Wein in neue Schläuche zu gießen. Fragen wie: „Stirbt der Staat und hat er seine Souveränität schon verloren?"79 oder „Sollten wir „das“ Verfassungsrecht vom Nationalstaat her denken, als europäischen Verbund, weltweit als Mehrebenensystem oder gar als Knoten in Netzwerken?“ 80 oder

${ }^{76} J$. Rux Ausforschung privater Rechner durch die Polizei- und Sicherheitsbehörden, JZ 2007, 292; B. Valerius Ermittlungsmaßnahmen im Internet, JR 2007, 279; $\boldsymbol{M}$. Kutscha Verdeckte Online-Durchsuchung und Unverletzlichkeit der Wohnung, NJW 2007, 1170.

${ }^{77}$ So auch (noch) nicht die USA: Der Foreign Intelligence Surveillance Act (50 U.S.C. $\$ \S 1801-1811,1821-29,1841-46$, and 1861-62) geht auch nach seiner Änderung durch den Protect America Act vom 3. August 2007 (Pub.L. 110-55, S. 1927) nicht so weit; so aber etwa $J$. Goldsmith The Internet and the Legitimacy of Remote Cross-Border Searches, http://papers.ssrn.com/sol3/papers.cfm?abstract_id=285732 (zuletzt aufgerufen am 25. 09. 2007), $10 \mathrm{ff}$.

$78 \mathrm{Vgl}$. BVerfGE 92, 26 (41) für die umgekehrte Situation.

${ }^{79}$ H. Steiger Geht das Zeitalter des souveränen Staates zu Ende?, Der Staat 41 (2002), 331; S. Oeter Souveränität - ein überholtes Konzept?, FS Steinberger, 2002, 259; S. Hobe Der kooperationsoffene Verfassungsstaat, Der Staat 37 (1998), 546; A. Peters Privatisierung (Fn. 38), 116; stark souveränitätsbetonend C. Hillgruber Der Nationalstaat in seiner überstaatlichen Verflechtung (Fn. 30), Rn. $36 \mathrm{ff}$.; U. Beck, Globalisierung (Fn. 3), $24 \mathrm{ff}$., 160 und 184.

${ }^{80}$ J. Kokott und T. Vesting Die Staatsrechtslehre und die Veränderung ihres Gegenstandes: Konsequenzen von Europäisierung und Internationalisierung, VVdStRL 63 (2003); I. Pernice, P. M. Huber, G. Lübbe-Wolff und C. Grabenwarter Europäisches und nationales Verfassungsrecht, VVdStRL 60 (2000); D. Grimm Die Verfassung im ProzeB der Entstaatlichung, FS Badura, 2004, 145; U. di Fabio Das Recht offener Staaten, 1998, $122 \mathrm{ff}$;; $G$. Teubner Globale Zivilverfassungen: Alternativen zur staatszentrierten Verfassungstheorie, ZaöRV 63 (2003), 3; A. Peters Privatisierung (Fn. 38), $114 \mathrm{ff}$. 
„Muß die auswärtige Gewalt neu vermessen werden?"81 hat die Vereinigung schon verhandelt. Für meine Zwecke müssen sie auch nicht unbedingt vorentschieden werden.

Statt dieser klassischen Themen möchte ich drei andere allgemeine Fragenkomplexe anreißen, und zwar: Globalisierung als Katalysator für eine historisierende und vergleichende Selbstreflexion (1.), Globalisierung als AnstoB für Differenzierungen im materiellen Verfassungsrecht (2.) und schließlich Globalisierung als Auslöser veränderter Rollenverständnisse von Gerichten und Wissenschaft (3.).

\section{Globalisierung als Katalysator für historisierende und vergleichende Selbstreflexion}

Das Recht der Sicherheit bietet für das deutsche Verfassungsrecht in besonderem $\mathrm{Ma} \beta$ Anlass, den eigenen historischen Standort angesichts eines neuen globalen Kontexts zu überdenken. Dies hatte sich schon Anfang der neunziger Jahre gezeigt, als das Bundesverfassungsgericht einen Parlamentsvorbehalt als Ausgleich für die Zulassung von Streitkräfteeinsätzen in kollektiven Sicherheitssystemen begründete. ${ }^{82}$ Eine allgemeinere Form der historisierenden Selbstreflexion im Sicherheitsbereich liegt in Überlegungen, die besondere Offenheit des Grundgesetzes sei durch den verlorenen Krieg und die Besatzungssituation bedingt ${ }^{83}$ und die exekutivfreundliche Rechtsprechung des Bundesverfassungsgerichts zur auswärtigen Gewalt sei durch die zwischenstaatlich geprägte Konstellation des Kalten Krieges erklärbar. ${ }^{84}$ Solche Überlegungen überzeugen letztlich nicht. Sie gewichten die älteren Wurzeln und das langfristig-konzeptionelle Denken der Mitglieder des Parlamentarischen Rats zu gering. ${ }^{85}$ Und sie überschätzen die Bedeutung bestimmter Sachverhaltskonstellationen, wie etwa der Nachrüstung, für die Dogmenbildung.

Wichtiger scheint mir, dass sich das deutsche Verfassungsrecht seit Beginn der neunziger Jahre auch über den Sicherheitsbereich hinaus

${ }^{81}$ K. Hailbronner, $R$. Wolfrum, L. Wildhaber und T. Öhlinger Kontrolle der auswärtigen Gewalt, VVdStRL 56 (1997).

82 BVerfGE 90, 286 (381 ff.).

${ }^{83}$ C. Hillgruber Der Nationalstaat in seiner überstaatlichen Verflechtung (Fn. 30), Rn. 114, $122 \mathrm{ff}$. und $125 \mathrm{ff}$.; F. Schorkopf Grundgesetz und Überstaatlichkeit (Fn. 26), 69; o. Lepsius Deutsche Staatsrechtslehre und amerikanische Rechtswissenschaft (Fn. 35), $357 \mathrm{f}$.

84 So etwa F. Schorkopf Grundgesetz und Überstaatlichkeit (Fn. 26), 137f., 221 und $284 \mathrm{ff}$.

85 JöR N.F. 1 (1951) 225 ff., 237. 
stärker in einem globalen Kontext wahrnimmt und sich dadurch seiner eigener Rolle und Besonderheiten bewusster geworden ist. ${ }^{86}$ Es wurde einerseits deutlich, dass das Grundgesetz seit den fünfziger Jahren von der Verfassungsgerichtsbarkeit und der Wissenschaft in einer Weise entfaltet worden war, die das deutsche Verfassungsrecht in den neunziger Jahren zu einer weltweit beachteten Referenzordnung hat werden lassen. ${ }^{87}$ Insbesondere das Verhältnismäßigkeitsprinzip ${ }^{88}$ und das Schutzpflichtkonzept mit seinen Drittwirkungsimplikationen ${ }^{89}$ sind in der Spruchpraxis internationaler Menschenrechtsorgane ${ }^{90}$ und in der Rechtsprechung ausländischer Verfassungsgerichte wieder aufgetaucht. Andererseits wurde aber auch klar, dass das deutsche Verfassungsrecht,

86 . Wahl Die zweite Phase des Öffentlichen Rechts in Deutschland, Der Staat 38 (1999), 495; U. Haltern Internationales Verfassungsrecht?, AöR 128 (2003), 512; W. Kahl Neue Entwicklungslinien der Grundrechtsdogmatik, AöR 131 (2006) 579 (582ff.).

87 P. Häberle Wechselwirkungen zwischen deutschen und ausländischen Verfassungen in: D. Merten/H.-J. Papier (Hrsg.) Handbuch der Grundrechte II, 2006, $\S 7$, Rn. 3, 11 f., 71; G. Casper The „Karlsruhe Republic“, GLJ 2 (2001), Nr. 18, Rn. 15 ff.; K. Stern Ausstrahlungswirkung des Grundgesetzes auf ausländische Verfassungen, in: Bundesministerium des Inneren (Hrsg.) Bewährung und Herausforderung, Die Verfassung vor der Zukunft, 1999, 249 (250); J. Kokott From Reception and Transplantation to Convergence of Constitutional Models, in: C. Starck (Hrsg.) Constitutionalism, Universalism and Democracy, 1999, 71 (74 und 132); M. Herdegen Verfassungsinterpretation (Fn. 35), $875 \mathrm{ff}$.

${ }^{88}$ C. Starck Grundgesetz und deutsche Verfassungsrechtsprechung im Spiegel ausländischer Verfassungsentwicklung, 1989, 28f.; K. Stern Ausstrahlungswirkung (Fn. 87), 255; C. Knill/F. Becker Divergenz Trotz Diffusion? Rechtsvergleichende Aspekte des Verhältnismäßigkeitsprinzips in Deutschland, Großbritannien und der Europäischen Union, DV 36 (2003), 447 (449, 454).

${ }^{89}$ D. Grimm The Protective Function of the State, in: G. Nolte (Hrsg.) (Fn. 35), 137 (154); H. Krieger in: R. Grote/Th. Marauhn (Fn. 63), Kap. 6, Rn. 119; G. Brunner The Constitutions of Central and Eastern European Countries and the Duty to Protect and to Ensure Human Rights, in: E. Klein (Hrsg.) The Duty to Protect and to Ensure Human Rights, 1999, 73 (86f.); P. Szczekalla Die sogenannten Schutzpflichten im deutschen und europäischen Recht, 2002, 909-975.

90 Zum Verhältnismäßigkeitsprinzip etwa EGMR, Dudgeon ./. the United Kingdom, Urteil vom 30. Januar 1981, Serie A Nr. 45, Rn. 60; Interamerikanischer Gerichtshof für Menschenrechte, Compulsory Membership in an Association Prescribed by Law for the Practice of Journalism, Serie B Nr. 5 (1985), Rn. 46; UN-Menschenrechtskommittee, General Comment Nr. 27 (1999), CCPR/C/21/Rev.1/Add.9, Rn. 14; für das Schutzpflichtkonzept vgl. die Rechtsprechungsanalyse von $H$. Krieger The Protective Function of the State, in G. Nolte (Hrsg.) (Fn. 35), 181; Inter-Amerikanische Kommission für Menschenrechte, Pueblo Bello Massacre v. Colombia, Entscheidung vom 31. 01. 2006, Serie C Nr. 134, Rn. 111; Afrikanische Kommission für Menschenrechte, Social and Economic Rights Action Center for Economic and Social Rights (SERAC) v. Nigeria, Comm. No. 155/96, Oktober 2001, Rn. 57. 
so wie es von der Rechtsprechung entfaltet worden ist, einige Merkmale aufweist, die international als Besonderheiten auffallen. Hierzu gehören eine vergleichsweise hohe verfassungsgerichtliche Kontrolldichte, ${ }^{91}$ die Reichweite des Parlamentsvorbehalts in seiner Ausprägung durch die Wesentlichkeitstheorie ${ }^{92}$ und die Anerkennung der allgemeinen Handlungsfreiheit als Grundrecht. ${ }^{93}$

Die Wahrnehmung des globalen Kontexts hat im deutschen Verfassungsrecht auch die Frage aufgeworfen, wie weit das Eigene historisch bedingt ist und neu vermessen werden sollte.94 Hatte sich die Verfassungsrechtsprechung, ,angetrieben von einer Art rechtsstaatlicher Eigenlogik“,95 in den ersten Jahrzehnten veranlasst gesehen, das Grundgesetz expansiv zu interpretieren, um eine nachkriegsbedingte Edukations- und Integrationsfunktion zu erfüllen, oder beruhte dies auf deutschem Perfektionismus, der sich in einer nach außen geschützten Wachstums- und Wohlstandsperiode ausleben konnte?96 Wenn die Schutzbereiche der Grundrechte heute nicht mehr so großzügig erweitert, ja sogar reduziert werden, und die Verhältnismäßigkeitsprüfung nicht immer mehr so empathisch beim Einzelnen ansetzt, dürfte dies auch damit zusammenhängen, dass der deutschen Verfassungsrechtsordnung bewusst wird, wie weit sie im internationalen Vergleich geht. ${ }^{97}$

91 C. Grewe Vergleich zwischen den Interpretationsmethoden europäischer Verfassungsgerichte und des Europäischen Gerichtshofs für Menschenrechte, ZaöRV 61 (2001) 463; R. Wahl Die zweite Phase (Fn. 86), 513; H. H. Klein Grundrechte am Beginn des 21. Jahrhunderts, in: D. Merten/H.-J.Papier (Hrsg.) Handbuch der Grundrechte, I, 2004, $§ 6$ Rn. 4; siehe aber auch M. Herdegen Verfassungsinterpretation (Fn. 35), 875; W. Hoffmann-Riem Kontrolldichte und Kontrollfolgen beim nationalen und europäischen Schutz von Freiheitsrechten in mehrpoligen Rechtsverhältnissen, EuGRZ 2006, 492 (496f.).

${ }^{92}$ K.-P. Sommermann Der entgrenzte Verfassungsstaat (Fn. 80), $413 \mathrm{ff}$; C. Grabenwarter/T. Marauhn in: R. Grote/T. Marauhn (Hrsg.) (Fn. 63), Kap. 7, Rn. 26; W. Kahl Entwicklungslinien (Fn. 86), 607.

$93 \mathrm{~W} . \mathrm{Kahl}$ Entwicklungslinien (Fn. 86), 611 ff., 614; H. Dreier in: ders. (Hrsg.) GG I, 2. Aufl., Art. 2 I, Rn. 19; G. Robbers Introduction to German Law, 1998, 52 f.

94 B.-O. Bryde Konstitutionalisierung des Völkerrechts und Internationalisierung des Verfassungsrechts, Der Staat 42 (2003), 61 (71ff.).

95 . Wahl Die zweite Phase (Fn. 86), $495 \mathrm{ff}$.

96 O. Lepsius Deutsche Staatsrechtslehre und amerikanische Rechtswissenschaft (Fn. 35), 358f.; C. Möllers Wandel der Grundrechtejudikatur, NJW 2005, 1973 (1978); R. Wahl Die zweite Phase (Fn. 86), 513f.; hierzu seinerseits kritisch W. Kahl Entwicklungslinien (Fn. 86), 592.

${ }^{97}$ C. Möllers Grundrechtsjudikatur (Fn. 96), 1978; W. Hoffmann-Riem Enge oder weite Gewährleistungsgehalte der Grundrechte?, in: Michael Bäuerle (Hrsg.) Haben wir wirklich Recht?, 2004, 53; R. Wahl Die zweite Phase (Fn. 86), 515. 


\section{Anstöße für Differenzierungen im materiellen Verfassungsrecht}

Wenn die Staatsverfassung heute auch im Licht „der“ Globalisierung gelesen wird, steht die Grundfrage im Raum, ob die Verfassungsinterpretation diesem Prozess nun eher defensiv oder eher offensiv begegnen soll. Zunächst ist gefragt worden, wo die Offenheit des Verfassungsstaates eine Grenze finden muss. ${ }^{98}$ Es mehren sich nun aber auch die Stimmen, welche unter Berufung auf die Relativierung des Gegensatzes von „innen“ und „außen“ für eine offensivere Auslegung der Verfassung plädieren. Der deutsche Staat müsse seine Schutzpflicht gerade auch im Ausland erfüllen und seine verfassungsrechtlichen Staatsziele auch bei seiner Außenpolitik beachten.99

Die eher defensive und die eher offensive Haltung der Verfassungsinterpretation sind keine Gegensätze, sondern ergänzen sich. Globalisierung fordert Staaten nach innen und außen heraus. Die Verfassungsgrundsätze sollten in einer Welt, in der Innen und Außen sowie Frieden und Notstand in vielen Bereichen nicht mehr klar getrennt werden können, gleichmäßiger angewendet werden. ${ }^{100}$ Gleichmäßigkeit darf dabei allerdings nicht schematisch verstanden werden, sondern muss an situativer und normativer Vergleichbarkeit orientiert sein, also skaliert verstanden werden. Zwangsmaßnahmen des VN-Sicherheitsrats sind situativ und normativ mit gewöhnlichen Rechtsakten der Europäischen Gemeinschaft eben nicht vergleichbar. Unter Umständen kann sogar der irreführende Eindruck entstehen, dass deutsche Grundrechte nach außen weitergehend gewährleistet werden müssen als nach innen. So müssen bestimmte Grundrechte auf deutschen Schiffen, also quasi auf deutschem Boden, nicht vollständig gewährleistet werden, ${ }^{101}$ andererseits dürfen deutsche Soldaten bei Friedensmissionen bestimmte andere Grundrechte der lokalen Bevölkerung unter keinen Umständen missachten. Die Erklärung für diesen Unterschied liegt, wie gesagt, nicht

98 BVerfGE 111, 307 (319); J. Isensee Integrationsziel Europastaat?, FS-Everling 1995, 567 (585 ff.); C. Hillgruber HStR II, 2004, § 32, Rn. 40 ff., 125 ff.; $F$. Schorkopf Grundgesetz und Überstaatlichkeit (Fn. 26), $229 \mathrm{ff}$. und $254 \mathrm{ff}$.

99 P.-T. Stoll Das Verfassungsrecht vor den Herausforderungen der Globalisierung, DVBl 2007, 1064 (1069); ähnlich auch T. Giegerich Grund- und Menschenrechte im globalen Zeitalter: Neubewertung ihrer territorialen, personalen und internationalen Dimension in Deutschland, Europa und den USA, EuGRZ 2004, 758, passim; skeptischer dagegen noch $K$. Hailbronner Kontrolle der auswärtigen Gewalt, VVDStRL 56 (1997), 7 (16).

100 P.-T. Stoll Verfassungsrecht (Fn. 99), 1070; K. U. Voss Rechtsstaat (Fn. 72), 78; ähnlich bereits Chr. Tomuschat, Der Verfassungsstaat im Geflecht der internationalen Beziehungen, VVdStRL 36 (1978) 7 (43).

101 B VerfGE 92, 26. 
in abstrakten Kategorien wie „innen“ und „außen“, sondern im kontextuell ermittelten Gewährleistungsgehalt der einschlägigen Grundrechte selbst. ${ }^{102}$

Dieser Gewährleistungsgehalt wird ermittelt unter Berücksichtigung des Menschenwürdeelements, der faktischen Möglichkeit der Gewährleistung durch den deutschen Staat, ${ }^{103}$ des Gewichts des Nachteils, der für die Allgemeinheit mit einer Schutzgewährung verbunden ist, ${ }^{104} \mathrm{der}$ Möglichkeitsbedingungen für internationale Zusammenarbeit ${ }^{105}$ und des dafür erforderlichen Aufwands im Verhältnis zu anderen verfassungsrechtlich legitimierten Zielen. ${ }^{106}$ Insbesondere muss festgestellt werden, ob bzw. wieweit es dem Sinn des Grundrechts entspricht, daß es auch außerhalb des von der Bundesrepublik allein beherrschten Bereichs gerade vom deutschen Staat geschützt wird. ${ }^{107}$

Dieser Ansatz für die Grundrechtsinterpretation bei Sachverhalten mit erheblicher Auslandsberührung entspricht einer modernen Tendenz in der Debatte zur allgemeinen Grundrechtsdogmatik. ${ }^{108}$ Sie schneidet formal-weitgesteckte Schutzbereiche und den weiten Eingriffsbegriff zurück. Stattdessen stellt sie auf den „Gewährleistungsgehalt“ eines Grundrechts ab, also auf seinen Sinn und Zweck als herausgehobenes Schutzgut innerhalb der Verfassung als einer Rahmenordnung. ${ }^{109}$ Diese Übereinstimmung dürfte kein Zufall sein. Die allgemeine Grundrechtsdogmatik konnte lange von dem relativ geschlossenen Weltbild ausgehen, wonach der Staat über die Möglichkeit verfügt, Grundrechtsgüter relativ genau berechenbar zu achten, zu schützen und einander zuzuord-

\footnotetext{
102 Siehe oben unter II. 4.; W. Hoffmann-Riem Enge oder weite Gewährleistungen der Grundrechte (Fn. 97), $59 \mathrm{ff}$.

${ }^{103}$ BVerfGE 92, 26 (41 f.).

104 BVerfGE 55, 349 (366); 92, 26 (47).

105 So, mutatis mutandis, EGMR, Agim Behrami and Bekir Behrami ./. Frankreich und Ruzhdi Saramati ./. Frankreich, Deutschland und Norwegen, Entscheidung der Großen Kammer vom 31. 05. 2007 Nr. 132.

106 BVerfGE 55, 349 (369).

${ }_{107}$ Im Ansatz ähnlich, allerdings zweifelnd F. Schorkopf, Grundgesetz und Überstaatlichkeit (Fn. 26), 123 ff.; vgl. auch BVerfGE 66, 39 (63 f.); BVerfGE 92, 26 (42).

${ }^{108} \mathrm{Zu}$ deren Bedeutung $F$. Schoch Gemeinsamkeiten und Unterschiede von Verwaltungsrechtslehre und Staatsrechtslehre, in: H. Schulze-Fielitz (Hrsg.) (Fn. 35), 177 (202f.).

${ }^{109}$ E. $-W$. Böckenförde Schutzbereich, Eingriff, verfassungsimmanente Schranken, Der Staat 42 (2003) 165 (174ff., 185ff.); W. Hoffmann-Riem (Fn. 97), 54ff.; ders. Grundrechtsanwendung unter Rationalitätsanspruch, Der Staat 43 (2004), 203; U. Volkmann Veränderungen der Grundrechtsdogmatik, JZ 2005, 261 (265ff.); kritisch dazu W. Kahl Vom weiten Schutzbereich zum engen Gewährleistungsgehalt, Der Staat 43 (2004), 167; ders. Entwicklungslinien (Fn. 86).
} 
nen. Die Forderung nach einer stärkeren Differenzierung und „Punktualisierung" 110 bei der allgemeinen Grundrechtsdogmatik passt in eine „globalisierte“ Welt mit ihren pluraler werdenden Gesellschaften, in denen Geltungsansprüche spezifischer begründet werden müssen.111 $\mathrm{Ob}$ sich die Hoffnungen auf eine größere Berechenbarkeit der Ergebnisse, die mit den modernen Tendenzen in der allgemeinen Grundrechtsdogmatik verbunden werden, ${ }^{112}$ erfüllen werden, möchte ich allerdings bezweifeln.113 Der "Gewährleistungsgehalt" eines Grundrechts ist regelmäßig komplex, er läßt sich im Schatten der internationalen Rechtsprechung nicht allzu sehr beschränken, und er enthebt auch meist nicht von der Prüfung der Verhältnismäßigkeit bzw. der Abwägung im Einzelfall. ${ }^{114}$

\section{Auslöser veränderter Rollenverständnisse von Gerichten und Wissenschaft}

Lösen solche Entwicklungen im materiellen Verfassungsrecht auch Veränderungen in den Rollen aus, die in der „Gesellschaft der Verfassungsinterpreten "115 gespielt werden? Bekanntlich hat Bernhard Schlink in den achtziger Jahren von der Entthronung der Staatsrechtswissenschaft durch das Bundesverfassungsgericht gesprochen. ${ }^{116}$ Wie immer man diese These bewertet, ${ }^{117}$ richtig war daran jedenfalls die Beobachtung, dass die Kommentierung der Rechtsprechung des Bundesverfassungsgerichts zu einem immer wichtigeren Betätigungsfeld der Staats-

110 W. Kahl Entwicklungslinien (Fn. 86), 581, 611 ff.; C. Möllers Grundrechtsjudikatur (Fn. 96), 1974.

111 Vgl. exemplarisch die Diskussion zur Religionsfreiheit C. Walter Religionsverfassungsrecht in vergleichender und internationaler Perspektive, 2005, $494 \mathrm{ff}$; $N$. Janz/ S. Rademacher Islam und Religionsfreiheit, NVwZ 1996, 706; W. Kahl Entwicklungslinien (Fn. 86), 619; M. Morlok in H. Dreier (Hrsg.) GG I, 2. Aufl. 2003, Art. 4, Rn. 47 ff.;

112 E.-W. Böckenförde Schutzbereich (Fn. 109), 165.

${ }^{113}$ So im Ergebnis, in den einzelnen Wertungen allerdings abweichend W. Kahl Vom weiten Schutzbereich (Fn. 109), $192 \mathrm{ff}$.

114 Die Kritik von C. Möllers Grundrechtsjudikatur (Fn. 96), 1976ff. geht insofern zu weit.

115 P. Häberle Die offene Gesellschaft der Verfassungsinterpreten, JZ 1975, 297.

116 B. Schlink Die Entthronung der Staatsrechtswissenschaft durch die Verfassungsgerichtsbarkeit, Der Staat 28 (1989) 161; siehe auch $M$. Jestaedt Verfassungsgerichtspositivismus, FS Isensee, 2002, 183 (188ff.).

${ }_{17}$ Kritisch dazu Friedrich Schoch Gemeinsamkeiten und Unterschiede (Fn. 108), $187 \mathrm{ff}$; vgl. auch $A$. Voßkuhle Die politischen Dimensionen der Staatsrechtslehre, in: H. Schulze-Fielitz (Fn. 35), 135 (140f.) m.w.N.; H. Schulze-Fielitz Staatsrechtslehre als Wissenschaft, ebd., 11 (21 f.). 
rechtswissenschaft geworden war. Heute kann man mit einem Körnchen Salz von einer Entthronung des Bundesverfassungsgerichts durch Europäisierung und Globalisierung sprechen. Damit ist nicht nur gemeint, dass die Rolle des Bundesverfassungsgerichts durch die europäischen Rechtsschutzsysteme relativiert worden ist. ${ }^{118}$ Vielmehr geht es auch um die Folgen einer stärkeren gegenseitigen Berücksichtigung ausländischer und internationaler Rechtsordnungen und deren Spruchpraxis für den Denk- und Begründungsstil des deutschen Verfassungsrechts. ${ }^{119}$

Die gegenseitige Berücksichtigung anderer Rechtsordnungen und ihrer Spruchpraxis dürfte auf die Dauer den Denk- und Begründungsstil fast aller Verfassungsgerichtsbarkeiten ändern. Jedenfalls soweit es die Grundrechte betriff, wird das Interesse, Konflikte mit anderen Gerichtsbarkeiten $\mathrm{zu}$ vermeiden und Gemeinsamkeiten $\mathrm{zu}$ betonen, $\mathrm{zu}$ stärker kasuistischen Begründungen Anlass geben. ${ }^{120}$ Eine solche Tendenz dürfte diejenigen Elemente des deutschen verfassungsrechtlichen Denkens schwächen, in denen systemorientiertes rechtsdogmatisches Denken oder ein Gesamtanspruch auf Verwirklichung der Verfassung zum Ausdruck kommt. ${ }^{121}$ Stattdessen dürfte eine Kombination von Kasuistik und ausfüllungsbedürftigen Prinzipien als Denk- und Begründungsstil in den Vordergrund rücken. Bedeutet dies dann tendenziell einen Abschied von der Dogmatik bzw. eine Amerikanisierung des deutschen verfassungsrechtlichen Denk- und Begründungsstils? ${ }^{122}$

118 Exemplarisch EGMR, von Hannover ./. Deutschland, Urteil vom 24. Juni 2004, ECHR 2004-VI, 41; hierzu $J$. Abr. Frowein Die traurigen Missverständnisse - BVerfG und EGMR, FS Delbrück, 2005, 279; C. Starck Das Caroline-Urteil des Europäischen Gerichtshofs für Menschenrechte und seine rechtlichen Konsequenzen, JZ 2006, 76.

119 B.-O. Bryde Konstitutionalisierung (Fn. 94), $68 \mathrm{ff}$;; A. Tschentscher Dialektische Rechtsvergleichung (Fn. 44), 814; aus europarechtswissenschaftlicher Sicht I. Pernice Europarechtswissenschaft oder Staatsrechtslehre?, in: H. Schulze-Fielitz (Fn. 35), 225 (242ff.).

120 Hierauf deutet etwa die Caroline von Hannover-Fallgestaltung hin, BVerfGE 101, 361 und EGMR Von Hannover . Deutschland, Urteil vom 24. Juni 2004, ECHR 2004-VI, 41; B.-O. Bryde Konstitutionalisierung (Fn. 94), 69f.; W. Kahl Entwicklungslinien (Fn. 86), $582 \mathrm{ff}$; vgl. auch $H$. Schulze-Fielitz Staatsrechtslehre (Fn. 117), $21 \mathrm{f}$.

${ }^{121}$ Zum systemorientierten Denken $O$. Lepsius Deutsche Staatsrechtslehre und amerikanische Rechtswissenschaft (Fn. 35), 326ff. und 345; F. Schoch Gemeinsamkeiten und Unterschiede (Fn. 117), 191f.; C. Möllers Gewaltengliederung, 2005, 153f.; C. Grewe Interpretationsmethoden (Fn. 91), $470 \mathrm{f}$.

122 B. Schlink Abschied von der Dogmatik. Verfassungsrechtsprechung und Verfassungsrechtsprechung im Wandel, JZ 2007, 157 (162); M. Ruffert Was kann die deutsche Europarechtslehre von der Europarechtswissenschaft im europäischen Ausland lernen?, in: H. Schulze-Fielitz (Fn. 35), 253 (257ff.); G. Biaggini Die Staatsrechtswissenschaft und ihr Gegenstand, in H. Schulze-Fielitz (Fn. 35), 267 (288). 
Ich vermute, dass wir es eher mit einer „EMRKanisierung“ der verfassungsgerichtlichen Rechtsprechung in Deutschland $\mathrm{zu}$ tun haben werden und nur zum Teil mit einer Amerikanisierung der Wissenschaft des Öffentlichen Rechts:

Die Rechtsprechung des EGMR ist durch ihre relativ einfache dogmatische Struktur gekennzeichnet. ${ }^{123}$ Dieser Gerichtshof praktiziert auf der Grundlage einer ausführlichen Sachverhaltsschilderung und mit Hilfe von Begründungsfiguren wie der „Erforderlichkeit in einer demokratischen Gesellschaft“ und der "Schutzpflicht“ eine relativ stark einzelfallorientierte Rechtsprechung. ${ }^{124}$ Dies ist naheliegend für ein Gericht, das in einer vergleichsweise heterogenen Umwelt auf eine gleichzeitig praktisch wirksame und möglichst konsistente Rechtsprechung achten muss. ${ }^{125}$ Ähnliches gilt für die Menschenrechtsorgane auf VN-Ebene bei Individualbeschwerdeverfahren. ${ }^{126}$ Wenn ein Gericht wie das Bundesverfassungsgericht in den Wirkungskreis solcher Spruchpraxis gerät, wird es sich deren Denk- und Begründungsstil auf die Dauer jedenfalls teilweise anpassen müssen. ${ }^{127}$ So könnte es etwa die generellabstrakten Teile seiner Urteilsbegründungen ${ }^{128}$ in Zukunft vorsichtiger und enger formulieren. ${ }^{129}$

${ }^{123}$ C. Grabenwarter Europäische Menschenrechtskonvention, 2. Aufl. 2005, $\S 14$, Rn. 5; zur relativen Methoden- und Dogmatikarmut im europäischen Gemeinschaftsrecht vgl. I. Pernice Europarechtswissenschaft oder Staatsrechtslehre (Fn. 119), 233, 240 und M. Ruffert Deutsche Europarechtslehre (Fn. 122), (257ff.).

${ }^{124}$ L. Wildhaber A Constitutional Future for the European Court of Human Rights?, HRLJ 23 (2002) 161; C. Grabenwarter EMRK (Fn. 123), § 14, Rn. 4; M. Herdegen Verfassungsinterpretation (Fn. 35), 875; EGMR, VO ./. Frankreich, Urteil der GroBen Kammer vom 8. Juli 2004, ECHR 2004-VIII, 67.

125 M. Pellonpää Kontrolldichte des Grund- und Menschenrechtsschutzes in mehrpoligen Rechtsverhältnissen, EuGRZ 2006, 483; W. Hoffmann-Riem Kontrolldichte (Fn. 91), 499; C. Grewe Interpretationsmethoden (Fn. 91), 465.

126 K. Ipsen in: ders., Völkerrecht, 5. Aufl. 2006, § 49, Rn. 1.

${ }_{127} \mathrm{Vgl}$. St. Oeter, Rechtsprechungskonkurrenz zwischen nationalen Verfassungsgerichten, Europäischem Gerichtshof und Europäischem Gerichtshof für Menschenrechte, VVdStRL 66 (2007), 362 (384); C. Grewe Interpretationsmethoden (Fn. 91), 462f. und 471; $M$. Oetheimer L'harmonisation de la liberté d'expression en Europe, 2001, 230, 248, 262.

${ }_{128}$ Vgl. $O$. Lepsius Deutsche Staatsrechtslehre und amerikanische Rechtswissenschaft, (Fn. 35), 326 und 355 zur normstrukturellen Orientierung des deutschen Richterrechts an generell-abstrakten Normen.

${ }^{129} \mathrm{Zu}$ Forderungen bzw. Prognosen zur Weiterentwicklung der Rechtsprechung des EGMR in einem stärker "dogmatischen" Sinn bei $L$. Wildhaber A Constitutional Future (Fn. 124), 164f.; C. Grabenwarter EMRK (Fn. 123), § 14, Rn. 4; R. Harmsen The European Convention on Human Rights After Enlargement, The International Journal of 
Der Denk- und Begründungsstil des US Supreme Court unterscheidet sich von demjenigen des EGMR. Das amerikanische Gericht zielt stärker auf fallübergreifende anwendungsfähige Aussagen, sog. tests, und nicht so sehr auf eine einzelfall- oder sachverhaltsorientierte Überprüfung. Diese tests sind auch durch ihren Zweck geprägt, Jurys zu einem Mindestma $B$ von Entscheidungskonsistenz zu zwingen. ${ }^{130}$ Die „tests“" werden zwar immer in genauer Anschauung konkreter Sachverhalte entwickelt und können auch in Anschauung bis dahin nicht bedachter Fallkonstellationen modifiziert werden. ${ }^{131}$ Sie heben das amerikanische Fallrecht aber über eine Kasuistik im Sinne des EGMR hinaus und verleihen ihm einen weitergehenden rechtsdogmatischen Anspruch. ${ }^{132}$ Dabei stößt es allerdings nicht zu allgemeinen Grundrechtslehren oder einer Systemorientierung wie in Deutschland vor. ${ }^{133}$ Auf Entscheidungen nicht-amerikanischer Gerichte nimmt der US Supreme Court nur ausnahmsweise so weit Rücksicht, dass dies in Differenzierungen der eigenen Rechtsprechung ablesbar wäre. ${ }^{134}$

Für die Wissenschaft des Öffentlichen Rechts in Deutschland würde eine Rechtsprechung des Bundesverfassungsgerichts, die im Kontext der Globalisierung kasuistischer wird, eine Gelegenheit zur Stärkung ihrer besonderen Funktion bedeuten. Die Funktion dieser Wissenschaft besteht - abgesehen von der Weiterentwicklung des rechtsdogmatischen Argumentationsreservoirs ${ }^{135}$ - in der Herausarbeitung übergreifender Zusammenhänge. ${ }^{136}$ Diese Funktion kann auf mindestens

Human Rights 5 (2001), Nr. 4, 18 (32ff.); S. Greer The European Convention on Human Rights - Achievements, Problems and Prospects, 2006, $165 \mathrm{ff}$.

${ }^{130}$ So etwa im Bereich des Verhältnisses von Meinungsfreiheit und Ehrenschutz, dazu G. Nolte Beleidigungsschutz in der freiheitlichen Demokratie, 1992, $214 \mathrm{ff}$.

$131 O$. Lepsius Deutsche Staatsrechtslehre und amerikanische Rechtswissenschaft (Fn. 35), $320 \mathrm{ff}$.; W. Brugger Grundrechte und Verfassungsgerichtsbarkeit in den Vereinigten Staaten von Amerika, 1987, 434.

${ }_{132} M$. Schefer Konkretisierungen von Grundrechten durch den U.S.-Supreme Court, 1997, 414ff;; weitergehend W. Brugger Grundrechte und Verfassungsgerichtsbarkeit (Fn. 131), $433 \mathrm{f}$.

${ }_{133}$ W. Brugger Einführung in das öffentliche Recht der USA, 2. Aufl. 2001, 92f;; ähnlich, die Kleinteiligkeit des amerikanischen Richterrechts aber wohl überbetonend, O. Lepsius Deutsche Staatsrechtslehre und amerikanische Rechtswissenschaft (Fn. 35), $326 \mathrm{ff}$.

134 Vgl. die Berücksichtigung des IGH durch den US Supreme Court mit der Vorgehensweise des BVerfG am Beispiel Konsularrechtskonvention, hierzu C. Hoppe Implementation (Fn. 37) mwN.

${ }^{135} P$. Lerche Rechtswissenschaft und Verfassungsgerichtsbarkeit, BayVBI. 2002, 649 (649f.); H. Schulze-Fielitz Staatsrechtslehre als Wissenschaft (Fn. 117), 30.

${ }^{136}$ H. Schulze-Fielitz Staatsrechtslehre als Wissenschaft (Fn. 117), $15 \mathrm{f} ., 20$. 
zweierlei Weise erfüllt werden. Die eine besteht in einer kritischen Begleitung der Rechtsentwicklung auf der Grundlage von metadogmatischen Theorien, also etwa ökonomischer, politikwissenschaftlicher, rechtsphilosophischer, historischer oder sonstig kritischer Art. Diese Herangehensweise wird besonders in den USA gepflegt. ${ }^{137}$ Die andere Herangehensweise besteht in der vergleichenden Identifizierung und kontextsensiblen Interpretation global relevanter Faktoren und Trends. ${ }^{138}$ Ein Beispiel für diesen approach ist die kritische rechtsvergleichende Aufarbeitung der Reaktionen der Gerichte in verschiedenen Staaten auf die Herausforderung des globalen Terrorismus. ${ }^{139}$ Eine solche Aufarbeitung erweist, dass hinter aller Kasuistik doch auch global übergreifende Trends am Werk sein können.

Beide Herangehensweisen zur übergreifenden Orientierung durch die Wissenschaft des Öffentlichen Rechts sind legitim. Allerdings dürften ihre Leistungen unter den gegenwärtigen Bedingungen unterschiedlich sein. Während der metadogmatische Ansatz eher die ,policy options" und damit tendenziell mögliche Gegensätze deutlich macht, ${ }^{140}$ dürfte die stärker induktive Herangehensweise häufig eher Gemeinsamkeiten oder Spielräume zwischen Gegensätzen identifizieren. Die stärker induktive Herangehensweise würde dann eher konstruktiv im Geist der klassischen Dogmatik wirken.

${ }^{137}$ A. v. Bogdandy, Wissenschaft vom Verfassungsrecht: Vergleich, in: Ius Publicum Europaeum, 2007, Rn 54f. und 57f.; O. Lepsius Deutsche Staatsrechtslehre und amerikanische Rechtswissenschaft (Fn. 35), 340f. und 361 ff.); C. Möllers Globalisierte Jurisprudenz (Fn. 1), $50 \mathrm{f} .54 \mathrm{f}$.

138 F. Schoch Gemeinsamkeiten und Unterschiede (Fn. 108), 208; S. Baer Verfassungsvergleichung und reflexive Methode: Interkulturelle und intersubjektive Kompetenz, ZaöRV 64 (2004) 735; Th. Rensmann, Wertordnung und Verfassung, 2007, $311 \mathrm{ff}$.; A. Tschentscher Dialektische Rechtsvergleichung (Fn. 44), 814f.; C. Möllers Globalisierte Jurisprudenz (Fn. 1), 53 ff.; $C$. Tietje Die Staatsrechtslehre und die Veränderung ihres Gegenstandes, DVB1. 2003, 1081 (1086); strukturell ähnlich für das Verwaltungsrecht $C$. Möllers Theorie, Praxis und Interdisziplinarität in der Verwaltungsrechtswissenschaft, VerwArch 93 (2002) 22 (56); für das Europarecht auch I. Pernice, Europarechtswissenschaft oder Staatsrechtslehre? (Fn. 119), 242ff.; A. von Bogdandy Beobachtungen zur Wissenschaft vom Europarecht, Der Staat 40 (2001), 3 (6ff.).

${ }^{139}$ Siehe oben II. 2.

${ }^{140}$ C. Möllers Theorie, Praxis und Interdisziplinarität (Fn. 138), 45f.; H.-H. Trute Staatsrechtslehre als Sozialwissenschaft?, in: H. Schulze-Fielitz (Fn. 35), 115 (121). 


\section{Schluss}

Mein Fazit ist: Wenn das Recht der Sicherheit symptomatische Herausforderungen der Globalisierung für das Verfassungsrecht enthält, dann geht es für das nationale Verfassungsrecht - ebenso wie für das Europa- und das Völkerrecht - darum, stärkere Spannungen auszuhalten und hierauf differenziert zu reagieren, ohne Essentialia preiszugeben. Es sollte keine pauschalen Rezepte wie „mehr oder weniger Freiheit“ oder „mehr oder weniger Staat" geben. Stattdessen sollte die Verfassungsinterpretation auf die globalen Entwicklungen ausgerichtet werden, um die Substanz der Verfassung auch unter veränderten Bedingungen gewährleisten zu können. Dadurch mag die Grundrechtsinterpretation ein Stück weit entdogmatisiert werden. Die Wissenschaft des Öffentlichen Rechts kann aber darauf hinwirken, dass sich die Rechtsprechung nicht in Kasuistik verliert.

Ein wichtiger Beitrag zur Wahrung der Substanz des staatlichen Verfassungsrechts dürfte - paradoxerweise - in der rechtsvergleichenden und völkerrechtlichen Analyse wichtiger Problemkonstellationen liegen. Das Beispiel der Reaktion unterschiedlicher Höchstgerichte auf exekutive und legislative Maßnahmen zur Terrorbekämpfung legt nahe, dass sich freiheitliche Standards einzelstaatlich nur dann halten lassen, wenn sie international abgesichert sind. 
Leitsätze des 1. Berichterstatters über:

\section{Das Verfassungsrecht vor den Herausforderungen der Globalisierung}

\section{Aspekte der Globalisierung}

1. "Die" Globalisierung hat viele Aspekte. Man kann drei Dimensionen unterscheiden: das Grundphänomen der weltweiten wirtschaftlich-technischkommunikativen Verflechtungsprozesse mit ihrer Relativierung der Rolle des Staates und dem Aufstieg anderer Akteure; die mehr oder weniger "normale“ Verarbeitung dieser Verfechtungsprozesse auf politischer, sozialer und kultureller Ebene; und schließlich die Pathologien dieser Prozesse, insbesondere Staatszerfall, globaler Terrorismus, wirtschaftlich-soziale Notlagen und Umweltzerstörung.

\section{Herausforderungen im Recht der Sicherheit}

2. Im Recht der Sicherheit manifestieren sich typische Herausforderungen der Globalisierung für das Verfassungsrecht zugespitzt und in größtmöglicher juristischer Schärfe. Der moderne globale Terrorismus und seine global koordinierte Bekämpfung fordern das Verfassungsrecht in seiner Kernfunktion heraus.

\section{(1) Die gezielten Sanktionen des VN-Sicherheitsrates}

3. Bei den sog. gezielten Sanktionen des VN-Sicherheitsrats besteht die Herausforderung für das Verfassungsrecht - und seine Wissenschaft darin zu klären, ob der im europäischen Kontext erfolgreiche Lösungsansatz auch auf das Verhältnis zur globalen Ebene übertragen werden kann und sollte.

4. Für Maßnahmen des VN-Sicherheitsrats besteht nach deutschem Verfassungsrecht eine besondere Legitimation, die sich aus einer Kombination des materiellen Ziels der Präambel, „dem Frieden der Welt zu dienen“ und der institutionellen Norm des Art. 24 Abs. 2 GG ableitet. Sie rechtfertigt es, gegenüber bindenden und ermächtigenden Maßnahmen der $V N$ nicht auf 
den gleichen Mindeststandards zu bestehen wie gegenüber allen partikularen zwischenstaatlichen Einrichtungen.

5. Der Schutz der Menschenwürde und damit verbundener elementarer rechtsstaatlicher Mindeststandards darf allerdings auch gegenüber dem Sicherheitsrat nicht preisgegeben werden. In Hinblick auf gezielte Sanktionen des Sicherheitsrates sollte der Begriff der. Menschenwürde am völkerrechtlichen Mindeststandard orientiert ausgelegt werden.

6. Die Unklarheit des völkerrechtlichen Mindeststandards sollte in diesem Zusammenhang nicht als Problem, sondern als Vorteil gesehen werden. Sie ermöglicht es den Gerichten, unbestimmte aber konstruktiv wirkende Drohungen mit Nichtumsetzung zu formulieren, die nur im Not-und Einzelfall verwirklicht werden müssen. Die Konkretisierung des völkerrechtlichen Mindeststandards erfolgt im Wege eines Rechtsprechungsdialogs zwischen internationalen und nationalen Spruchkörpern.

\section{(2) Reaktionsmuster bei der Terrorbekämpfung außerhalb der VN}

7. Nach den Anschlägen des 11. September 2001 haben Gerichte in Verfassungsstaaten nach anfänglichem Zögern übersteigerten neuen Anti-Terrormaßnahmen Widerstand entgegengesetzt.

8. Durch eine informell koordinierte Rechtsprechung in Fragen der Terrorismusbekämpfung wird das gemeinsame Interesse der Gerichtsbarkeit in allen Verfassungsstaaten gewahrt, einen grundrechtlichen race to the bottom und Verschiebungen im Gewaltengefüge zu vermeiden.

\section{(3) Wirkkraft der Grundrechte bei Sachverhalten mit erheblicher Auslandsberührung}

9. Die Bemühungen der Wissenschaft, für die grundrechtliche Beurteilung von Sachverhalten mit erheblicher Auslandsberührung klare abstrakte Maßstäbe zu entwickeln, haben sich angesichts der Vielfalt solcher Sachverhalte als vergeblich erwiesen.

10. Grundrechte wirken bei Sachverhalten mit erheblicher Auslandsberührung nicht immer so stark wie bei inländisch geprägten Sachverhalten.

11. Auch wenn es in manchen Bereichen zur Fiktion wird, ist bei Maßnahmen deutscher Staatsorgane auf deutschem Staatsgebiet grundsätzlich von einem Inlandssachverhalt mit voller Grundrechtswirkung auszugehen. 
III. Allgemeine Herausforderungen für das Verfassungsrecht und seine Wissenschaft

12. Das deutsche Verfassungsrecht nimmt sich seit Beginn der neunziger Jahre stärker in einem globalen Kontext wahr und ist sich dadurch seiner eigenen Rolle und Besonderheiten bewusster geworden.

13. Die Wahrnehmung des globalen Kontexts hat im deutschen Verfassungsrecht auch die Frage aufgeworfen, wie weit das Eigene historisch bedingt ist und neu vermessen werden sollte.

14. Die Grundrechtsinterpretation im Hinblick auf Sachverhalte mit erheblicher Auslandsberührung entspricht mit ihrer Betonung des Gewährleistungsgehalts einer modernen Tendenz in der Debatte zur allgemeinen Grundrechtsdogmatik.

15. Die Forderung nach einer stärkeren Differenzierung bei der allgemeinen Grundrechtsdogmatik passt in eine "globalisierte“ Welt mit ihren pluraler werdenden Gesellschaften, in denen Geltungsansprüche spezifischer begründet werden müssen.

16. Die gegenseitige Berücksichtigung anderer Rechtsordnungen und ihrer Spruchpraxis dürfte auf die Dauer den Denk- und Begründungsstil fast aller Verfassungsgerichtsbarkeiten ändern. Jedenfalls soweit es die Grundrechte betrifft, wird das Interesse, Konflikte mit anderen Gerichtsbarkeiten $z u$ vermeiden und Gemeinsamkeiten zu betonen, zu stärker kasuistischen Begründungen Anlass geben.

17. Für die Wissenschaft des Öffentlichen Rechts in Deutschland bedeutet eine Rechtsprechung des Bundesverfassungsgerichts, die im Kontext der Globalisierung kasuistischer wird, eine Gelegenheit zur Stärkung ihrer besonderen Funktion, also der Herausarbeitung übergreifender Zusammenhänge.

18. Diese Funktion kann - abgesehen von der Weiterentwicklung des rechtsdogmatischen Argumentationsreservoirs - auf mindestens zweierlei Weise erfüllt werden. Die eine besteht in einer kritischen Begleitung der Rechtsprechung auf der Grundlage von metadogmatischen Theorien, die andere in der vergleichenden Identifizierung und kontextsensiblen Interpretation global relevanter Faktoren und Trends.

19. Ein wichtiger Beitrag zur Wahrung der Substanz des staatlichen Verfassungsrechts dürfte - paradoxerweise - in der rechtsvergleichenden und völkerrechtlichen Analyse wichtiger Problemkonstellationen liegen. 
Zweiter Beratungsgegenstand:

\section{Das Verfassungsrecht vor den Herausforderungen der Globalisierung}

2. Bericht von Professor Dr. Ralf Poscher, Bochum

Inhalt

Seite

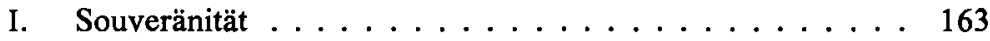

1. Faktische Globalisierungsphänomene . . . . . . . 163

2. Regulative Globalisierungsphänomene . . . . . . . 163

a) Völkerrechtliche Verträge . . . . . . . . . . . . 164

b) Internationale Regulierungen jenseits des Völkervertragsrechts .............. 165

c) Autonome internationale Funktionssysteme . . . . . 167

3. Funktion der Souveränität . . . . . . . . . . 169

II. Demokratie ..................... 172

1. Die identitärdemokratische Tradition und der

Defizitkonsens . . . . . . . . . . . . . 172

2. Kompensationsstrategien .............. 174

a) Nationale Gegensteuerung . . . . . . . . . . 174

b) Demokratisierung der internationalen Ebene . . . . 174

c) Legitimation durch Leistung . . . . . . . . . . . . 176

d) Die Weimarer Konstellation . . . . . . . . . . . 177

3. Kontextbezogenes realistisches Verständnis des

Demokratieprinzips . . . . . . . . . . . . . 178

a) Der Kontext internationaler Kooperation . . . . . . 179

b) Partizipation, Responsivität, Gemeinwohl . . . . . . 181

III. Gewaltenteilung . . . . . . . . . . . . . . . . 182

1. Entscheidungsrechte des Bundestags ... . . . . . 184

2. Besondere Beteiligungsrechte in Angelegenheiten der Europäischen Union . . . . . . . . . . . . . . . 184

3. Ausweitung der frühen Parlamentsbeteiligung $\ldots \ldots 186$

IV. Grundrechte . . . . . . . . . . . . . . . . . 190

1. Allgemeine Grundrechtsbindung in internationalen Kontexten .................. 191

2. Relativierung des Grundrechtsschutzes bei der Übertragung und Beschränkung von Hoheitsrechten . . 194 
Die Globalisierung ${ }^{1}$ hat eine Reihe faktischer und regulativer Phänomene hervorgebracht, die das nationale Verfassungsrecht provinziell erscheinen lassen. Für faktische Phänomene wird regelmäßig auf die durch die Globalisierung bedingten Möglichkeiten hingewiesen, sich nationalen Rechts- und Verfassungsordnungen zu entziehen. ${ }^{2}$ So ermöglicht das mediale Paradigma der Globalisierung, das Internet, ${ }^{3}$ die weltweite Verlagerung von Inhalten, wodurch nationale Regelungen ins Leere zu laufen drohen. ${ }^{4}$ Für die regulativen Phänomene wird auf Normsetzungen privater Akteure hingewiesen, die sich jenseits aller Staatlichkeit zu vollziehen scheinen. ICANN, eine private Vereinigung kalifornischen Rechts, verwaltet in der globalisierten Welt so wesentliche Dinge wie die Vergabe von Domain-Namen. ${ }^{5}$ Die Lex Mercatoria wird als Ausdruck einer sich autonom konstitutionalisierenden internationalen Wirtschaft gefeiert. ${ }^{6}$ Jenseits des Staates vollziehen sich auch die Regulierungen intergouvernementaler Kommissionen. Im Basler Ausschuss legen Mitglieder nationaler Bankenaufsichtsbehörden jen-

${ }^{1}$ Ein quantitativer Globalisierungsbegriff stellt auf den Anstieg des internationalen Verkehrs von Personen, Kapital, Waren, Kommunikation, etc. ab. Die quantitative Entwicklung der Globalisierung verläuft keineswegs linear. So wurde die ökonomische Verflechtungsdichte von 1914 erst in den 70er Jahren wieder erreicht, J. Osterhammel/ N. P. Peterson Geschichte der Globalisierung, 2003, 109. Darin lag jedoch keine Rückkehr zu früheren Verhältnissen. Als wesentliche Änderungen der Globalisierungsstruktur macht etwa L. Brock Die Grenze der Demokratie, in: B. Kohler-Koch (Hrsg.), Regieren in entgrenzten Räumen, PVS Sonderheft 29 (1998), 271 (272) mwN, den Übergang vom komplementären zum substitutiven Welthandel und die Standardisierung von Lebensstilen aus. Ein anspruchsvollerer Globalisierungsbegriff, der auf dem quantitativen aufbaut, stellt auf die gestiegene Anzahl von Phänomenen ab, die sinnvoll nur noch in global oder jedenfalls international koordinierten Strategien behandelt werden können, etwa C. Tietje Internationalisiertes Verwaltungshandeln, 2001, 165.

${ }^{2}$ C. Engel International Review of Law Computers \& Technology, 20 (2000), $1 \mathrm{ff}$; ders. Berichte der Deutschen Gesellschaft für Völkerrecht 39 (2000), $353 \mathrm{ff}$.

${ }^{3}$ Paradigmatisch ist das Internet besonders auch deshalb, weil es die Reflexivität der Globalisierung im Alltagsbewusstsein erhöht hat.

${ }^{4} \mathrm{Zu}$ den unterschiedlichen Szenarien C. Engel International Review of Law Computers \& Technology, 20 (2000), $381 \mathrm{ff}$.

${ }^{5}$ C. Engel International Review of Law Computers \& Technology, 20 (2000), 2; s.a. C. Brömmelmeyer Internet Governance, in: M. Anderheiden/S. Huster/S. Kirste (Hrsg.) Globalisierung als Problem von Gerechtigkeit und Steuerungsfähigkeit des Rechts, 2001, $81 \mathrm{ff}$.

6 G. Teubner 'Global Bukowina', in: ders. (ed.), Global Law without a State, 1997, 3 (3 f.); ders. ZaöRV 63 (2003), 2 ff.; ähnlich für das elektronische Verbraucherschutzrecht G.-P. Calliess Globale Kommunikation - staatenloses Recht, in: M. Anderheiden/ S. Huster/S. Kirste (Hrsg.) Globalisierung als Problem von Gerechtigkeit und Steuerungsfähigkeit des Rechts, 2001, 61 (70). 
seits des Völkervertragsrechts Kreditvergabestandards fest, an denen sich Finanzierungen vom Häuslebau bis zum Investitionskredit für Großunternehmen messen lassen sollen. ${ }^{7}$ Nicht zuletzt entfalten internationale Organisationen immer weiter um sich greifende regulatorische Aktivitäten. In der WTO entscheiden letztlich mit drei Experten besetzte Panels $^{8}$ nicht nur über Zölle und Quoten, sondern auch über die Zulässigkeit nationaler oder gemeinschaftsrechtlicher Standards des Umweltschutzes 9 und der Gentechnik ${ }^{10} .11$ Wie Herr Nolte gerade berichtet hat, entscheidet der Sicherheitsrat der Vereinten Nationen personengenau über einschneidende Eingriffsmaßnahmen. ${ }^{12}$

Alle diese Phänomene wirken auf den Verfassungsraum des Grundgesetzes ein und fordern zentrale Verfassungsgrundsätze heraus. Was kann die in Art. 20 Abs. 2 GG garantierte Volkssouveränität ihnen gegenüber noch bedeuten? Wie verhält sich die Verlagerung wesentlicher Regulierungsaufgaben in den internationalen Raum zum Demokratieprinzip des Grundgesetzes ${ }^{13}$ An den Internationalisierungen sind häufig nur Regierungsvertreter beteiligt. Wie wirkt sich dies auf das gewaltenteilige Verhältnis von Exekutive und Legislative aus? Schließlich stellt sich die Frage nach der Bedeutung der materiellen Verfassungsgarantien des Grundgesetzes - besonders der Grundrechte, aber auch des Sozialstaatsgebots -, die einen wesentlichen Aspekt der Identität der Verfassung ausmachen.

${ }^{7}$ Zum Ursprung der Basler Mindestreserveverpflichtungen in der amerikanischen Innenpolitik Brock Grenze der Demokratie (Fn. 1), 282f.; zum Teil werden die Standards sogar für Rezessionen verantwortlich gemacht A.-M. Slaughter A New World Order, 2004, 219. Auch zu weiteren exemplarischen Kooperationen C. Möllers Zä̈RV 65 (2005), $351 \mathrm{ff}$., der einen Gesetzesvorbehalt annimmt, ebd. $373 \mathrm{ff}$.

${ }^{8}$ Art. 8 Abs. 5, Art. 17 Abs. 1 Dispute Settlement Understanding (DSU). Die Empfehlungen des Standing Appellate Body können nur durch einen Konsens des mit den Regierungsvertretern besetzten Dispute Settlement Body abgelehnt werden (Art. 16 Abs. 4 DSU), was in der Praxis nicht vorkommt, da dann auch die obsiegende Partei eines Verfahrens die Entscheidung ablehnen müsste, $R$. Reusch Die Legitimation des WTO Streitbeilegungsverfahrens, 2007, 46; V. Röben Außenverfassungsrecht, 2007, 166.

9 US - Gasoline, WT/DS2/AB/R, 29. 4. 1996; US - Shrimp, WT/DS58/AB/R, 12. 10. 1998; US - Shrimp. 21.5, WT/DS58/AB/RW, 22. 10. 2001.

${ }^{10}$ Zur vorerst letzten Entscheidung des WTO-Panels P.-T. Stoll EuZW 2007, $471 \mathrm{ff}$.

${ }^{11} E$.-W. Böckenförde Die Zukunft politischer Autonomie, in: ders., Staat, Nation, Europa, 1999, 103 (124); M. Herdegen Entformalisierung und Entparlamentarisierung politischer Entscheidungen als Gefährdungen der Verfassung?, VVDStRL 62 (2003), 7 (24).

12 Zum System der Maßnahmen als einer Art internationalisiertem Notstandsregime K. L. Scheppele The international State of Exception, Manuskript 2006, $4 \mathrm{ff}$.

${ }^{13} M$. Ruffert Die Globalisierung als Herausforderung an das öffentliche Recht, 2003, $61 \mathrm{ff}$. 


\section{Souveränität}

Art. 20 Abs. 2 GG liegt ein relativ anspruchsloser, aber rechtlich beschreibbarer Begriff der innerstaatlichen Souveränität ${ }^{14} \mathrm{zu}$ Grunde. ${ }^{15} \mathrm{Er}$ verlangt, dass alle Staatsgewalt vom Volke ausgeht oder - retrospektiv formuliert - auf Wahlen oder Abstimmungen des Volkes zurückgeführt werden kann. Dogmatisch markiert die Souveränität einen Ableitungszusammenhang ${ }^{16}$ für die Ausübung hoheitlicher Gewalt.

\section{Faktische Globalisierungsphänomene}

Bereits strukturell kann diese verfassungsrechtliche Souveränität durch Globalisierungsphänomene rein faktischer Natur nicht tangiert werden. Die mit dem Internet und anderen Globalisierungsprozessen verbundenen Evasionsstrategien rückten erst dann in den Horizont eines Problems für Art. 20 Abs. 2 GG, wenn die Durchsetzung der vom Volk abgeleiteten Hoheitsgewalt nachhaltig eingeschränkt wäre. Davon kann jedoch keine Rede sein. Vielmehr werden die mit der Globalisierung verbundenen Möglichkeiten der Rechtsumgehung durch gesteigerte Durchsetzungsmöglichkeiten der Behörden kompensiert, die sich gerade auch aus der internationalen Kooperation und den neuen - besonders den informationellen - Techniken ergeben, die die Globalisierung tragen. ${ }^{17}$

\section{Regulative Globalisierungsphänomene}

Internationale regulative Anstrengungen, die auf hoheitliches Handeln im Geltungsbereich des Grundgesetzes angelegt sind, können die Souveränität tangieren, wenn sich für sie kein entsprechender Ableitungszusammenhang rekonstruieren ließe.

14 In diesem schwachen Sinn lässt sich Souveränität staatsrechtlich an Art. 20 Abs. 2 GG „festmachen“, pessimistischer C. Hillgruber HStR II, 3. Aufl. 2004, §32 Rn. 52.

${ }_{15}$ Grundlegend zur Geschichte des staatstheoretischen Konzepts $H$. Quaritsch Souveränität, 1986; für eine neuere historische Übersicht $S$. Oeter Souveränität - ein überholtes Konzept?, in: H. J. Cremer u. a. (Hrsg.), FS Steinberger, 2002, 257 (261 ff.); eine kulturwissenschaftliche Analyse der Souveränität als Chiffre für die verdrängten irrationalen Elemente des Politischen bei U. Haltern Was bedeutet Souveränität?, 2007.

${ }^{16}$ Auf eine ähnliche Ableitungsstruktur verweist auch die völkerrechtliche Souveränität vgl. Oeter Souveränität (Fn. 15), 278 ff.; B. Fassbender Die Souveränität des Staates als Autonomie im Rahmen der völkerrechtlichen Verfassung, in: H.-P. Mansel (Hrsg.), FS Jayme, Bd. 2, 2004, $1089 \mathrm{ff}$.

17 C. Engel International Review of Law Computers \& Technology, 20 (2000), $8 \mathrm{ff}$.; Calliess Globale Kommunikation (Fn. 6), 67f. 


\section{a) Völkerrechtliche Verträge}

Für das Völkervertragsrecht ergibt sich der Ableitungszusammenhang bereits aus der dualistischen Konzeption des Grundgesetzes..$^{18}$ Völkerrechtliche Verträge bedürfen nicht nur im Anwendungsbereich von Art. 59 Abs. $2 \mathrm{~S} .1 \mathrm{GG}$ der Umsetzung in nationales Recht. ${ }^{19}$ Dies gilt auch für sekundäre Rechtsakte internationaler Organisationen, ${ }^{20}$ einschließlich der zweiten und dritten Säule der Europäischen Union ${ }^{21}$.

Eine Ausnahme bilden insoweit nur supranationale Organisationen, denen nach Art. 23 oder 24 GG Hoheitsrechte übertragen wurden. Aber auch für ihre Rechtsakte ist der Ableitungszusammenhang zum einen durch das Übertragungsgesetz, ${ }^{22}$ zum anderen gleichsam negativ dadurch gewahrt, dass die Hoheitsrechte nicht aufgegeben, sondern nur zur Ausübung überlassen wurden. Die Ausübung und ihre Grenzen werden durch das Bundesverfassungsgericht überwacht. ${ }^{23}$ Die Übertra-

${ }_{18}$ C. Hillgruber HStR II, 3. Aufl. 2004, $\$ 32$ Rn. 116; zu deren Entwicklung in der deutschen Verfassungstradition $F$. Schorkopf Grundgesetz und Überstaatlichkeit, 2007, 38 ff.; besonders in der jüngeren Rechtsprechung bestätigt sieht sie $S$. Hobe Zur Öffnung der innerstaatlichen Rechtsordnung für das Völkerrecht und die internationale Zusammenarbeit in der jüngeren Rechtsprechung des Bundesverfassungsgerichts, in: K. P. Berger u. a. (Hrsg.), FS Horn, 2006, 423 (433). Auch monistische Systeme führen nicht notwendig zu einem unbedingten Vorrang des Völkerrechts, s. D. Thürer SZIER 1999, 217 (222 ff.).

${ }^{19}$ Auch soweit das Bundesverfassungsgericht aus der Völkerrechtsfreundlichkeit des Grundgesetzes für nicht transformierte Verträge eine Verfassungspflicht ableitet, „die die Bundesrepublik Deutschland bindenden Völkerrechtsnormen zu befolgen und Verletzungen nach Möglichkeit zu unterlassen“, BVerfGE 112, 1 (26); s. auch BVerfG, NJW 2007, 499 (501 f.), ergibt sich daraus keine unmittelbare innerstaatliche Wirkung des Völkerrechts, s. auch BVerfGE 68, 1 (87); aA U. Fastenrath DöV 2006, 1015 (1024). Die unter dem Möglichkeitsvorbehalt stehende verfassungsrechtliche Berücksichtigungspflicht ist nationalen Ursprungs und hat einen anderen Inhalt als die völkerrechtliche Vertragspflicht, die unkonditioniert gilt.

${ }^{20}$ Dies gilt etwa für Urteile des Europäischen Gerichtshofs für Menschenrechte, BVerfGE 111, 307 (331).

${ }^{21}$ BVerfGE 113, 273 (300f.).

22 BVerfGE 89, 155 (190); aA 1 . Pernice Europäisches und nationales Verfassungsrecht, VVDStRL 60 (2001), 148 (183f.): originäre Verfassungsgebung auf der Ebene der Europäischen Gemeinschaft.

${ }^{23}$ BVerfGE 89, 155 (188); 102, 147 (162ff.); BVerfG, DVBl. 2001, 1130 (1131 f.); BVerfG, NJW 2001, 1267 (1267f.); BVerfG, NVwZ 2004, 1346 (1346f.); BVerfGE, 111, 307 (319); BVerfG, NVwZ 2007, 937 (938); BVerfG, NVwZ 2007, 942; damit steht das Bundesverfassungsgericht stellvertretend für eine Reihe von mitgliedstaatlichen Verhältnisbestimmungen, eine Zusammenstellung einschlägiger Urteile bei Haltern Souveränität (Fn. 15), 100 Fn. 159. 
gung steht ferner unter dem Vorbehalt der Aufhebung, ${ }^{24}$ die auch völkerrechtlich nach den allgemeinen Grundsätzen ${ }^{25}$ zulässig ist. ${ }^{26}$

\section{b) Internationale Regulierungen jenseits des Völkervertragsrechts}

Der Umsetzung, die den Ableitungszusammenhang im Sinne von Art. 20 Abs. 2 GG herstellt, bedürfen erst recht internationaler Regulierungen, die keinen Vertragscharakter aufweisen. Hierzu zählen intergouvernementale Absprachen, ${ }^{27}$ rechtlich nicht bindende Empfehlungen internationaler Organisationen ${ }^{28}$ und durch internationale private Vereinigungen gesetzte Standards ${ }^{29}$, wie sie besonders in technischen Bereichen anzutreffen sind. Auch die Basler Kreditierungsstandards gehören hierher. Bei ihnen besteht noch nicht einmal eine völkerrechtliche Pflicht zur Umsetzung. Der Ableitungszusammenhang wird durch die nationalen oder gemeinschaftsrechtlichen ${ }^{30}$ Akte hergestellt, mit denen die Übernahme der Standards politisch verantwortet wird.

${ }^{24}$ Auch bei der Übertragung von Hoheitsrechten kann zwischen der Aufhebung der Übertragung - etwa durch eine verfassungsgerichtliche Nichtigkeitserklärung des Übertragungsgesetzes oder einen actus contrarius - und der Aufhebung der völkerrechtlichen Verpflichtung unterschieden werden. Zur (teilweisen) Aufhebung eines Umsetzungsgesetzes bei fortbestehender völkerrechtlicher Verpflichtung s. BVerfGE 30, 272 (287f.); 72, 200 (202); G. Boehmer Der völkerrechtliche Vertrag im deutschen Recht, 1965, 76; aus der älteren Literatur A. Affolter AöR 6 (1891), 378 (401 f.), P. Heilborn AöR 12 (1897), 141 (173).

${ }^{25}$ Art. 62, 65-70 WVRK.

26 BVerfGE 89, 155 (188); BVerfG, DVBl. 2001, 1130 (1131 f.); C. Tomuschat EuGRZ 1993, 489-496; $R$. Streinz EuZW 1994, 329 (331 f.); E. Pfrang Das Verhältnis zwischen europäischem Gemeinschaftsrecht und deutschem Recht nach der Maastricht-Entscheidung des Bundesverfassungsgerichts, 1997, 356; A. v. Bogdandy KritV (2000), 284-297; aA I. Pernice in: H. Dreier (Hrsg.) Grundgesetz Kommentar, 2. Aufl. 2006, Art. 24 Rn. 23; R. C. van Ooyen Die Staatstheorie des Bundesverfassungsgerichts und Europa, 2006, 23-31. Der Reformvertragsentwurf vom 5. 10. 2007 sieht nun für Art. 35 Abs. $1 \mathrm{EU}$ n.F. ausdrücklich eine Kündigungsmöglichkeit vor.

${ }^{27}$ Zur Bedeutung und zu den Vorteilen intergouvernementaler Regulierungen grundlegend $R$. O. Keohane/A. Moravcsik/A.-M. Slaughter International Organization 54 (2000), 457 ff.; Slaughter World Order (Fn. 7).

${ }^{28}$ Beispiele bei $S$. Hobe Der offene Verfassungsstaat zwischen Souveränität und Interdependenz, 1998, $267 \mathrm{ff}$. Ihnen kann jedoch normative Bedeutung zukommen, wenn sie etwa als Standard bei der Auslegung verbindlicher völkerrechtlicher Rechtsakte herangezogen werden. Ein Beispiel bildet etwa die Rechtsprechung der WTO-Streitschlichtungspanels zur Bedeutung des Codex Alimentarius, dazu etwa Tietje Verwaltungshandeln (Fn. 1), $439 \mathrm{ff}$.

${ }^{29}$ Dazu C. Tietje Zeitschrift für Rechtssoziologie 24 (2003), 27 (37 ff.).

${ }^{30}$ Bei einer Umsetzung durch das Gemeinschaftsrecht, dazu C. Walter DVBl. 2000, 1 (3), wird der Ableitungszusammenhang über die Vertragsgesetze zu den Gemeinschaftsverträgen und die Beteiligung im Rat hergestellt. 
Bei der Übernahme in das nationale Recht können entsprechende Standards in Bezug genommen werden, wenn eine ausreichende Publizität gewährleistet ist. ${ }^{31}$ Wegen des geforderten Ableitungszusammenhangs sind solche Verweisungen jedoch grundsätzlich unzulässig, wenn sie nicht mehr statisch, ${ }^{32}$ sondern dynamisch erfolgen..$^{33} \mathrm{Zwar}$ ließe sich über das verweisende Gesetz ein Ableitungszusammenhang konstruieren, ${ }^{34}$ doch in der dynamischen Verweisung liegt eine Übertragung von Hoheitsrechten. ${ }^{35}$ Für die Übertragung von Hoheitsgewalt reicht aber kein beliebiger Ableitungszusammenhang, ${ }^{36}$ sondern nur ein solcher, der im Grundgesetz vorgesehen ${ }^{37}$ oder zumindest vorausgesetz ${ }^{38}$ ist.

${ }^{31}$ Dazu L. Michael Private Standardsetter und demokratisch legitimierte Rechtssetzung, in: H. Bauer/P. M. Huber/K.-P. Sommermann (Hrsg.) Demokratie in Europa, 2005, 431 (445f); für eine Differenzierung des Publizitätserfordernisses nach den betroffenen Verkehrskreisen Tietje Verwaltungshandeln (Fn. 1), 619f. Dem wird man jedoch nur zustimmen können, wenn die Publizität auch für mögliche Drittbetroffene gewahrt bleibt.

32 Zur Zulässigkeit statischer Verweisungen auf internationale Regulierungen BVerfG, Beschluss v. 26. 1. $2007-2$ BvR 2408/06, Rn. 12; allgemein BVerfGE 47, 285 (311ff.); vgl. auch BVerfGE 5, 25 (31); 22, 330 (346); 26, 338 (365f.).

${ }^{33}$ B VerfGE 26, 338 (366f.), räumt dem Bundesgesetzgeber die Befugnis eines dynamischen Verweises auf Landesrecht ein. Demgegenüber lässt BVerfGE 47, 285 (312), offen, ob an dieser „bisherigen Rechtsprechung“ trotz der an ihr geäußerten Kritik festgehalten werden soll. Ablehnend etwa P. Marburger Die Regeln der Technik im Recht, 1979, 390; E. Denninger Verfassungsrechtliche Anforderungen an die Normsetzung im Umwelt- und Technikrecht, 1990, $142 \mathrm{ff}$; großzügiger $M$. Schwierz Die Privatisierung des Staates am Beispiel der Verweisungen auf die Regelwerke privater Regelgeber im Technischen Sicherheitsrecht, 1986, 84f.

34 Tietje Verwaltungshandeln (Fn. 1), $609 \mathrm{ff}$.

${ }^{35} \mathrm{Zu}$ dynamischen Verweisungen als verdeckte Kompetenzverlagerungen BVerfGE 47, 285 (311).

36 Die Staatsgewalt kann auch von den Volksvertretern nicht beliebig delegiert werden. Dies hindert den Gesetzgeber etwa daran, Hoheitsgewalt auf die Mehrheitspartei oder eine parteinahe Stiftung zu übertragen.

${ }^{37}$ Vorgesehen ist im Grundgesetz auch die Privatautonomie (zur grundrechtlichen Verortung $W$. Höfling Vertragsfreiheit, 1991, $6 \mathrm{ff} . \mathrm{mwN}$ ), in deren internationalisierten Erscheinungsformen ebenfalls eine Internationalisierung von Rechtssetzungsgewalt gesehen werden könnte. $\mathrm{Zu}$ den unterschiedlichen theoretischen Rekonstruktionen der Privatautonomie F. Kirchhof Private Rechtsetzung, 1987, 138ff.; J. Köndgen AcP 206 (2006), $477 \mathrm{ff}$.

${ }^{38}$ Ausgeschlossen ist grundsätzlich eine Übertragung von Hoheitsrechten auf andere Staaten. Eine Ausnahme gilt für traditionelle Formen der Hoheitsrechtsübertragung in grenznahen Konstellationen, wie der Nacheile ausländischer Sicherheitskräfte, M. Baldus Transnationales Polizeirecht, 2001, 274, oder bei Verwaltungsenklaven im Grenzraum - s. etwa den Vertrag zwischen der Schweizerischen Eidgenossenschaft und der Bundesrepublik Deutschland über die Einbeziehung der Gemeinde Büsingen v. 23. 11. 1964, http://www.admin.ch/ch/d/sr/0_631_112_136/index.html (Abruf: 12. 10. 2007) - 
Der Topos der offenen und völkerrechtsfreundlichen Staatlichkeit des Grundgesetzes $^{39}$ kann einen solchen Übertragungstatbestand nicht ersetzen. ${ }^{40}$ Verfassungswidrig war etwa eine Vorschrift des Handelsgesetzbuchs ${ }^{41}$ zur internationalen Rechnungslegung, soweit sie als dynamische Verweisung auf die Standards des International Accounting Standard Commitee, ${ }^{42}$ einer privaten Vereinigung von Wirtschaftprüferverbänden, ${ }^{43}$ verstanden werden musste. ${ }^{44}$

\section{c) Autonome internationale Funktionssysteme}

Auch die Kronzeugen für die Entwicklung eigenständiger Rechtsordnungen in internationalen Funktionssystemen - die Regulierung des Internets und die Lex Mercatoria - ${ }^{45}$ wirken nicht aus eigener Kraft in den Geltungsbereich des Grundgesetzes hinein. Anders als etwa das Gemeinschaftsrecht beanspruchen sie nicht einmal nach ihrem dogmatischen Selbstverständnis einen Vorrang vor dem nationalen Recht und

die durch das Grundgesetz nicht in Frage gestellt werden sollten. Diese traditionellen Ausnahmen umfassen auch noch die Fortentwicklung der grenznahen Kooperationsformen, wie sie sich jetzt etwa im Prümer Vertrag, BGBl. 2006, II, $626 \mathrm{ff}$., Ausführungsgesetz, BGBl. 2006, I, $1458 \mathrm{ff}$, finden, hierzu W. Hummer Der Vertrag von Prüm, EuR 2007, 517-530. Vorausgesetzt sind auch die mit dem internationalen Privatrecht verbundenen dynamischen Verweisungen auf das anzuwendende ausländische Recht, zu entsprechenden Rekonstruktionen des Internationalen Privatrechts $B$. Schinkels Normsatzstruktur des IPR, 2007, $54 \mathrm{ff}$. mwN.

${ }^{39}$ Grundlegend $K$. Vogel Die Verfassungsentscheidung des Grundgesetzes für eine internationale Zusammenarbeit, 1964, $35 \mathrm{ff}$.

${ }^{40} \mathrm{~S}$. aber den Hinweis auf die Verpflichtung zur internationalen Zusammenarbeit bei Tietje Verwaltungshandeln (Fn. 1), $615 \mathrm{f}$.

${ }^{41} \S 292$ a HGB a.F.; die Nachfolgeregelung des Gemeinschaftsrechts zur Anwendung internationaler Rechnungslegungsstandards, Verordnung (EG) Nr. 1606/2002 des Europäischen Parlaments und des Rates v. 19. 7. 2002, AB1. L 243, v. 11. 9. 2002, kennt hingegen nur eine statische Verweisung mit einer Anpassungsbefugnis der Kommission.

${ }^{42} \mathrm{Zu}$ dessen Geschichte, Zusammensetzung und Verfahren Michael Private Standardsetter (Fn. 31), $431 \mathrm{ff}$.

${ }^{43}$ So etwa W. D. Bude/E. Steuber DStR 1998, 504 (507f.); Michael Private Standardsetter (Fn. 31), 444f.; dazu auch $H$. Bauer Internationalisierung des Wirtschaftsrechts, in: H. Bauer/D. Czybulka/A. Vosskuhle (Hrsg.) Umwelt, Wirtschaft und Recht, 2001, 69 (81 ff.).

${ }^{44}$ Der Wortlaut der Vorschrift enthielt keine unmittelbare Verweisung, sondern verlangte einen Abschluss nach ,international anerkannten Regeln“, der u.U. auch der verfassungskonformen - Auslegung im Sinne einer generalklauselartigen Verweisung offen gestanden hätte, vgl. J. Hellermann NZG 2000, 1097 (1100). Zu dieser wegen des staatlichen Letztentscheidungsrechts über den anzuwenden Standard zulässigen Verweisungsform Denninger Normsetzung (Fn. 33), $142 \mathrm{ff}$. mwN.

${ }_{45}$ Dazu Teubner'Global Bukowina' (Fn. 6), 4f.; A. Fischer-Lescano ARSP 88 (2002), 349 (371 f.); Teubner ZaöRV 63 (2003), 2 ff. 
sind in ihrer Umsetzung von ihm abhängig. Die Entscheidung, wer welchen Domain-Namen nutzen darf, fällen im Geltungsbereich des Grundgesetzes deutsche Gerichte nach deutschem Zivil- und Kollisionsrecht. ${ }^{46}$ Dies spiegelt sich in den Statuten von ICANN wider. Nach ihnen sind der Registrierung die Entscheidungen der nationalen Gerichte zugrunde zu legen ${ }^{47}$. Auch die Lex Mercatoria muss die bindenden Regeln des jeweils geltenden nicht-dispositiven Privatrechts anerkennen ${ }^{48}$ und setzt im Konfliktfall die Anerkennung und Vollstreckung durch staatliche Gerichte voraus. ${ }^{49}$ Darin unterscheidet sie sich strukturell nicht von nationalen Ausdrucksformen der Privatautonomie. Auch faktisch funktionieren die ,autonomen" Funktionssysteme nur im „Schatten der Hierarchie" des staatlichen Rechts. ${ }^{50}$ ICANN wurde auf Druck der US-Regierung gegründet, arbeitet unter deren Aufsicht und steht wegen Leistungsdefiziten immer wieder vor der Ablösung durch eine intergouvernementale Regulierung. ${ }^{51}$

${ }^{46}$ S. etwa BGHZ 148, 1 ff.; 148, 13 ff.; 149,191 ff.

${ }^{47}$ ICANN, Uniform Domain Name Dispute Resolution Policy, v. 26. 8. 1999, http://www.icann.org/dndr/udrp/policy.htm (Abruf: 16.10. 2007), Punkt 3 b.

${ }^{48}$ D. Martiny in: F. J. Säcker/R. Rixecker (Hrsg.) Münchener Kommentar zum Bürgerlichen Gesetzbuch, Bd. 10, 4. Aufl. 2001, Art. 27 EGBGB Rn. 37. Daraus, dass der Vorrang noch nichts über die praktische Bedeutung der einzelnen Regelungen aussagt, U. Stein Lex mercatoria, 1995, $195 \mathrm{ff}$., folgt nichts Gegenteiliges.

${ }^{49}$ K. F. Röhl/S. Magen ZfRSoz. 1996, 1 (39); auch Calliess Globale Kommunikation (Fn. 6), $77 \mathrm{f}$;; zur empirischen Bedeutung der staatlichen Vollstreckungsmacht s. etwa die Fallstudie zur Holzindustrie von W. Konradi Lex Mercatoria als globales Recht der Wirtschaft?, 2007, $33 \mathrm{f}$.

so Die Betonung des dogmatischen und faktischen Vorrangs des staatlichen Rechts ist nicht als Einwand gegenüber Konzeptionen des Rechtspluralismus zu verstehen. Ein auch historischer Überblick über die rechtssoziologische Pluralismusdiskussion bei B. Tamanaha, Understanding Legal Pluralismus, demnächst Sydney Law Review, 2008, mwN. Neben der staatlichen Rechtsordnung lassen sich eine Fülle weiterer Normensysteme beobachten, die in ganz unterschiedlichen Verhältnissen zur staatlichen Rechtsordnung stehen (Völkerrecht, Kirchenrecht, unterschiedliche Ausdrucksformen der Privatautonomie wie die Verbandsordnungen und die Lex Mercatoria). Für alle ist zwischen dem dogmatisch-normativen Selbstverständnis und der soziologischen Bedeutung zu unterscheiden. Das staatliche Normsystem ist insoweit durch zwei Eigenschaften gekennzeichnet: Erstens seinen dogmatischen Vorranganspruch - darin unterscheidet es sich etwa vom Verbandsrecht oder der Lex Mercatoria, nicht aber vom Völkerrecht; zweitens durch seine faktische Durchsetzungskraft, die unter anderem auch darauf beruht, dass es andere Normensysteme in konfliktvermeidender Weise in Bezug nimmt. In der Betonung dieser beiden Eigenschaften des staatlichen Rechts liegt weder eine Staatsfixierung, noch werden sie durch den Pluralismus als solchen in Frage gestellt.

51 Zur Bedeutung der staatlichen Regulierung für die Entwicklung von ICANN ein konziser Überblick bei $J$. Hofmann IPG 2005, 10 (17ff.). 


\section{Funktion der Souveränität}

Mit einer gewissen verfassungsrechtlichen Beruhigung lässt sich also feststellen, dass der von Art. 20 Abs. 2 GG geforderte Ableitungszusammenhang auch in den Globalisierungsprozessen gewahrt bleibt. Entsprechend selbstbewusst und dogmatisch zutreffend konstatiert das Bundesverfassungsgericht: „Das Grundgesetz erstrebt die Einfügung Deutschlands in die Rechtsgemeinschaft friedlicher und freiheitlicher Staaten, verzichtet aber nicht auf die in dem letzten Wort der deutschen Verfassung liegende Souveränität." 52 Doch worin liegt die Bedeutung dieses im dogmatischen Sinn souveränen "letzten Wortes“? ${ }^{53}$ Sie liegt nicht darin, dass Deutschland kraft seiner Verfassung gegenüber dem globalisierten Weltenlauf über faktische Entscheidungsfreiheit verfügt. Doch der verfassungsrechtlich geforderte Ableitungszusammenhang koppelt die Rechtsordnung unter dem Grundgesetz nur lose ${ }^{54}$ an die internationalisierten Entwicklungen. ${ }^{55}$ Die Kopplungsstellen geben damit die verfassungsrechtliche Möglichkeit, internationale Regulierungen anzupassen, aber auch sich einer internationalen Normsetzung zu entziehen. ${ }^{56}$ So nutzt das Bundesverfassungsgericht die Entscheidung zum Europäischen Haftbefehl zu dem Hinweis, dass „die mitgliedsstaatlichen Legislativorgane die politische Gestaltungsmacht im Rahmen der Umsetzung, notfalls auch durch die Verweigerung der Umsetzung, behalten."57 Die Souveränität schaltet zwischen die nationale Rechtsordnung

\footnotetext{
52 BVerfGE 111, 307 (319); vgl. auch BVerfGE 112, 1 (25f.); U. di Fabio Der Verfassungsstaat in der Weltgesellschaft, 2001, $90 \mathrm{ff}$.

53 Skeptisch etwa Ruffert Globalisierung (Fn. 13), 58.

54 Lose Kopplungen unterscheiden sich von strikten dadurch, dass die Reaktion des einen Systems auf ein anderes einer Entscheidung unterliegt, die auch Modifikationen einschließen kann. Das Konzept der losen Kopplung wurde von K. E. Weick Der Prozeß des Organisierens, 1985, 161 (163ff.), in die Organisationstheorie eingeführt und dann besonders auch in der Systemtheorie, s. etwa $N$. Luhmann Die Gesellschaft der Gesellschaft, 1997, $196 \mathrm{ff}$, fruchtbar gemacht. Zur „losen Kopplung ${ }^{\star}$ von Verfassungs- und internationalen Gerichten $S$. Oeter Rechtsprechungskonkurrenz zwischen nationalen Verfassungsgerichten, Europäischem Gerichtshof und Europäischem Gerichtshof für Menschenrechte, VVDStRL 66 (2007), 361 (367ff.).

$55 \mathrm{Zu}$ einem ähnlichen Konzept in der amerikanischen Literatur Röben Außenverfassungsrecht (Fn. 8), 528.

56 Gegen eine Auflösung des Spannungsverhältnisses von nationalem und internationalem Recht auch Schorkopf Überstaatlichkeit (Fn. 18), 27 f., 299 ff.

57 BVerfGE 113, 273 (301); zum Souveränitätsbezug der Entscheidung Schorkopf Überstaatlichkeit (Fn. 18), 91 f; der auch darin deutlich wird, dass die Entscheidung in unmittelbarem zeitlichen Kontext von EuGH, Rs. C-105/03, Pupino, Slg. 2005, I-5285 Rn. 59 f. erging, die eine rahmenbeschlusskonforme Auslegung des nationalen Rechts fordert, dazu auch die abw. Meinung von M. Gerhardt BVerfGE 113, 339 (340).
} 
auf der einen und den internationalen Regulierungen auf der anderen Seite einen im Einzelnen unterschiedlich ausgestalteten nicht nur rechtlichen, sondern auch politischen Filter. ${ }^{58}$

Sie erfüllt damit auch für die internationale Ordnung zwei wichtige Funktionen. Zum einen ermöglicht sie die akkommodierende Wahrung nationaler Eigenheiten, ${ }^{59}$ die letztlich auch der Implementierung des sanktionsschwachen internationalen Rechts dient, indem sie seine Befolgung auf das Ganze gesehen wahrscheinlicher macht. ${ }^{60}$ Aus der jüngsten Rechtsprechung sei etwa an die Entscheidung zur Dresdner Waldschlösschenbrücke erinnert. Sie versucht, der Besonderheit unmittelbar demokratischer Entscheidungen gegenüber der Welterbekonvention Rechnung zu tragen. ${ }^{61}$ Hierher gehört auch, dass das Bundesverfassungsgericht zwar die Berücksichtigung der Entscheidungen internationaler Gerichte verlangt, ${ }^{62}$ aber selbst bei der Verurteilung wegen einer Menschenrechtsverletzung keine „schematische Vollstreckung“ erwartet, „... wenn es sich bei dem einschlägigen nationalen Recht um ein ausbalanciertes Teilsystem des innerstaatlichen Rechts handelt" ${ }^{* 63}$.

Zum anderen hat die Souveränität den Effekt einer „Rute im Fenster“, der gegenüber sich verselbständigenden Internationalisierungsprozessen disziplinierend wirken kann. Dies hat etwa die Solange-I-Entscheidung ${ }^{64}$ des Bundesverfassungsgerichts gezeigt, ${ }^{65}$ in der ein wesentlicher Grund für den Ausbau des Grundrechtsschutzes durch den Europäischen Gerichtshof gesehen wird. ${ }^{66}$ Bezeichnenderweise verlangt der Eu-

\footnotetext{
s8 Vgl. zu einem ähnlichen Souveränitätsverständnis J. H. H. Weiler ZaöRV 64 (2004), 547 (562).

59 Di Fabio Verfassungsstaat (Fn. 52), 39f.; C. Möllers Globalisierte Jurisprudenz, in: M. Anderheiden/S. Huster/S. Kirste (Hrsg.) Globalisierung als Problem von Gerechtigkeit und Steuerungsfähigkeit des Rechts, 2001, 41 (50ff.).

${ }^{60}$ Zur Bedeutung von Differenzierungen für das Gelingen internationaler Kooperationen Slaughter World Order (Fn. 7), 213 ff.; zur Bedeutung der Souveränität in Form der Anerkennung als internationaler Akteur für die "Compliance" in internationalen Regulierungszusammenhängen $A$. Chayes/A. Handler Chayes The New Sovereignty, 1995,22 ff.

${ }^{61}$ BVerfG, 2 BvR 695/07 vom 29. 5. 2007, Rn. 35.

62 BVerfGE 74, 358 (370); 111, 307 (318); BVerfG, NJW 2007, 499 (503).

${ }^{63}$ BVerfGE 111, 307 (LS, 323, 327); BVerfG, NJW 2007, 499 (503); s. auch die Divergenzen zwischen dem Europäischen Gerichtshof für Menschenrechte und BVerwGE 111, 223 (225ff.), zum Aufenthaltsrecht bei einer Bedrohung durch einen Bürgerkrieg. ${ }^{64}$ B VerfGE 37, 271 ff.

${ }^{65}$ In EuGH, Rs. 4/73, Nold, Slg. 1974, 491, hat der Europäische Gerichtshof sogar versucht, der Entscheidung des Bundesverfassungsgerichts zuvor zu kommen.

${ }^{66} \mathrm{~J}$. A. Frowein Europäisches Gemeinschaftsrecht und Bundesverfassungsgericht, in: C. Starck, Bundesverfassungsgericht und Grundgesetz, 1976, 187 (201 ff.); G. Ress Die
} 
ropäische Gerichtshof - entgegen seiner sonstigen Rechtsprechung zur Wirkung völkerrechtlicher Verträge ${ }^{67}$ - eine Umsetzung des WTORechts. ${ }^{68}$ Dies erlaubt der Gemeinschaft und ihren Mitgliedsstaaten, sich bei Verfahren mit hochpolitischen Gegenständen - Hormonfleisch, Gentechnik - einer unfreiwilligen Integration ${ }^{69}$ durch die WTO-Expertengremien zu entziehen und die völkerrechtlichen Sanktionen in Kauf zu nehmen. ${ }^{70}$ Wenn der Generaldirektor der WTO nun dafür plädiert, nationale Regelungen $\mathrm{zu}$ privilegieren, die für die Identität politischer Gemeinschaften von besonderer Bedeutung sind,71 mag dies auch auf die von der Europäischen Union genutzte Entkoppelung zurückzuführen sein. ${ }^{72}$ Dabei versteht sich, dass der Dialog zwischen dem Grundgesetz und den internationalen Entwicklungen asymmetrisch ist. Internationale Entwicklungen können bereits strukturell nicht beliebig auf Idiosynkrasien einzelner Rechtssysteme eingehen. Doch die lose Kopplung bietet Gelegenheit, dort Modifikationen einzuführen und Impulse zu geben, wo Internationalisierungen über wesentliche politische Selbstbestimmungen hinwegzugehen drohen.

\footnotetext{
Verwaltung 20 (1987), 177; W. Zeidler Wandel durch Annäherung, in: W. Brandt (Hrsg.), FS Simon, 1987, 727 ( 733 f.); ein weiteres gemeinschaftsrechtliches Beispiel deutete sich bei der Umsetzung des Stabilitätspaktes an, $F$. W. Scharpf Legitimationskonzepte jenseits des Nationalstaats, in: G. F. Schuppert/I. Pernice/U. Haltern (Hrsg.) Europawissenschaft, 2005, 705 (731).

${ }^{67}$ St. Rspr. siehe nur EuGH, Rs. C-63/99, Gloszczuk, Slg. 2001, I-6393, Rn. 30; EuGH, Rs. C-171/01, Wählergruppe Gemeinsam, Slg. 2003, I-4320, Rn. 54; EuGH, Rs. C-265/03, Simutenkov, Slg. 2005, I-2596 Rn. 21; R. Mögele in: R. Streinz (Hrsg.) EUV/ EGV, 2003, Art. 300 EGV Rn. 77; C. Tomuschat EuGRZ 2007, 1 (3).

${ }^{68}$ EuGH, Rs. C-149/96, Portugal/Rat, Slg. 1999, I-8395 Rn. 47; Rs. C-307/99, OGT Fruchthandelsgesellschaft, Slg. 2001, I-3159 Rn. 24; Rs. C-122/00, Omega Air u.a, Slg. 2002, I-2569, Rn. 93; Rs. C-76/00 P, Petrotub und Republica, Slg. 2003, I-79, Rn. 53; Rs. C-377/02, Léon Van Parys NV, Slg. 2003, I-10497 Rn. 52.

${ }^{69}$ Gegen ein Integrationsmodell der WTO etwa $A$. v. Bogdandy KJ 2001, 425 (426ff.).

${ }^{70} \mathrm{C}$. Tietje The WTO Sanctions Regime and International Constitutional Political Economy, 2007, $2 \mathrm{f}$.

${ }^{71}$ P. Lamy The Emergence of Collective Preferences in International Trade, 2004, $8 \mathrm{ff}$., http://trade.ec.europa.eu/doclib/docs/2004/september/tradoc_118925.pdf (Abruf: 11. 8. 2007); zu entsprechenden Vorschlägen iE Reusch Legitimation (Fn. 8), 237 ff.; eine gewisse Parallele findet dieser Vorschlag in den Staatsnotstandsklauseln bilateraler Investitionsschutzabkommen; zur Bedeutung des Staatsnotstands und entsprechender Klauseln für privatrechtliche Ansprüche BVerfG, NJW 2007, $2610 \mathrm{ff}$.

72 Sollen diese Rückkopplungsmöglichkeiten erhalten bleiben, spricht auch nichts für eine Stärkung des Sanktionssystems der WTO, so aber Tietje The WTO Sanctions Regime (Fn. 70), 3; P.-T. Stoll DVBl. 2007, 1064 (1070).
} 


\section{Demokratie}

Mögen die Ableitungsketten für einen schwachen rechtlichen Begriff der Souveränität noch ausreichend sein - sind sie aber nicht zu lang, wenn sie an den Anforderungen des Demokratieprinzips gemessen werden? Viele Reaktionen, nicht nur in der Staatsrechtslehre, gehen zumindest implizit von einem demokratischen Defizit der Internationalisierung aus.

\section{Die identitärdemokratische Tradition und der Defizitkonsens}

Vor dem Hintergrund der demokratietheoretischen Tradition der deutschen Staatsrechtslehre ist diese Wahrnehmung der Globalisierung ausgesprochen nahe liegend. Die Weimarer Diskussion kennzeichnet fast durchgängig ein identitäres Demokratieverständnis. ${ }^{73}$ Demokratie ist danach die Herrschaft der Regierten über sich selbst, die Aufhebung des Herrschaftsproblems in kollektiver Autonomie. Ihre Idealform ist die unmittelbare Demokratie durch Volksabstimmungen oder Akklamation, in denen sich der Volkswille unvermittelt zum Ausdruck bringt. ${ }^{74}$ Repräsentative, parlamentarische Formen der Demokratie gelten als defizitär und nur den widrigen Umständen großer Flächenstaaten geschuldet. $^{75}$

Auch wenn die demokratietheoretische Diskussion in der Politikwissenschaft, die seit den 50er Jahren weitgehend von einem anti-identitären Konsens geprägt wird, ${ }^{76}$ nicht spurlos an der Staatsrechtslehre vorübergegangen ist, finden sich dort auch heute noch identitäre Untertöne. ${ }^{77}$ So versäumt der entsprechende Abschnitt im Handbuch des Staatsrechts zwar nicht eine „Kritik des identitär-unmittelbaren Demo-

${ }^{73}$ R. Poscher Vom Werterelativismus zu einer pluralistischen Demokratietheorie, in: C. Gusy (Hrsg.) Demokratisches Denken in der Weimarer Republik, 2000, 191 (211); C. Schönberger Demokratisches Denken in der Weimarer Republik: Anfang und Abschied, ebd. 664 (666f.).

74 Eine aufschlussreiche spieltheoretische Rekonstruktion der rousseauschen Demokratievorstellung bei $F$. W. Scharpf Interaktionsformen, 2000, $258 \mathrm{ff}$.

$75 \mathrm{Vgl}$. etwa so unterschiedliche Autoren wie $H$. Kelsen Vom Wesen und Wert der Demokratie, (1. Aufl. 1920), in: M. Jestaedt/O. Lepsius (Hrsg.) Verteidigung der Demokratie, 2006, 11; C. Schmitt Die geistesgeschichtliche Lage des heutigen Parlamentarismus, 3. Aufl. 1961, $28 \mathrm{f}$.

${ }^{76}$ Zum politikwissenschaftlichen Mainstream der Zeit H. Abromeit Wozu braucht man Demokratie?, 2002, $69 \mathrm{ff}$.

77 G. Lübbe-Wolff Europäisches und nationales Verfassungsrecht, VVDStRL 60 (2001), 246 (250) mwN. 
kratieverständnisses"78. Dennoch beruht auch diese kritische Rekonstruktion - wie auch andere ${ }^{79}$ - noch auf einem als „reale Größe ${ }^{480}$ gedachten einheitlichen Volkswillen. ${ }^{81}$ Vor allem aber bleibt das Verhältnis zwischen repräsentativer und unmittelbarer Demokratie hierarchisch:82 „Dabei hat die repräsentative Demokratie gegenüber der unmittelbaren den größeren Legitimationsbedarf.“"83 Der Punkt - der mit einzelnen Äußerungen selbst an noch so prominenter Stelle auch gar nicht zu belegen wäre - ist nicht, dass sich die demokratietheoretische Tradition Weimars in der Staatsrechtslehre der Bundesrepublik ungebrochen fortgesetzt hätte. ${ }^{84}$ Doch der Hintergrund - sei es diffuser oder gebrochener, expliziter oder impliziter - identitärer Vorstellungen könnte das häufig vorausgesetzte Hierarchieverhältnis zwischen unterschiedlichen Institutionalisierungsformen demokratischer Prozesse erklären, das bei der Bewertung der Globalisierungsphänomene zwangsläufig zur Wahrnehmung eines Defizits führt.

Aus einer Perspektive, die typischerweise bereits unmittelbare und parlamentarische Demokratie hierarchisiert, müssen die vorgestellten Globalisierungsphänomene dem Demokratieprinzip Hohn sprechen.

${ }^{78}$ E.-W. Böckenförde HStR III, 3. Aufl. 2005, § 34 Rn. 4.

${ }^{79}$ M. Sachs in: ders. (Hrsg.) Grundgesetz Kommentar, 4. Aufl. 2007, Art. 20, Rn. 16: „es besteht in gewissem Sinne Identität von Regierenden und Regierten, freilich schon durch die Mehrheitsentscheidung, nicht erst durch Repräsentation mediatisiert"; H. Dreier in: ders. (Hrsg.) Grundgesetzkommentar, Bd. 2, 2. Aufl. 2006, Art. 20, Rn. 71: „Die der staatlichen Rechtsordnung Unterworfenen sollen im Sinne der Selbstbestimmung des Volkes deren autonome Schöpfer, die Adressaten der Rechtsnormen zugleich deren Autoren sein".

${ }^{80} E$.-W. Böckenförde HStR III, 3. Aufl. 2005, § 34 Rn. 4.

81 E.-W. Böckenförde HStR III, 3. Aufl. 2005, $\$ 34$ Rn. 4: „Der Volkswille ist ... aus sich selbst heraus zunächst unformiert und diffus, er enthält in sich Möglichkeiten des konkreten selbst, ... um ... eine konkrete Bestimmtheit anzunehmen, bedarf er der Formung in einem Verfahren ... <das> ihn ... zum ,Sprechen "bringt. “; J. Isensee HStR II, 3. Aufl. 2004, § 15, Rn. 120: „Der herrschaftliche Verband bildet die Entscheidungseinheit, über die sich der im Ursprungsbereich noch diffuse Wille des Volkes artikuliert und realisiert."

${ }^{82}$ P. Badura HStR II, 3. Aufl. 2004, § 25 Rn. 35, 41, zum überschießend programmatisch-utopischen Moment der Demokratie als Volksherrschaft ohne Staat in der unmittelbaren Demokratie.

${ }^{83}$ E.-W. Böckenförde HStR III, 3. Aufl. 2005, $\$ 34$ Rn. 1; auch für die angelsächsische Diskussion wird z.T. beobachtet, dass die „gute alte Bürgerversammlung“ als demokratisches Ideal angesetzt wird, $R$. Dworkin Freiheit, Selbstregierung und der Wille des Volkes, in: S. Gosepath/G. Lohmann (Hrsg.) Philosophie der Menschenrechte, 1999, 292 (297).

${ }^{84}$ Kritisch bereits $M$. Kriele Das demokratische Prinzip im Grundgesetz, VVDStRL 29 (1971), 46 (55 ff.); Lübbe-Wolf Verfassungsrecht (Fn. 77), $252 \mathrm{f}$. 
Demokratische Legitimation können sie allenfalls noch in homöopathischen Dosen enthalten - so weit haben sie sich vom Unmittelbarkeitsideal entfernt.

\section{Kompensationsstrategien}

Dieser Defizitwahrnehmung entspricht eine Reihe von Strategien, mit denen der Globalisierung begegnet wird. ${ }^{85}$

\section{a) Nationale Gegensteuerung}

Zum Teil wird das festgestellte Demokratiedefizit zum Anlass genommen, die Forderung nach nationaler Gegensteuerung zu erheben. „Soll Staatlichkeit erhalten bleiben, erscheint ein Gegensteuern im Globalisierungsprozess notwendig, und zwar in Form eines Kampfes um die Reetablierung des Primats der Politik in beherrschbaren Räumen. “86 Angesichts des alle Gesellschaftsbereiche durchdringenden Epochencharakters der Globalisierung verspricht ein solcher Kampf jedoch allenfalls sehr begrenzte Erfolge.

\section{b) Demokratisierung der internationalen Ebene}

Während diese Strategie gleichsam zum historischen Rückzug rät, eilen andere der Zeit voraus. Das nationale Demokratiedefizit soll durch eine Demokratisierung der internationalen Ebene kompensiert werden. Die Vorschläge reichen von der Konstitutionalisierung und Demokratisierung der Vereinten Nationen, 87 über die Etablierung internationalisierter deliberativer, ${ }^{88}$ assoziativer oder auch autonomer ${ }^{89}$ Governancestrukturen unter Beteiligung von Nichtregierungsorganisationen, 90 bis

$85 \mathrm{Vgl}$. ähnliche Typologien bei $A$. Peters Elemente einer Theorie der Verfassung Europas, 2001, 628ff.; A. v. Bogdandy ZaöRV 63 (2003), 853 (860ff.).

86 Böckenförde Die Zukunft politischer Autonomie (Fn. 11), 123.

87 J. Habermas Hat die Konstitutionalisierung des Völkerrechts noch eine Chance?, in: ders., Der gespaltene Westen, 2004, 113 ff.; B. Fassbender Grund und Grenzen der konstitutionellen Idee im Völkerrecht, in: O. Depenheuer u.a. (Hrsg.), FS Isensee, 2007, $73 \mathrm{ff}$.; skeptisch $D$. Grimm Die Verfassung im Prozess der Entstaatlichung, in: M. Brenner/P. M. Huber/M. Möstl (Hrsg.), FS Badura, 2004, 145 (165 ff.).

${ }^{88} K$. D. Wolf Die neue Staatsräson, $2000,192 \mathrm{ff}$. Vor einer vulgär-deliberativen Umdeutung expertokratischer Strukturen warnt $C$. Möllers ZaöRV 65 (2005), $382 \mathrm{ff}$.

${ }^{89}$ Teubner 'Global Bukowina' (Fn. 6), 3 (4ff.); Teubner ZaöRV 63 (2003), 2; A. Fischer-Lescano/G. Teubner Regime-Kollisionen, 2006, $25 \mathrm{ff}$.

90 T. Risse Transnational governance and legitimacy, in: A. Benz/Y. Papadopoulos (eds.), Governance und Democracy, 2006, 177 (192ff.), eine Rückkopplung der De- 
hin zur Einrichtung eines - und sei es nur komplementären - Weltstaats $^{91}$ mit einem Weltparlament ${ }^{92}$ als demokratischem Schlussstein.

Doch so zukunftsweisend diese Perspektiven auch sein mögen, gehen sie auf absehbare Zeit an der Realität der Globalisierung vorbei.93 Mit der - demokratietheoretisch umstrittenen - ${ }^{94}$ Ausnahme der Europäischen Union sind weder internationale Organisationen noch internationalisierte Funktionssysteme demokratisiert.95 Ferner bieten sie keine Antwort auf die häufig erst wahrhaft politische Frage nach der Koordination unterschiedlicher Systemansprüche. ${ }^{96}$ Auch unter verstärkter Einbeziehung von Nichtregierungsorganisationen können Governancestrukturen von - wie es Martin Shapiro formuliert hat - „Experten und Enthusiasten“97 allein keine demokratische Legitimation vermit-

liberationen in internationalen Governancestrukturen mit den nationalen Diskursen fordern.

91 O. Höffe Demokratie im Zeitalter der Globalisierung, 1999, $296 \mathrm{ff}$.

92 R. Falk/A. Strauss Stanford Journal for International Law 36 (2000), $191 \mathrm{ff}$;; im politischen Raum vgl. die Kampagne für die Einrichtung eines UN-Parlaments u.a. von EP-Parlamentariern aus vier Fraktionen, http://de.unpacampaign.org/index.php (Abruf: 9. 10. 2007); kritisch C. Walter Vereinte Nationen und Weltgesellschaft, in: S. v. Schorlemer (Hrsg.), Globale Probleme und Zukunftsaufgaben der Vereinten Nationen, 2006, 218 (232ff.).

${ }^{93}$ Beispiele für internationale Organisationen, die mit Repräsentationsgremien versehen sind, bei $S$. Kadelbach Die parlamentarische Kontrolle des Regierungshandelns bei der Beschlussfassung internationaler Organisationen, in: R. Geiger (Hrsg.) Neuere Probleme der parlamentarischen Legitimation im Bereich der auswärtigen Gewalt, 2003, 41 (56f.); L. Gramlich, Möglichkeiten einer „demokratischen Legitimation“ des Völkerrechts, in: L. Gramlich (Hrsg.) Zwischen Legitimität und Effektivität, 2006, 1 (13ff.).

${ }^{94}$ Skeptisch $D$. Grimm JbStaatsuVerwWiss 6 (1992/93), 13 ff.; F. W. Scharpf Demokratie in der transnationalen Politik, in: W. Streeck (Hrsg.) Internationale Wirtschaft, nationale Demokratie, 1998, 151 (153 ff.); aus kulturwissenschaftlicher Perspektive $U$. Haltern AöR 128 (2003), 511 (545); eher optimistisch I. Pernice Verw. 1993, 449 (487f.); C. Calliess Optionen zur Demokratisierung der Europäischen Union, in: H. Bauer/ P. M. Huber/K.-P. Sommermann (Hrsg.) Demokratie in Europa, 2005, $281 \mathrm{ff.}$

95 Scharpf Interaktionsformen (Fn. 74), 349; W. Bausback Demokratieprinzip in der Krise?, in: Gramlich (Hrsg.) Zwischen Legitimität und Effektivität, 2006, 137 (151); T. D. Zweifel International Organizations and Democracy, 2006, $13 \mathrm{ff}$.

${ }^{96}$ Zum Problem der „Entfesselung des Sektoralen“ $R$. Wahl Internationalisierung des Staates, in: J. Bohnert (Hrsg.), FS Hollerbach, 2001, 193 (209); konkret zu den Schwierigkeiten der Koordination des WTO- mit dem internationalen Umweltschutzrecht s. etwa M. Hilf NVwZ 2000, $481 \mathrm{ff}$. Zu der - noch - ablehnenden Haltung der WTOPanels gegenüber dem im Protokoll von Cartagena über die biologische Sicherheit zum Übereinkommen über die biologische Vielfalt, ABl.EG Nr. L 201 v. 31. 7. 2002, S. 48, anerkannten Vorsorgeprinzip Stoll EuZW 2007, 471 ff.

${ }^{97}$ M. Shapiro Indiana Journal of Global Legal Studies 8 (2001), 369 (376). 
teln. ${ }^{98}$ Und die Weltregierung bleibt vorerst ein - je nach kosmopolitischer Couleur - Menschheitstraum oder -albtraum ${ }^{99}$. Zumindest einige dieser Strategien stehen in der Gefahr dessen, was Michel Foucault in anderem Zusammenhang die „Auslassung der Gegenwart" genannt hat. ${ }^{100}$

\section{c) Legitimation durch Leistung}

Eine dritte Strategie setzt mehr oder weniger offen nicht mehr auf Demokratie, sondern auf eine technokratische Legitimation durch die Globalisierungsgewinne. „Aufgabe der Staatsrechtslehre heute muss es ... sein, ... Legitimationstheorien zu entwickeln, die ... auf komplexe ... transnationale Regelungsstrukturen Anwendung finden können. ... hierunter $\langle i s t\rangle$ zu verstehen, dass ... entterritorialisierte Regelungsmechanismen dann gerechtfertigt sind, ,wenn sie durch ihre (weitgehend indirekten) Leistungen ... zum Wohlergehen (einschließlich Selbstbestimmung) ${ }^{101}$ der Bürger beitragen'. " ${ }^{102}$ Entsprechende leistungsbezogene Legitimationskonzepte werden heute zumeist über den von Fritz Scharpf ${ }^{103}$ entwickelten Gedanken der Output-Legitimation als Element eines komplexen Demokratieverständnisses nobilitiert.

Doch müssen demokratietheoretisch Demokratie und Legitimation auseinander gehalten werden. Wie Max Weber dies für die faktische Legitimität gezeigt hat, ${ }^{104}$ kann auch normative Legitimation unterschiedliche Quellen haben. Dabei liegt die normative Legitimation durch Leis-

\footnotetext{
${ }^{98}$ Kritisch etwa auch Herdegen Entformalisierung (Fn. 11), 27 ff.; Slaughter World Order (Fn. 7), 9 ff., 224.

${ }_{99}$ Zur Kritik der Weltstaatsidee etwa $M$. Zürn Regieren jenseits des Nationalstaats, 1998, 354; D. v. Daniels Vier Asse und ein Revolver, in: G.-P. Calliess/M. Mahlmann (Hrsg.), Der Staat der Zukunft, 2002, $55 \mathrm{ff}$.

${ }_{100}$ M. Foucault, Geschichte der Gouvernementalität II, 2004, 264.

${ }^{101}$ Wenn die Wahrung der Selbstbestimmung in den Leistungskatalog eingestellt wird - s. auch Peters Elemente (Fn. 85), 580 - droht die Argumentation zirkulär zu werden: Leistungen legitimieren demokratische Selbstbestimmung, wenn sie demokratische Selbstbestimmung leisten. Die Einbeziehung der Selbstbestimmung in den legitimierenden Leistungskatalog hat dann eine rein salvatorische Funktion gegenüber dem Technokratieverdacht.

102 C. Tietje DVBl. 2003, 1081 (1095), in Anlehnung an Peters Elemente (Fn. 85), 580 ff.; kritisch Wahl Internationalisierung (Fn. 96), 218; Bausback Demokratieprinzip in der Krise (Fn. 95), 147f. Ähnlich bereits die neofunktionalistischen Argumentationen bei $J$. H. Kaiser Bewahrung und Veränderung demokratischer und rechtsstaatlicher Verfassungsstruktur der internationalen Gemeinschaft, VVDStRL 23 (1966), 23 f.; H. P. Ipsen Fusionsverfassung Europäische Gemeinschaften, 1969, 60; ders. Verfassungsperspektiven der Europäischen Gemeinschaften, 1970, $14 \mathrm{ff}$.

${ }^{103}$ F. W. Scharpf Demokratietheorie zwischen Utopie und Anpassung, 1975, $21 \mathrm{ff}$.

${ }^{104} M$. Weber. Wirtschaft und Gesellschaft, 5. Aufl. 1972, 16.
} 
tung, Output oder gar Outcome ${ }^{105}$ quer zu der Legitimation durch eine bestimmte Herrschaftsform, wie sie Art. 20 Abs. 2 GG fordert. Allen Herrschaftsformen ist gemein, dass sie eines gewissen Maßes an Leistungsfähigkeit bedürfen. ${ }^{106}$ Dies gilt für Monarchien und Aristokratien, ebenso wie für die Demokratie. ${ }^{107}$ Legitimation durch Leistung ist gerade kein Spezifikum demokratischer Herrschaft und kann die verfassungsrechtlich geforderte spezifisch demokratische Legitimation nicht ersetzen. ${ }^{108}$ Dies letztlich auch deshalb nicht, weil die demokratische „Verständigung über die substantielle Rationalität von Entscheidungen dem Denken in Kategorien der Output-Legitimation vorhergehen muss“. 109

\section{d) Die Weimarer Konstellation}

Mit einiger Zuspitzung ließe sich sagen, dass die Wahrnehmung der Globalisierung aus der Perspektive des demokratischen Defizits zwar nicht politisch, aber strukturell zu einer Weimarer Konstellation führt. Wie der Parlamentarismus in Weimar gilt die Internationalisierung als Abfall vom demokratischen Ideal. Das Leiden an der demokratischen Wirklichkeit führt zu einer Orientierung an der Vergangenheit, zur Entwicklung von utopienahen Entwürfen oder gar zur Abkehr von der Demokratie als Legitimationsform politischer Herrschaft.

${ }^{105}$ Der Demokratiekritiker bei $R$. Dahl Democracy and its Critics, 1989, 174, verlangt "Outcome“.

106 Selbst wenn es zuträfe, dass die Entscheidung für die Demokratie letztlich auf ihrer Leistungsfähigkeit beruht, Peters Elemente (Fn. 85), $647 \mathrm{f}$., so ist diese Entscheidung mit Art. 20 Abs. 2 GG bereits gefallen. Sollten sich andere Regierungsformen - etwa technokratische - als leistungsfähiger erweisen, entsprächen sie dadurch nicht dem Demokratieprinzip in Art. 20 Abs. 2 GG.

${ }^{107}$ M. Greven Output-Legitimation, in: M. Buckmiller/J. Perels (Hrsg.) Opposition als Triebkraft der Demokratie, FS Seifert, 1999, 477 (477f.).

108 Auch für Scharpf Legitimationskonzepte (Fn. 66), 733, sind jedenfalls Verteilungsentscheidungen letztlich nur über eine Input-Orientierung zu legitimieren, vgl. aber auch ders. Demokratie (Fn. 94), 228 (242): Für die transnationale Politik spiele „die input-orientierte Legitimation weder positiv noch negativ eine besondere Rolle."; zur Kritik an output-orientierten Legitimationsstrategien K. Kaiser Internationale Politik 1998, 3 (8f.); Abromeit Demokratie (Fn. 76), 19, 173; D. Fuchs Gemeinwohl und Demokratieprinzip, in: G. F. Schuppert/F. Neidhardt (Hrsg.) Gemeinwohl, 2002, 87 (101), der u.a. auf die paternalistischen Implikationen der Output-Orientierung hinweist, dazu auch F. W. Scharpf Interdependence and Democratic Legitimation, in: S. J. Pharr/R. D. Putnam (eds.) Disaffected Democracies, 2000, 101 (116).

109 Brock Demokratie (Fn. 1), 288; vgl. auch Abromeit Demokratie (Fn. 76), 166; zur Kritik technokratischer Internationalisierungskonzepte auch $\mathrm{Wahl}$ Internationalisierung (Fn. 96), 193 (218). 


\section{Kontextbezogenes realistisches Verständnis des Demokratieprinzips}

Eine andere Perspektive ergibt sich, wenn der Beurteilung der aufgezeigten Globalisierungsphänomene ein kontextbezogenes realistisches Modell der Demokratie zugrunde gelegt wird. ${ }^{110}$ Entsprechende Ansätze in der Demokratietheorie orientieren sich an den realen Verwirklichungsbedingungen demokratischer Institutionen, ohne dabei normative Ansprüche aufzugeben. ${ }^{111}$ Nach ihnen bewirkt Demokratie keine Aufhebung des Herrschaftsproblems, sondern konstituiert eine Form der Herrschaft - im Idealfall - von Mehrheiten über Minderheiten. ${ }^{112}$ In Demokratien herrscht nicht ein als Einheit gedachter Volkswille, sondern in Demokratien konkurrieren unterschiedliche Konzeptionen des Gemeinwohls ${ }^{113.114}$ Demokratie verlangt keine Identität von Regierenden und Regierten, sondern ist durch unterschiedliche Formen der Partizipation sowie der Verantwortlichkeit und Responsivität ${ }^{115}$ der Regierenden gegenüber den Regierten gekennzeichnet, deren Gemein-

$110 \mathrm{Vgl}$. mit ähnlicher Stoßrichtung das Plädoyer für ein realistisches Verständnis des Parlamentarismus bei $M$. Morlok Entformalisierung und Entparlamentarisierung politischer Entscheidungen als Gefährdungen der Verfassung?, VVDStRL 62 (2003), 39 (65f.).

111 Einen mangelnden Kontextbezug in der europäischen Demokratiediskussion beobachtet etwa Abromeit Demokratie (Fn. 76), 64.

112 Zum hierarchischen Charakter demokratischer Herrschaft Scharpf, Interaktionsformen (Fn. 74), $281 \mathrm{ff}$.

$113 \mathrm{Zu}$ den unterschiedlichen Konzeptionen des Gemeinwohls R. Mayntz Wohlfahrtsökonomische und systemtheoretische Ansätze zur Bestimmung des Gemeinwohls, in: H. Münkler/K. Fischer (Hrsg.) Gemeinwohl und Gemeinsinn, 2002, $111 \mathrm{ff}$. Mit ihnen hängt auch die für die demokratische Legitimation der Europäischen Union kontrovers diskutierte Frage nach den soziokulturellen Voraussetzungen der Demokratie zusammen. Nach $F$. W. Scharpf Regieren in Europa, 1999, 20, setzt das Gemeinwohl bereits begrifflich eine kollektive Identität voraus, die über die aggregierten individuellen Präferenzen hinausgeht; ähnlich Dworkin Freiheit (Fn. 83), 300ff. Besonders umstritten ist insoweit auch die Temporalisierung. Die Priorität der kollektiven Identität betonend etwa Grimm JbStaatsuVerwWiss 6 (1992/93), 13 ff.; die Prägung von Identitäten durch Institutionen unterstreichend etwa B.-O. Bryde StW 1994, 305 (307ff.).

114 Mit den Mehrheitskonzeptionen verbindet sich auch kein politischer Wahrheitsanspruch. Hierin unterscheiden sich realistische von deliberativen Modellen, die letztlich auch output-orientiert sind, Abromeit Demokratie (Fn. 76), 100ff. Über die Vorstellung der Einheit der Vernunft stehen sie identitären Demokratiemodellen nahe. Zu den Parallelen E. Kennedy Geschichte und Gesellschaft 1986, 380 (402ff.).

115 R. Dahl Polyarchy, 1971, 1: „key characteristic ... the continuing responsiveness of the government to the preferences of its citizens, considered as political equals“; Fuchs Demokratieprinzip (Fn. 108), 101: „Responsivität als Standard zur Beurteilung demokratischer Prozesse“; Abromeit Demokratie (Fn. 76), 176. 
wohlorientierung sie sichern. ${ }^{116}$ Normatives Ideal entsprechender Demokratietheorien sind nicht möglichst unmittelbare Institutionalisierungen, sondern kontextangemessene. In einer solchen kontextbezogenen realistischen Perspektive stehen die verfassungsrechtlichen Organisationsformen internationaler Kooperation in ihrer demokratischen Würdigkeit nicht a limine hinter denen für nationale Kontexte zurück.

\section{a) Der Kontext internationaler Kooperation}

Mit Blick auf die Internationalisierung ist zunächst von Bedeutung, dass eine sinnvolle Konzeption auch eines verfassungs rechtlichen Demokratieprinzips nicht ausschließen kann, dass ein demokratischer Verfassungsstaat sich an internationalen Kooperationen beteiligt. Realistischerweise sind diese Kooperationsformen - abgesehen vom Spezialfall der Europäischen Union - zurzeit nur in internationalen Verhandlungssystemen möglich. Dies ist in einer kontextbezogenen Perspektive aber ebenso wenig ein demokratischer Malus wie die parlamentarische Repräsentation im Flächenstaat. Für eine kontextbezogene Demokratiekonzeption rücken vielmehr die durch die Internationalisierungsprozesse gesteigerte Handlungsfähigkeit des Verfassungsstaats ${ }^{117}$ und die damit gesteigerten Partizipationschancen seiner Bürger in das Blickfeld. Nur durch die Internationalisierung lassen sich drängende Klima-, Umwelt- und Sicherheitsfragen sinnvoll adressieren. ${ }^{118}$ Erst durch die Internationalisierung können die Bürger überhaupt an der Lösung entsprechender Probleme partizipieren.

Die beschränkte Leistungsfähigkeit einzelstaatlicher Politik hat allerdings Einfluss auf das, was von dieser Partizipation erwartet werden kann. Mit demokratischer Herrschaft verbindet sich keine Omnipotenz, ${ }^{119}$ sondern ihr Möglichkeitsraum ${ }^{120}$ ist bei realistischer Betrachtung

116 Zur Funktionsweise der Rückkopplungen Scharpf Interaktionsformen (Fn. 74), 305 ff.; grundlegend $C$. Friedrich Constitutional Government and Politics, 1937, 16.

${ }^{117}$ Hobe Verfassungsstaat (Fn. 28), $435 \mathrm{f}$.

118 R. Mayntz Die Handlungsfähigkeit des Nationalstaats in Zeiten der Globalisierung, in: L. Heidbrink/A. Hirsch (Hrsg.) Staat ohne Verantwortung? 2007, 267 (274), hat zu Recht darauf hingewiesen, dass die Globalisierung nicht zu einer Einschränkung, sondern zu einer Überforderung der einzelstaatlichen Problemlösungskapazitäten geführt hat.

119 Vgl. aber etwa U. Volkmann AöR 127 (2002), 575 (577), der darin, dass die Globalisierung nicht politisch beherrschbar ist, das Grundproblem für die Demokratie sieht.

${ }^{120}$ Allgemein zum Möglichkeitsraum eines politischen Systems Mayntz Bestimmung des Gemeinwohls (Fn. 113), 123: „Das erreichbare Optimum auf Systemebene ist immer historisch kontingent: es besteht in einem Möglichkeitsraum, der durch die Merk- 
von vornherein auf das in einem bestimmten internationalen Kontext Erreichbare ${ }^{121}$ beschränkt. ${ }^{122}$ Es kann aber immerhin erwartet werden, dass das Verhandlungsergebnis besser ausfält als die beste einzelstaatliche Alternative. ${ }^{123}$ Für die europäische Union hat diese Mindesterwartung ihren verfassungs-, ${ }^{124}$ gemeinschafts- ${ }^{125}$ und unionsrechtlichen ${ }^{126}$ Ausdruck im Subsidiaritätserfordernis gefunden, das nach dem jetzigen Stand des Reformvertrags durch die Beteiligung der nationalen Parlamente weiter gestärkt werden soll. ${ }^{127}$

male des Ist-Zustands eines Systems, sein Entwicklungs- und Selbststeuerungspotential begrenzt ist." Der Möglichkeitsraum wird dabei maßgeblich durch politische Machtverhältnisse determiniert. Dass dadurch aber besonders auch in kleineren Staaten das demokratische Selbstverständnis nicht notwendig leiden muss, zeigt sich etwa bereits begrifflich am „autonomen Nachvollzug“ von Gemeinschaftsrecht in der Schweiz, dazu A. R. Ziegler ZEuS 2007, 247 (255 f.), auch G. Biaggini, in diesem Band.

121 Scharpf Interdependence (Fn. 108), 117; vgl. bereits ders., Demokratische Politik in der internationalisierten Ökonomie, in: M. Greven (Hrsg.) Demokratie - eine Kultur des Westens?, 1998, 81 (98ff.). Vgl. die aus der Perspektive grundrechtlicher Schutzaufträge getroffene Feststellung in BVerfGE 44, 141 (178), „daß bei internationalen Vertragsverhandlungen der Kreis der möglichen Verhandlungsergebnisse sich auf das dem Verhandlungspartner gegenüber politisch Erreichbare verengt. ${ }^{\text {“ }}$

122 Grundsätzlich ist Demokratie ein systemrelatives Konzept, dessen Beurteilung je nach Systemreferenz unterschiedlich ausfallen kann. Eine undemokratische Umwelt schließt Demokratie innerhalb eines Systems nicht aus. So können auch Dissidentengruppen in Diktaturen demokratisch organisiert sein. Komplexer werden die Verhältnisse aber, wenn die Willensbildungsprozesse auf Umwelt- und Systemebene - wie in inter- und supranationalen Kooperationen - miteinander verbunden werden. Insoweit muss besonders eine angemessene Informationsverarbeitung gewährleistet sein, um den demokratischen Charakter der Willensbildung auf der Systemebene zu erhalten, dazu unten "C“.

${ }^{123}$ Scharpf Interdependence (Fn. 108), 117: "better than the best alternative to the negotiated agreement (BANTA), and that it approaches nationally defined aspirations as closely as possible, given bargaining conditions and the BANTA positions of the other countries.“; vgl. auch ders., Demokratie in der internationalen Politik, in: U. Beck (Hrsg.), Politik der Globalisierung, 1998, 228 (235 f.). Ebd. 247, auch dazu, dass die externen Zwänge die Wahl zwischen Alternativen auch dann nicht demokratisch delegitimieren, wenn alle Alternativen mit der Auferlegung von Opfern verbunden sind.

124 Zum Grundsatz der Subsidiarität BVerfGE 89, 155 (210ff); 113, 273 (299), dort auch die abw. Meinung von $S$. Broß, BVerfGE 113, $319 \mathrm{ff}$,, der das Subsidiaritätsprinzip durch das Europäische Haftbefehlsgesetz bereits verletzt sah. Aus der Literatur etwa $M$. Heger ZIS 2007, $221 \mathrm{ff}$. mwN.

125 Art. 5 Abs. 2 EGV.

126 Art. 2 Abs. 2 EUV.

${ }^{127}$ Art. 5 Abs. 3 EUV i.d.F. des Reformvertragsentwurfs v. 23. 7. 2007 iVm dem Protokollentwurf v. 23. 7. 2007 über die Anwendung der Grundsätze der Subsidiarität und Verhältnismäßigkeit. So wurde die Stellungnahmefrist für die nationalen Parlamente verlängert und im Falle einer negativen Stellungnahme einer einfachen Mehrheit der 


\section{b) Partizipation, Responsivität, Gemeinwohl}

Doch auch ein kontextbezogenes Demokratieverständnis kann nicht, ohne seinen normativen Anspruch aufzugeben, eine Realität für demokratisch erklären, nur weil es zu ihr keine Alternativen gibt. Auch in den Internationalisierungsprozessen müssen sich die Partizipations-, Verantwortlichkeits- und Rückkopplungsstrukturen sowie der Gemeinwohlbezug umsetzen lassen. Diese Rahmenbedingungen sind jedoch auch in den internationalen Kooperationen grundsätzlich gewährleistet. Über Wahlen partizipieren die Bürger an den Globalisierungsthemen ebenso wie an anderen Politikfeldern. ${ }^{128}$ Sie wissen, dass sich die zur Wahl stehenden politischen Tendenzen auch auf internationale Kooperationen auswirken können. Die periodischen Wahlen bilden damit auch für Globalisierungsthemen die Grundlage der politischen Verantwortlichkeit und Responsivität der Abgeordneten und der Regierung, die den Gemeinwohlbezug sichern. ${ }^{129}$ Dabei kann eine realistische Wahrnehmung der internationalen Handlungsmöglichkeiten auch die verantwortungsverschleiernden „two level games" ${ }^{130}$ der Regierung erschweren. ${ }^{131}$ Angesichts der knappen Aufmerksamkeitsressourcen der Öffentlichkeit verlangt die Responsivität keine durchgängige öffentliche Begleitung ${ }^{132}$ der internationalen Kooperationen, sondern lediglich deren realistische Möglichkeit.133 Dass diese Möglichkeit besteht, zeigen etwa die öffent-

Gesamtzahl der den nationalen Parlamenten zugewiesenen Stimmen ein besonderes Entscheidungsverfahren zur Subsidiarität im Rat und im Europäischen Parlament eingeführt (Art. 7 des Protokollentwurfs).

${ }^{128}$ Zur Bedeutung der Ablehnung der Beteiligung am Irakkrieg durch den amtierenden Bundeskanzler im Bundestagswahlkampf 2002 G. Hellmann „... um diesen deutschen Weg zu Ende gehen zu können.", in: C. Egle/R. Zohlndörfer (Hrsg.) Ende des rot-grünen Projekts, 2007, 453 (463).

129 A. Benz Ansatzpunkte für ein europäisches Demokratiekonzept, in: B. KohlerKoch (Hrsg.), Regieren in entgrenzten Räumen, PVS Sonderheft 29 (1998), 345 (350).

${ }^{130} R$. D. Putnam International Organization 42 (1988), 425 (433ff.).

131 Scharpf Interdependence (Fn. 108), 119.

${ }^{132}$ Sie wirkt als Zensor, der den Gemeinwohlbezug der Internationalisierungspolitik sichern hilft, J. Elster The Market and the Forum, in: J. Elster/A. Hylland (eds.), Foundations of Social Choice Theory, 1986, 103-132. Das schließt nicht aus, dass partikularistische Positionen für Konzeptionen des Gemeinwohls ausgegeben werden. Doch machen sie sich gerade damit angreifbar, Scharpf Interdependence (Fn. 108), 118.

${ }^{133}$ Untersuchungen zu internationalen Regierungs- und Verwaltungskooperationen zeigen, dass bereits die Möglichkeit der Politisierung von Regelungsfragen einen erheblichen Einfluss auf die Verhandlungsführung hat, $W$. Wessels Die Öffnung des Staates, 2000, 420; Mayntz Handlungsfähigkeit (Fn. 118), 276: „drohende elektorale Bestrafung als stark empfundene Restriktion“. 
lichen Auseinandersetzungen um die Dienstleistungsrichtlinie ${ }^{134}$ oder den internationalen Klimaschutz. ${ }^{135}$

Das Plädoyer für eine kontextbezogene realistische Demokratiekonzeption soll nicht so verstanden werden, als würden die Internationalisierungsprozesse nicht auch eine Herausforderung für das Demokratieprinzip darstellen. Es sollte jedoch aufzeigen, dass die durch das Grundgesetz über die Art. 23, 24, 32, 59 GG ermöglichten internationalen Kooperationsformen auch im Zuge der Globalisierung nicht in ein grundsätzliches Spannungsverhältnis zum Demokratieprinzip treten, sondern es in demokratietheoretisch rekonstruierbarer Weise ausgestalten.

\section{Gewaltenteilung}

Die Qualität der demokratischen Legitimation der Globalisierungsphänomene hängt ganz wesentlich davon $a b$, inwieweit es gelingt, effektive demokratische Verantwortlichkeit für internationalisierte Regulierungen zu etablieren. In diesem Zusammenhang liegt in der die Globalisierung gewaltenteilig prägenden Stärkung der Exekutive ${ }^{136}$ die zentrale Entwicklung. ${ }^{137} \mathrm{Je}$ mehr Themen und Politikfelder in internationale Regulierungen eingebunden werden, desto häufiger werden Entscheidungen in Regierungsverhandlungen getroffen, und desto häufiger kann das Parlament - soweit es überhaupt beteiligt ist - nur noch bereits feststehende Verhandlungsergebnisse anerkennen. ${ }^{138}$

Als eindrucksvolles Negativbeispiel wird regelmäßig auf die Verabschiedung des WTO-Abkommens verwiesen. ${ }^{139}$ Erst kurz vor der Ab-

${ }^{134}$ Zur Wirksamkeit der Proteste A. Hatje NJW 2007, 2357 mwN.

135 Darin dürfte auch bei dem jetzigen Entwicklungsstand der internationalen Gemeinschaft die demokratietheoretische Funktion deliberativer Prozesse auf der internationalen Ebene unter Einbeziehung von Nichtregierungsorganisationen liegen: Sie tragen zu Transparenz und Öffentlichkeit bei, die die Grundlage auch nationaler Diskussionen bilden können, auf die Regierungen und Parlamente reagieren müssen.

${ }^{136}$ C. Tomuschat Der Verfassungsstaat im Geflecht der internationalen Beziehungen, VVDStRL 36 (1978), 7 (28ff); $R$. Schmidt Der Verfassungsstaat im Geflecht der internationalen Beziehungen, VVDStRL 36 (1978), 65 (100); Kadelbach Parlamentarische Kontrolle (Fn. 93), 41 (43).

${ }_{137}$ C. Walter DVB1. 2000, 1 (8) mwN.

${ }^{138} \mathrm{~S}$. bereits die eingehende Beschreibung bei Tomuschat Verfassungsstaat (Fn. 136), $28 \mathrm{ff}$.

${ }^{139}$ Ein Gegenbeispiel bildet das Multilaterale Investitionsschutzabkommen, das nicht zuletzt aufgrund des Widerstands in der Öffentlichkeit gescheitert ist, in der es als mas- 
stimmung lag den Parlamentariern eine vorläufige amtliche Übersetzung der 26000 Seiten der Schlussakte von Marrakesch vor. ${ }^{140}$ Nach Einschätzung von WTO-Experten waren sich nicht einmal die beteiligten Regierungen - geschweige denn die Parlamente oder gar die Öffentlichkeit - bewusst, welche Entscheidungskompetenzen auf die WTO übertragen wurden. ${ }^{141}$ Aus demokratie- und verfassungstheoretischer Perspektive liegt das Problem entsprechender Prozesse darin, dass gerade parlamentarische Auseinandersetzungen und die durch sie hergestellte Öffentlichkeit dazu beitragen können, Globalisierungsphänomene zu politisieren und damit Verantwortlichkeiten deutlich und Rückkopplungen möglich zu machen.142

Im Sinne einer realistischen Demokratietheorie erscheint eine angemessene Beteiligung des Parlaments an internationalen Kooperationen auch noch aus einem anderen Grund vorteilhaft, auf den Fritz Scharpf hingewiesen hat. Wenn die nationalen Parlamente nicht in die realistischen Optionen der internationalen Verhandlungspolitik einbezogen werden, kann es zu unrealistischen Anforderungen an die Politik kommen, die das politische System insgesamt desavouieren, ohne realistische Lösungen anbieten zu können. ${ }^{143}$ Auch dies hätte eine strukturelle Parallele zu Weimar, das gerade auch unter unrealistischer Gesinnungspolitik gelitten hat. Es gibt daher demokratie- und verfassungstheoretisch gute Gründe, die Beteiligungskompetenzen des Parlaments bei den unterschiedlichen Kooperationsformen dogmatisch auszuloten. ${ }^{144}$

sive Beschränkung nationaler Wirtschafts-, Umwelt- und Sozialpolitik zugunsten internationaler Konzerne kritisiert wurde, s. dazu $J$. Karl ZVgIRWiss 99 (2000), 143 (149f.).

${ }^{140} M$. Hilf Negotiating and Implementing the Uruguay Round, in: J. H. Jackson/ A. O. Sykes (eds.), Implementing the Uruguay Round, 1997, 121 (127); Reusch Legitimation (Fn. 8), 149.

${ }^{141}$ J. Jackson The World Trade Organization, 1998, 33; zur Überraschung der europäischen Regierungen nach der Hormon-Entscheidung der Streitbeilegungsorgane der WTO Reusch Legitimation (Fn. 8), $145 \mathrm{f}$.

${ }^{142}$ W. Ismayr Bundestag, in: S. Schmidt/G. Hellmann/R. Wolf (Hrsg.) Handbuch zur deutschen Außenpolitik, 2007, 175. Auch zwischen der Regierung und den sie unterstützenden Fraktionen kann es zu Meinungsverschiedenheiten kommen, doch haben diese anders als die Opposition meist kein Interesse daran, dass sie öffentlich werden, $R$. A. Lorz Interorganrespekt im Verfassungsrecht, 2001, 300; Ismayr ebd. 184.

143 Scharpf Interdependence (Fn. 108), 101 (120).

144 Hintergrund der Beteiligungskompetenzen des Bundestags ist eine weit - auch in die Tradition der Vereinigung - zurückreichende Debatte um den Charakter der Auswärtigen Gewalt, Nachweise bei $U$. Fastenrath Kompetenzverteilung im Bereich der auswärtigen Gewalt, 1986, 71 ff.; Kadelbach Parlamentarische Kontrolle (Fn. 93), 43; $R$. Wolfrum Kontrolle der auswärtigen Gewalt, VVDStRL 56 (1997), 38 (39f.); Röben Außenverfassungsrecht (Fn. 8), 1 ff. Für die Beurteilung einzelner Beteiligungsrechte 


\section{Entscheidungsrechte des Bundestags}

Neben seinen allgemeinen Befassungs- und Entschließungsrechten ${ }^{145}$ hat der Bundestag im Rahmen der auswärtigen Gewalt eine Reihe von besonderen Entscheidungsrechten. ${ }^{146}$ Er verfuigt über ein Zustimmungsrecht bei völkerrechtlichen Verträgen und die exklusive Befugnis zur Übertragung von Hoheitsrechten. Ferner hat das Bundesverfassungsgericht für die Einsätze der Bundeswehr einen Parlamentsvorbehalt entwickelt. ${ }^{147}$ Gerade dieser Parlamentsvorbehalt zeigt, wie sehr die Beteiligung des Bundestags zu einer Politisierung internationaler Kooperationen beitragen kann. Die Auslandseinsätze sind regelmäßig Thema in der öffentlichen Diskussion und sogar schon Gegenstand einer Vertrauensfrage gewesen. ${ }^{148}$

\section{Besondere Beteiligungsrechte in Angelegenheiten der Europäischen Union}

Aufgrund des im parlamentarischen Regierungssystem zu erwartenden Gleichklangs von Parlamentsmehrheit und Regierung sind für die politische Auseinandersetzung jedoch Entscheidungsrechte des Bundestags von geringerer Bedeutung als die Tatsache, dass der Bundestag überhaupt an internationalen Prozessen beteiligt wird. ${ }^{149}$ Bereits seine bloße Beteiligung kann durch die öffentliche Auseinandersetzung zwi-

\footnotetext{
kann die kontroverse Beurteilung einer systematischen Beschreibung der auswärtigen Kompetenzen jedoch nicht ausschlaggebend sein; allenfalls kann sich aus einer dogmatischen Untersuchung der einzelnen Kompetenzen ein systematisches Bild ergeben.

145 Entsprechende Beschlüsse sind verfassungsrechtlich zulässig, wenn auch gegenüber der Regierung nicht verbindlich, H. Butzer AöR 119 (1994), 61 (94f.); B. Kempen in: H. v. Mangoldt/F. Klein/C. Starck (Hrsg.), Das Bonner GG, 5. Aufl. 2005, Art. 59 Rn. 39; A. L. Paulus Die Wirkung parlamentarischer Beschlüsse im Bereich der auswärtigen Politik, in: L. Gramlich (Hrsg.) Zwischen Legitimität und Effektivität, 2006, 53 (57f.); anders zum Teil noch in der älteren Literatur $K$.-A. Sellmann Der schlichte Parlamentsbeschluss, 1966, 43f.; $E$. Menzel Die auswärtige Gewalt der Bundesrepublik, VVDStRL 12 (1953), 179 (195f.).

146 Besonders für die Verteidigungs- und Rüstungspolitik ist ferner das Haushaltsrecht von Bedeutung, Ismayr Bundestag (Fn. 142), 182.

${ }_{147}$ BVerfGE 90, 286 (381 ff.); zustimmend etwa W. Heun JZ 1994, 1073 (1074); kritisch G. Roellecke Der Staat 34 (1995), 415 (423 ff.). Vgl. auch $\$ 8$ Abs. 1 S. 4 BPolG, der eine Information des Bundestags über Auslandseinsätze der Bundespolizei verlangt und dem Bundestag das Recht, eine Beendigung des Einsatzes zu verlangen, einräumt. $\mathrm{Zu}$ den verfassungsrechtlichen Fragen, die ein Verständnis der Vorschrift als Entscheidungsvorbehalt des Parlaments aufwirft, A. Fischer-Lescano AöR 128 (2003), 52 (78ff.); W. Schreiber NVwZ 1995, 521 (523f.).

148 BT-Drs. 14/4740.

149 Vgl. bereits Tomuschat Verfassungsstaat (Fn. 136), 36ff.
} 
schen Regierung und Opposition wesentlich zur Klärung politischer Verantwortlichkeit und damit zu demokratischen Rückkopplungsprozessen beitragen. 150

Darin liegt auch eine wesentliche Bedeutung der besonderen Beteiligungsrechte des Bundestags nach Art. 23 Abs. 2 und 3 GG in Angelegenheiten der Europäischen Union. ${ }^{51}$ Über diese Beteiligungsrechte soll der Bundestag stärker in die Rechtssetzung der Union eingebunden werden. Art. 23 GG setzt damit auf eine Neuorientierung der politischen Aufmerksamkeit und des Selbstverständnisses des Bundestags. ${ }^{152} \mathrm{Er}$ setzt voraus, dass sich der Bundestag nicht mehr nur als Hauptakteur nationaler Rechtssetzung begreift, sondern auch als eines von vielen am Alltagsgeschäft der Unionsrechtssetzung beteiligten Organe. Mit der im Reformvertrag vorgesehenen Überwachung der Subsidiarität durch die nationalen Parlamente würde diese neue Funktion verstärkt.

Die damit verbundenen institutionellen Umlernprozesse müssen sich auch gegen die narzisstische Kränkung durchsetzen, die mit dem Wechsel von der Haupt- in eine Nebenrolle verbunden ist. ${ }^{153}$ Allerdings gibt es deutliche Anzeichen, dass der Bundestag seine neue Rolle annimmt. ${ }^{154}$ Mag die Anzahl der Stellungnahmen nach Art. 23 GG gemes-

${ }^{150}$ A. Benz Postparlamentarische Demokratie und kooperativer Staat, in: C. Leggewie/R. Münch (Hrsg.), Politik im 21. Jahrhundert, 2001, 263 (277f.).

${ }^{151}$ Im Einzelnen wird das Verfahren im Gesetz über die Zusammenarbeit von Bundesregierung und Deutschem Bundestag in Angelegenheiten der Europäischen Union v. 12. 03. 1993, BGBI. I, 311, zuletzt geändert durch Art. 2 Abs. 1 des Gesetzes v. 17. 11. 2005, BGBI. I, 3178, und die interinstitutionelle Vereinbarung des Bundestags und der Bundesregierung, BGB1. I 2006, 2177, ausgestaltet. Unionsrechtlich werden die Beteiligungsrechte der nationalen Parlamente durch das Protokoll Nr. 9 zum Amsterdamer Vertrag, ABl. EG 1997 Nr. C 340/113f., abgesichert.

152 Schorkopf Grundgesetz und Überstaatlichkeit (Fn. 18), 333 ff.; zu den strukturellen Schwierigkeiten einer internationalen Orientierung von Parlamenten Slaughter World Order (Fn. 7), 105.

153 Ismayr Bundestag (Fn. 142), 189, erachtet die Verfahrensreform zwar nicht als faktisch wirkungslos, sieht aber immer noch eine erhebliche Dominanz der Exekutive.

154 Nach einer vergleichenden Studie zum Einfluss der nationalen Parlamente auf die Unionsentscheidungen gehört der Bundestag nach den Parlamenten der skandinavischen Staaten und Österreichs zu den einflussreichsten in der Europäischen Union, das hauptsächlich aufgrund des oppositionsübergreifend konsensualen Stils der Europapolitik weniger deutlich in Erscheinung tritt, $A$. Maurer/W. Wessels National Parliaments after Amsterdam, in: A. Maurer/W. Wessels (eds.) National Parliaments on their Ways to Europe, 2001, 425 (462). Nach anderen empirischen Untersuchungen sind immerhin ein Viertel der Großen Anfragen und ein Siebentel der Aktuellen Stunden außen- und europapolitischen Themen gewidmet, $M$. F. Feldkamp Datenhandbuch zur Geschichte des Deutschen Bundestags 1994 bis 2003, 2005, 617ff. Auch ein erheblicher Teil der Anträge, die auf einen schlichten Parlamentsbeschluss gerichtet sind, gelten außenpoli- 
sen an der Gesamtzahl der EU-Vorlagen auch gering anmuten, ${ }^{155}$ finden sich gerade Stellungnahmen ${ }^{156}$ zu Rechtsakten, die auch in der späteren Umsetzung kontrovers diskutiert wurden - wie etwa zur Gleichbehandlungsrichtlinie ${ }^{157}$ oder zur Vorratsdatenspeicherung158. Bei einigen politisch besonders umstrittenen Themen nutzt der Bundestag bereits die Möglichkeit, selbst auf jenen zwei Ebenen zu spielen, ${ }^{159}$ die ihm die Struktur der losen Kopplung bietet. 160

\section{Ausweitung der frühen Parlamentsbeteiligung}

Angesichts der stetig steigenden Bedeutung der Internationalisierungsprozesse sollte das in Art. 23 Abs. 2 und 3 GG angelegte Beteiligungssystem zu einer allgemeinen Kooperationsform zwischen Bundestag und Bundesregierung fortentwickelt werden. ${ }^{161}$ Schon prima facie

tischen Fragen, Ismayr Bundestag (Fn. 142), 183. Sie werden auch genutzt, um die Verhandlungsposition der Bundesrepublik durch eine gemeinsame Position von Bundestag und Bundesregierung zu stärken; Ismayr ebd.

155 2-3\% in der 14. Wahlperiode, Ismayr Bundestag (Fn. 142), 189; Zahlen auch bei Maurer/Wessels National Parliaments after Amsterdam (Fn. 154), 450: 111 Empfehlungen des Europaausschusses für eine Plenarentscheidung zu Angelegenheiten der Europäischen Union von 1995-1999.

156 Zum Teil werden die Stellungnahmen durch Anhörungen vorbereitet, s. etwa zur Europäischen Vollstreckungsanordnung die Tagesordnung der 37. Sitzung des Ausschusses für die Angelegenheiten der Europäischen Union am 4. 7. 2007, http://www. bundestag.de/ausschuesse/221/tagesordnungen/archiv/to-37-e.pdf. (Abruf: 16. 10. 2007).

157 BT-Plenarprotokoll 14/170 v. 17. 05. 2001, 16614D.

${ }^{158}$ BT-Plenarprotokoll $15 / 154$ v. 27. 01. 2005, 14418B.

159 In der Entwicklung zum "multilevel player" sehen auch Maurer/Wessels National Parliaments after Amsterdam (Fn. 154), 463 f., das unionspolitische Potential der mitgliedstaatlichen Parlamente. Ein weiterer Beleg furr die Internationalisierung der Parlamentsarbeit kann darin gesehen werden, dass neben den Tagungen der COSAC die Anzahl der informellen, an Sachgebieten orientierten bi- und multilateralen Treffen mit Parlamentariern aus anderen Mitgliedstaaten zugenommen haben, Maurer/Wessels National Parliaments after Amsterdam (Fn. 154), 458; G. Kretschmer Die Zusammenarbeit nationaler Parlamente bei der Ausarbeitung europäischer Übereinkommen, in: R. Geiger (Hrsg.) Neuere Probleme der parlamentarischen Legitimation im Bereich der auswärtigen Gewalt, 2003, $91 \mathrm{ff}$.

160 Dabei nutzt er den arbeitsteiligen Vorteil des Art. 45 Abs. 2 GG. Von der generellen Ermächtigung nach $\S 93$ a Abs. 3 S. 3, S. 2 GO-BT hat der Ausschuss häufiger Gebrauch gemacht und dadurch nach Einschätzung von Beteiligten auch „wichtige Effekte“ auf der Europäischen Ebene erzielt, M. Fuchs ZParl. 2004, 3 (15f.); vgl. auch Ismayr Bundestag (Fn. 142), 189. Wegen des Verfahrensaufwands nicht genutzt wurde die Einzelermächtigung nach $\$ 93 a$ Abs. 2 GO-BT.

161 Weitergehende Vorschläge zielen auf eine Beteiligung von Bundestagsmitgliedern an den Verhandlungsdelegationen, Zürn Regieren (Fn. 99), 352; vgl. auch Kadelbach 
vermag nicht einzuleuchten, dass der Bundestag beim auswärtigen Handeln der Europäischen Union in dem Verfahren nach Art. 23 Abs. 2 und 3 GG beteiligt werden muss, während für das auswärtige Handeln der eigenen Regierung nur geringere Beteiligungsrechte bestehen. ${ }^{162} \mathrm{De}$ constitutione ferenda sollten die besonderen Beteiligungsrechte allgemein auf auswärtige Angelegenheiten erstreckt ${ }^{163}$ und die Delegationsmöglichkeit des Art. 45 S. 2 GG $^{164}$ zur Steigerung der Leistungsfähigkeit des Bundestags insoweit auf die Fachausschüsse ausgeweitet werden. 165

Doch ein wesentliches Element der Beteiligungsrechte aus Art. 23 GG lässt sich bereits aus dem geltenden Verfassungsrecht ableiten. Für die neue Rolle des Bundestags als ein Akteur in internationalisierten Rechtssetzungsverfahren ist die umfassende und „frühestmögliche“ Information entscheidend. ${ }^{166}$ Stellungnahmen kann der Bundestag auch ohne die ausdrückliche Ermächtigung in Art. 23 Abs. 2 GG abgeben; dass diese dann von der Regierung „berücksichtigt“ werden, ist im parlamentarischen Regierungssystem eine politische Selbstverständlichkeit.

Ein Informationsrecht des Bundestags gegenüber der Bundesregierung korrespondiert grundsätzlich seinen allgemeinen Befassungs- und Kontrollrechten ${ }^{167}$ sowie den Rechten der Abgeordneten aus Art. 38

Parlamentarische Kontrolle (Fn. 93), 54; s. auch den Vorschlag zur Erteilung von Verhandlungsmandaten durch den Bundestag, Röben Außenverfassungsrecht (Fn. 8), $100 \mathrm{f}$.

${ }^{162}$ Auch für den Abschluss von völkerrechtlichen Verträgen kann dies nicht mit Hinweis auf das Letztentscheidungsrecht des Bundestags nach Art. 59 Abs. 2 S. 1 GG erklärt werden, dessen Wegfall auf Gemeinschaftsebene kompensiert werden soll. Das Beteiligungsrecht gilt auch für Verträge, die im Rahmen der Europäischen Union abgeschlossen werden und jedenfalls nach dem Verständnis des Bundesverfassungsgerichts Art. 59 Abs. 2 S. 1 GG unterfallen, BVerfGE 113, 273 (301).

${ }^{163} \mathrm{Vgl}$. bereits Herdegen Entformalisierung (Fn. 11), 27; für eine Ausweitung der Beteiligungsrechte auch $C$. Walter DVBI. 2000, 1 (8); für eine Erstreckung de constitutione lata Röben Außenverfassungsrecht (Fn. 8), 246.

164 Morlok Entformalisierung (Fn. 110), $75 \mathrm{ff}$.

165 Das Modell des Art. 45 S. 2 GG ist noch zu sehr von einem sektoralen Verständnis internationaler Kooperation geprägt. Zur Erforderlichkeit einer verfassungsrechtlichen Grundlage für die Delegation B. Pieroth in: H. D. Jarass/B. Pieroth (Hrsg.) Grundgesetz, 9. Aufl. 2007, Art. 40 Rn. 4; G. Axer ZRP 2007, 82 (83); aA W. Berg Der Staat 9 (1970), 21 (33f., 37 ff.); R. Pietzner Petitionsausschuss und Plenum, 1974, 76ff.; N. Achterberg Parlamentsrecht, 1984, 681.

166 So auch Wolfrum Kontrolle (Fn. 144), 63. Dazu, dass die Frühzeitigkeit auch nach der Neuregelung noch nicht in allen Fällen gewährleistet ist, Ismayr Bundestag (Fn. 142), 189.

${ }^{267}$ Bereits BVerfGE 13, 123 (125); zur Ableitung aus der Kontrollkompetenz des Bundestags BVerfGE 67, 100 (130); zur Entwicklung der Rechtsprechung und zum Meinungsstand in der Literatur $\boldsymbol{H}$. $\boldsymbol{H}$. Klein in: T. Maunz/G. Dürig (Hrsg.) Grundgesetz, Bd. 4, 43. Lfg. 2004, Art. 43 Rn. 75 ff. 
Abs. 1 GG. 168 Dass die Informationen jedenfalls im gegenständlichen Anwendungsbereich von Art. 59 Abs. 2 S. 1 GG, der besonders auch die Entwicklung in internationalen Organisationen einschlie $\beta t{ }^{169}$ so umfassend und besonders auch so frühzeitig verlangt werden dürfen, dass der Bundestag sich noch während der Verhandlungen einbringen kann, folgt aus dem Grundsatz der Organtreue ${ }^{170} .{ }^{171}$ Gerade im Kontext der Beteiligung des Bundestags an der Entwicklung völkerrechtlicher Verträge hat das Bundesverfassungsgericht hervorgehoben, dass oberste Staatsorgane bei der Ausübung ihrer Kompetenzen gegenseitige Rücksicht nehmen müssen. ${ }^{172}$ Die Praxis des Bundestags bei der Zustimmung zu völkerrechtlichen Verträgen nimmt in vielfacher Weise Rücksicht auf die Handlungsfähigkeit der Regierung. So erlaubt die Geschäftsordnung des Bundestags nur eine pauschale Abstimmung über Vertragsgesetze; ${ }^{173}$ der Bundestag ermächtigt die Regierung zum Teil vorab zur Än-

168 BVerfGE 13, 123 (125); 57, 1 (5); 70, 324 (355); 80, 188 (218).

169 In den gegenständlichen Anwendungsbereich des Art. 59 Abs. 2 S. 1 GG fallen alle internationalen Organisationen. Angesichts ihrer gestiegenen Bedeutung werden Verträge zur Beteiligung an internationalen Organisationen - anders als dies etwa für den Beitritt zur FAO, WHO und UNESCO gesehen wurde - regelmäßig auch dann die politischen Beziehungen des Bundes im Sinn von Art. 59 Abs. 2 GG betreffen, wenn ihnen nicht die Kompetenz zum Erlass bindender Regelungen eingeräumt wird, Kadelbach Parlamentarische Kontrolle (Fn. 93), 46. Im Zusammenspiel der unterschiedlichen internationalen Rechtsakte kann gerade auch unverbindlichen Regelungen normative Bedeutung zukommen, dazu Tietje Verwaltungshandeln (Fn. 1), $439 \mathrm{ff}$.

170 BVerfGE 29, 221 (233); 35, 193 (199); 45, 1 (39); grundlegend W.-R. Schenke Die Verfassungsorgantreue, 1977; umfassend Lorz Interorganrespekt (Fn. 142); s.a. V. Mehde AöR 127 (2002), 655 (664ff.).

171 So auch Lorz Interorganrespekt (Fn. 142), 300f.; Kadelbach Parlamentarische Kontrolle (Fn. 93), 54; H. J. Cremer Das Verhältnis von Gesetzgeber und Regierung im Bereich der auswärtigen Gewalt in der Rechtsprechung des Bundesverfassungsgerichts, 29 ff. u. Diskussionsbeitrag, ebd. 36; L. Gramlich Möglichkeiten (Fn. 93), 8; C. Calliess HStR IV, 3. Aufl. 2006, $\$ 83$ Rn. 49; von einer auch in der Praxis „grundsätzlich anerkannten Pflicht zur Information des Bundestags über laufende Verhandlungen“ geht auch G. Tebe Der Ruf nach begleitender parlamentarischer Kontrolle von Vertragsverhandlungen, in: L. Gramlich (Hrsg.) Zwischen Legitimität und Effektivität, 2006, 37 (40), aus; grundsätzlich für eine Weiterentwicklung der parlamentarischen Mitwirkung durch deren Vorverlagerung auch Wolfrum Kontrolle (Fn. 144), 43.

172 BVerfGE 90, 286 (337); allgemein zur Organtreue BVerfGE 29, 221 (233); 35, 193 (199); 45, 1 (39); 89, 155 (191); 97, 350 (374f.).

$173 \S 81$ Abs. 4 S. 2 und $\S 82$ Abs. 2 GO-BT schließen Einzelabstimmungen und Änderungsanträge aus. $\mathrm{Zu}$ der umstrittenen Frage, ob sich dies bereits aus der Verfassung ergibt Lorz Interorganrespekt (Fn. 142), 300; C. Calliess HStR IV, 3. Aufl. 2006, $\$ 83$ $\mathrm{Rn} .30$; in diesem Sinn wohl BVerfGE 90, 286 (358). 
derung von Abkommen ${ }^{174}$ und die Regierung nutzt die Möglichkeit, internationale Organisationen ohne formelle Vertragsänderung - häufig auch inkrementell - weiter zu entwickeln ${ }^{175}$. Das Bundesverfassungsgericht hat diese - zum Teil großzügig gehandhabte - Praxis gerade unter Hinweis auf die allgemeinen Befassungs- und Kontrollrechte des Bundestags gebilligt. ${ }^{176}$ Wenn die Rücksicht auf die internationale Handlungsfähigkeit der Regierung den Bundestag aber auf seine allgemeinen Befassungs- und Kontrollrechte verweist, dann verlangt die von der Organtreue geforderte Gegenseitigkeit der Rücksichtnahme, dass der Bundestag umfassend und „frühestmöglich“ informiert wird. Die ihm verbliebenen Rechte muss er so ausüben können, dass sie noch in den Verhandlungen relevant werden können.

Der Transparenz, Effektivierung und Konkretisierung des Informationsrechts sowie seinem Interorgancharakter entspräche es, ein Verfahrensreglement in einer Interorganvereinbarung ${ }^{177}$ zwischen Bundestag und Bundesregierung festzuhalten ${ }^{178}$. Nach dem Motto „More of the same!" könnte eine umfassendere internationale Einbindung den Bun-

174 Dazu BVerfGE 58, 1 (37); Wolfrum Kontrolle (Fn. 144), 55; A. Steinbach DöV 2007, 555 (558).

${ }^{175}$ Dazu BVerfGE 104, 151 (209); BVerfG, Urteil v. 3. 7. 2007, 2 BvE 2/07, Rn. 43; kritisch die abweichende Meinung in BVerfGE 90, 286 (375); Kadelbach Parlamentarische Kontrolle (Fn. 93), 46f.; A. Weber in: D. C. Umbach/T. Clemens (Hrsg.) Grundgesetz, Bd. 2, 2002, Art. 59 Rn. 69; Kempen (Fn. 145), Art. 59 Rn. 51.

176 BVerfGE 90, 286 (364f); 104, 151 (208); ferner mit dem Hinweis auch auf das konstruktive Misstrauensvotum BVerfGE 68, 1 (89).

$177 \mathrm{Zu}$ Interorganvereinbarungen über die Beteiligung der Parlamente bei Staatsverträgen in den Ländern S. Hölscheidt DÖV 1993, 593 (599); allgemein zu Interorganvereinbarungen $K .-E$. Gebauer Verfassungsergänzende Vereinbarungen zwischen Parlament und Regierung, in: A. Benz (Hrsg.), FS König, 2004, 341 ff. Der Bruch einer Vereinbarung, die die gegenseitigen Treuepflichten konkretisiert, würde gegen die Organtreuepflicht zu abredegemäßem Verhalten verstoßen, ähnlich $J$. Schwarze EuR 1995, Beiheft 2, 49 (61). Der Grundsatz der Organtreue bildet auch den Hintergrund der Vereinbarung zwischen Bundestag und Bundesregierung zur Währungsunion, BVerfGE 89, 155 (190f.). Die Entscheidung erkennt damit kein über Art. 59 Abs. 2 GG hinausgehendes Entscheidungsrecht des Bundestags bei der Umsetzung völkerrechtlicher Verträge an, A. Puttler ZRP 1998, 168 (172).

178 Als Modell könnte insoweit die interinstitutionelle Vereinbarung zur Beteiligung des Europäischen Parlaments bei Vertragsverhandlungen der Gemeinschaft dienen, ABI. 2001 Nr. C 121 S. 128, Nr. 2, so auch C. Calliess HStR IV, 3. Aufl. 2006, $\$ 83$ Rn. 49. In ihnen hat sich die Kommission verpflichtet, das Europäische Parlament über die Phase der Vorbereitung internationaler Übereinkommen sowie Verhandlungsleitlinien „frühzeitig und eindeutig“ zu informieren, „um im Rahmen des Möglichen den Standpunkten des Europäischen Parlaments gebührend Rechnung tragen zu können.“ (Nr. 2 der Vereinbarung, ebd.). 
destag bei der Entwicklung seiner neuen internationalisierten Rolle und eines neuen internationalisierten Selbstverständnisses fördern, das dem Stand der Globalisierung entspricht. ${ }^{179}$

\section{Grundrechte}

Die vom Grundgesetz nur hergestellte lose Kopplung zwischen dem nationalen Recht und den internationalen Regulierungen dient gerade auch dazu, materielle Standards der Verfassung, wie sie besonders die Grundrechte, aber auch das Sozialstaatsgebot enthalten, in die Globalisierungsprozesse einzubringen. In den Globalisierungsprozessen haben diese materiellen Vorgaben im Wesentlichen zwei Funktionen: Die erste Funktion steht im unmittelbaren Zusammenhang mit der demokratischen Willensbildung. Demokratie als Mehrheitsherrschaft ist nur legitim, wenn Minderheitspositionen - auch in internationalen Kooperationen - geschützt werden. ${ }^{180}$ Die zweite Funktion zielt auf den Schutz der Identität der Gesellschaft in den Globalisierungsprozessen, die sich gerade auch über die materiellen Garantien der Verfassung konstituiert. ${ }^{181}$

Die Konstellationen, in denen besonders die Grundrechte mit Globalisierungsprozessen in Berührung geraten, sind ausgesprochen vielgestaltig. Sie lassen sich in zwei Grundkategorien einteilen: Zum einen sind es Konstellationen, in denen das Handeln deutscher Hoheitsträger mit fremden Rechtsordnungen in Berührung kommt. Zu ihnen zählen

\footnotetext{
${ }^{179}$ Gegen eine Ausweitung der Informationsrechte wird zum Teil die beschränkte Leistungsfähigkeit des Bundestags angeführt, I. Winkelmann Das Verhältnis von Exekutive und Gesetzgeber in der zweiten und dritten Säule der Europäischen Union, in: R. Geiger (Hrsg.) Neuere Probleme der parlamentarischen Legitimation im Bereich der auswärtigen Gewalt, 2003, 67 (77ff.); Tebe Kontrolle (Fn. 171), 40; für die Unionsangelegenheiten s. die Zahlen bei M. Große Hüttmann APuZ 2007, 39 (44f.). Demgegenüber ist zu bedenken, dass die Organadäquanz eine Gleichung mit zwei Variablen ist, ähnlich Kadelbach Parlamentarische Kontrolle (Fn. 93), 53 f. Sollten die Kapazitäten des Bundestags nicht ausreichen, wäre er personell, institutionell und sachlich so auszustatten, dass er auch seinen neuen Aufgaben gerecht werden kann.

180 Zur grundrechtlichen Absicherung als notwendiges Element der - und nicht als Gegensatz - zur demokratischen Legitimation Dworkin Freiheit (Fn. 83), 303 ff.; Scharpf Interdependence (Fn. 108), 104f.; ders. Interaktionsformen (Fn. 74), 299 ff.; Abromeit Demokratie (Fn. 76), 142.

181 Hobe Verfassungsstaat (Fn. 28), 402ff.; Wahl Internationalisierung (Fn. 96) 2001, 217f.; Scheppele International State (Fn. 12), 60 ff., u.a. unter Hinweis auf die deutsche Verfassungsrechtsprechung.
} 
das Handeln deutscher Hoheitsträger im Ausland, ${ }^{182}$ die kollisionsrechtliche Anwendung ausländischen Rechts und die Zurechnung objektiv vorhersehbarer Grundrechtsbeeinträchtigungen durch fremde Hoheitsgewalt. Zum anderen sind es Konstellationen, in denen unterschiedliche primäre und sekundäre internationale Regulierungen auf das nationale Recht einwirken.

\section{Allgemeine Grundrechtsbindung in internationalen Kontexten}

Aufgrund der nicht an das Hoheitsgebiet, sondern an die Ausübung von Hoheitsgewalt ${ }^{183}$ anknüpfenden Grundrechtsbindung gemäß Art. 1 Abs. 3 GG $^{184}$ lässt sich dem Grundgesetz kein Hinweis darauf entnehmen, dass die Grundrechte in Fällen mit Auslands- oder Internationalisierungsbezug nicht oder nur abgeschwächt gelten. Aus der offenen Staatlichkeit des Grundgesetzes ergibt sich keine Reduktion des Grundrechtsschutzes auf einen international anerkannten Mindeststandard im Falle des Auslandsbezugs. ${ }^{185}$ Allerdings sind bei Auslandsbezügen u.U. die besonderen faktischen Verhältnisse und die beschränkten rechtlichen Handlungsoptionen in Rechnung zu stellen.

Der Auslandsbezug relativiert nicht den grundrechtlichen Maßstab, aber derselbe grundrechtliche Maßstab kann aufgrund der abweichenden Verhältnisse im Ausland Maßnahmen rechtfertigen, die unter den

${ }^{182}$ Zur Zurücknahme des Geltungsanspruchs der Europäischen Menschenrechtskonvention bei Einsätzen im Rahmen der Vereinten Nationen außerhalb des Vertragsgebiets EGMR, NJW 2003, 413 (415); vgl. auch EGMR, NJW 2005, 1849 (1850); dazu Röben Außenverfassungsrecht (Fn. 8), $411 \mathrm{ff}$.

${ }^{183} \mathrm{Zu}$ den dogmatischen Fragen, die bei einer Anwendung im Verteidigungsfall aufgeworfen werden, A. Podlech in: R. Wassermann (Hrsg.) AK-GG, 1984, Art. 2 Abs. 2 Rn. 26; $M$. Kutscha NVwZ 2004, 801 (803); kritisch zur Anwendbarkeit der Grundrechte im Verteidigungsfall J. Isensee HStR V, 2. Aufl. 2000, §115 Rn. 90 Fn. 201.

184 BVerfGE 57, 9 (23); 100, 313 (362ff.).

185 So aber $R$. Hofmann Grundrechte und grenzüberschreitende Sachverhalte, 1994, 232f.; ähnlich $K$. Stern Das Staatsrecht der Bundesrepublik Deutschland, Bd. 3/1, 1988, $1231 \mathrm{ff}$; $H$. Krieger Die gerichtliche Kontrolle von militärischen Operationen, in: D. Fleck (Hrsg.) Rechtsfragen der Terrorismusbekämpfung durch Streitkräfte, 2004, 223 (237f.); restriktiv auch $M$. Heintzen Auswärtige Beziehungen privater Verbände, 1988, 151; aA A. Bleckmann/B. Busse DVB1. 1977, 794 (796); S. Scheller Ermächtigungsgrundlagen für die internationale Rechts- und Amtshilfe zur Verbrechensbekämpfung, 1997, 170; differenzierend C. Gröpl ZRP 1995, 13 (16); vgl. D. Lorenz Der territoriale Anwendungsbereich der Grund- und Menschenrechte, 2005, $179 \mathrm{ff}$., für eine „strukturelle“ Grundrechtsgeltung. 
Verhältnissen des Inlands nicht gerechtfertigt wären. ${ }^{186}$ So hat das Bundesverfassungsgericht in der Zweitregisterentscheidung bei der Kontrolle der ausländischen Entgeltregelungen auf den geringeren Lebensstandard und die geringeren Lebenshaltungskosten in den Herkunftsstaaten der ausländischen Matrosen hingewiesen. ${ }^{187}$ Speziell für verfassungsrechtliche Schutzaufträge ${ }^{188}$ folgt aus den eingeschränkten rechtlichen und faktischen Handlungsmöglichkeiten bei Auslandsbezügen ein besonders weiter politischer Gestaltungsspielraum, der allenfalls unter ganz exzeptionellen Umständen die Annahme einer Handlungspflicht erlauben wird. ${ }^{189}$

Ferner können globalisierungsspezifische Politikziele - wie andere Politikziele auch - Grundrechtsbeschränkungen rechtfertigen. Die vor Art. 9 und Art. 3 GG rechtfertigungsbedürftige Entscheidung, die in einem Zweitregister geführten ausländischen Seeleute dem kollektiven Arbeitsrecht ihres Heimatstaates zu unterstellen, hat das Bundesverfassungsgericht auch damit gerechtfertigt, dass ansonsten wegen des internationalen Wettbewerbs mit einer weitgehenden Ausflaggung deutscher Handelsschiffe zu rechnen sei. Die besonderen faktischen und rechtlichen Gegebenheiten, die mit dem Auslandsbezug u.U. einhergehen, und die besonderen internationalen Politikziele, können in dem beschriebenen Sinn zu einer „Minderung des Grundrechtsstandards“190 führen, von dem in der Zweitregisterentscheidung die Rede ist. Im Übrigen gilt jedoch die frühe und zutreffende Aussage des Gerichts zum internationalen Privatrecht, nach der auch Sachverhalte mit Aus-

\footnotetext{
186 Vgl. zur entsprechenden Rechtsprechung des Europäischen Gerichtshofs für Menschenrechte; s. etwa EGMR, EuGRZ 1975, 298 (301); J. Meyer-Ladewig Europäische Menschenrechtskonvention, 2. Aufl. 2006, Einl. Rn. 39. Hierhin gehört auch die Legitimationsfigur der Herbeiführung eines Zustands, der „näher am Grundgesetz ist“, BVerfGE 4, 157 (170); 12, 281 (290ff.); 112, 1 (35ff.); hierzu $R$. Bernhardt HStR VII, $1992, \S 174$ Rn. 23 ff.; K. Harms Verfassungsrecht in Umbruchsituationen, 1999, 25ff.; Schorkopf Überstaatlichkeit (Fn. 18), 145.

187 BVerfGE 92, 26 (52).

${ }^{188}$ Dies bezieht sich nur auf besondere Schutzaufträge der Verfassung wie etwa aus Art. 1 Abs. 1 GG. Dass allgemeine grundrechtliche Schutzpflichten für Auslandssachverhalte nicht greifen, zeigt bereits ihre abwehrrechtliche Rekonstruktion, die auf den Eingriff durch die staatliche Regelung abstellt, $R$. Poscher Grundrechte als Abwehrrechte, 2003, 380ff. Auslandssachverhalte werden gerade nicht durch deutsche Hoheitsgewalt geregelt.

$189 \mathrm{Vgl}$. BVerfGE 44, 141 (178).

190 BVerfGE 92, 26 (42); vgl. auch BVerfGE 100, 313 (363); 108, 129 (136f.); 109, 13 (26).
} 
landsbezug „in vollem Umfang an den Grundrechten zu messen“191 sind. 192

Die internationale Kooperationsfähigkeit der Bundesrepublik erfordert keine allgemeine Anpassung des nationalen Grundrechtsmaßstabs an ein völkerrechtliches Mindestniveau. ${ }^{193}$ Zum einen hat sich die Grundrechtsbindung weder in der Vergangenheit als größeres Kooperationshindernis erwiesen, noch ist absehbar, dass die Grundrechte in $\mathrm{Zu}$ kunft erstrebenswerten internationalen Kooperationen entgegenstehen. Zum anderen würden Maßstab und Objekt vertauscht. Nicht die Grundrechte müssen sich an ihrer internationalen Kooperationsfähigkeit messen lassen, sondern die internationalen Kooperationen an den Grundrechten.

Daher setzen die materiellen Garantien des Grundgesetzes der Globalisierung auch Grenzen. Insoweit sei exemplarisch auf eine Entwicklung im Privatschulwesen verwiesen. Bereits jetzt drängen global operierende Bildungskonzerne mit weitgehend über hohe Schulgelder finanzierten "Internationalen Schulen" teilweise unter Umgehung der allgemeinen Ersatzschulregelungen auf den deutschen Markt. ${ }^{194}$ Wie immer sich die Liberalisierung des Handels mit Bildungsdienstleistungen

${ }^{191}$ BVerfGE 31, 58 (73f.); ferner hat das Bundesverfassungsgericht die Grundrechte ohne erkennbare Maßstabsreduktion auf nicht ratifizierte, BVerfGE 63, 343 (345, 353f.) und ratifizierte völkerrechtliche Verträge, BVerfGE 4, 157 (176); 6, 290 (295); 77, 170 (215); 94, 12 (35), angewandt und in ihnen einen Maßstab für grenzüberschreitende Datenerhebungen gesehen, B VerfGE 100, 313 (362 ff.); zu den Besonderheiten, die sich aus der Rechtskraft ausländischer Vollstreckungstitel ergeben, BVerfGE 63, 343 (377f.); zur Bedeutung rechtsstaatlicher Grundsätze s. BVerfGE 91, 335 (340ff.).

192 So auch $C$. Tomuschat HStR VII, 1992, § 172, Rn. 54: Reduktion nur im Rahmen von Art. 24 GG; Baldus Polizeirecht (Fn. 38), $134 \mathrm{ff}$; Schorkopf Überstaatlichkeit (Fn. 18), 124. Eine Ausnahme von diesem Grundsatz gilt jedoch für aufenthaltsbeendende Maßnahmen, BVerfGE 18, 112 (120f.); 59, 280 (282f.); 63, 332 (337); 75, 1 (19); 108, 129 (136f.); 109, 13 (26); 113, 273 (299f.).Diese Besonderheit dürfte sich durch den insoweit spezielleren Art. 16a GG erklären. Würde die Absehbarkeit jeder Grundrechtsverletzung bei aufenthaltsbeendenden Maßnahmen ausreichen, so bedürfte es der Regelung des Art. 16a GG nicht, da jede politische Verfolgung schon aufgrund von Art. 3 Abs. 3 GG mit einer Grundrechtsverletzung verbunden wäre; kritisch zu diesem Argument $J$. Schwabe Urteilsanmerkung, NJW 1974, 1044f. So steht für BVerfGE 76, 143 (158), nicht jede absehbare Verletzung der Religionsfreiheit einer Ausweisung entgegen.

193 So aber F. Waitz von Eschen BayVB1. 1991, 321 (324); Hofmann Grundrechte und grenzüberschreitende Sachverhalte (Fn. 185), 27, 30, 69 f., 101 f.; K. Graßhof/R. Backhaus EuGRZ 1996, 445 (448); ähnlich wie hier D. Lorenz Der territoriale Anwendungsbereich der Grund- und Menschenrechte, 2005, 181.

194 R. Poscher/M. Neupent RdJB 2005, 244 (248, 250ff.). 
im Rahmen des GATS entwickeln wird, ${ }^{195}$ markiert das Verbot einer sozialen Sonderung der Schüler aus Art. 7 Abs. 4 S. 3 GG auch als Ausdruck des Sozialstaatsprinzips eine verfassungsrechtliche Grenze der Liberalisierung.

\section{Relativierung des Grundrechtsschutzes bei der Übertragung und Beschränkung von Hoheitsrechten}

Modifikationen des grundrechtlichen Maßstabs ergeben sich nur im Rahmen der Übertragung und Beschränkung von Hoheitsrechten. ${ }^{196}$ Die Zurücknahme ${ }^{197}$ der Grundrechtskontrolle auf Fälle, in denen ein vergleichbarer supranationaler Grundrechtsschutz systematisch versagt, ${ }^{198}$ findet ihre dogmatische Grundlage darin, dass Art. 23 und 24 GG mit der Übertragung und Beschränkung von Hoheitsrechten zu Verfassungsänderungen ermächtigen, ${ }^{199}$ für die Art. 23 GG nun auch die allgemeinen verfassungsändernden Mehrheiten verlangt. In der Sache findet sie ihre Rechtfertigung darin, dass dort, wo Hoheitsrechte übertragen oder beschränkt werden, auch die grundrechtliche Verantwortlichkeit auf die Einrichtung übergeht, die die Hoheitsrechte ausübt.

Als Beschränkung von Hoheitsrechten kann die Zurücknahme des nationalen Grundrechtsschutzes auch in den Fällen greifen, in denen

195 Zum Stand des WTO-Rechts im Bildungswesen C. Scherrer RdJB 2003, $86 \mathrm{ff}$.; J. Rux RdJB 2003, 239 (245).

196 Nicht erstreckt wird die Zurücknahme des nationalen Grundrechtsschutzes auf die Europäische Union, BVerfGE 113, 273 (300f.). Dies ist angesichts insoweit unzureichender Kompetenzen des Europäischen Gerichtshofs konsequent. So sehr ein harmonisierter materieller Grundrechtsschutz auch den Zielen der Europäischen Union nützlich sein könnte, so wenig sinnvoll ist es, einen solchen Standard dezentral durch die jeweiligen Verfassungsgerichte entwickeln zu lassen.

197 Dass die Rechtsprechung den zurückgenommenen Grundrechtsschutz im Maastricht-Urteil über Art. 1 Abs. 3 GG hinausgehend auf die Akte der Gemeinschaftsorgane erweitert hat, BVerfGE 89, 155 (174f.); vgl. auch BVerfG, DVBl. 2001, 1130; kritisch C. Walter AöR 129 (2004), 39 (53 ff.), ist demgegenüber von geringerer und eher symbolisch kompensatorischer Bedeutung. Soweit wie etwa bei Gestaltungsentscheidungen von transnationaler Bedeutung nicht an nationale Umsetzungsakte - und sei es im Rahmen der Vollstreckung - angeknüpft werden kann, wäre allenfalls an eine Verpflichtung der deutschen Staatsorgane zu denken, in den Organen der Gemeinschaft auf Revisionen hinzuwirken, Walter ebd. 73 f.; Röben Außenverfassungsrecht (Fn. 8), 424f.; vgl. B VerfGE 95,39 ( $46 \mathrm{ff}$.).

198 BVerfGE 89, 155 (174f.); 102, 147 (161 ff.); BVerfG, NVwZ 2007, 937 (938f.); NVwZ 2007, 942; zur Bindung an die Gemeinschaftsgrundrechte bei der Umsetzung von Gemeinschaftsrecht EuGH, JZ 2007, 39 (42f.).

${ }^{199}$ S. bereits Kaiser Bewahrung (Fn. 102), 18. 
deutsche Hoheitsträger - besonders deutsche Soldaten ${ }^{200}$ und Polizeibeamte - im Rahmen von Systemen kollektiver Sicherheit ${ }^{201}$ im Ausland handeln. ${ }^{202}$ Auch im Rahmen von Art. 24 Abs. 2 GG setzt dies aber einen vergleichbaren anderweitigen Grundrechtsschutz voraus, bei dessen Bewertung wiederum die besonderen Verhältnisse des jeweiligen Landes in Rechnung zu stellen sind. ${ }^{203}$

Da das Bundesverfassungsgericht für das Aufleben des nationalen Grundrechtsschutzes ein systematisches Versagen auf der supranationalen Ebene verlangt, liegt die Messlatte für den Nachweis verfassungsrechtlich relevanter Schutzdefizite hoch. Dass sie trotzdem gerissen werden kann, zeigen die Entscheidungen des Europäischen Gerichts erster Instanz ${ }^{204} \mathrm{zu}$ den Listingverfahren des Sicherheitsrats der Vereinten Nationen. ${ }^{205}$ Bliebe es bei dem gemeinschaftsrechtlichen Verzicht auf eine inhaltliche Kontrolle und bei dem Fehlen jeglicher Rechtsbehelfe auf der Ebene der Vereinten Nationen, läge darin ein strukturelles Schutzdefizit. ${ }^{206}$ Wenn supra- und internationale Organisationen in der Art eines Verfassungsstaats auf Grundrechtspositionen von Individuen zugreifen wollen, müssen sie selbst eine Konstitutionalisierungsleistung erbringen oder diese weiterhin den Verfassungsstaaten überlassen.

An Punkten wie diesen muss sich die lose Kopplung von Verfassungsund internationalem Recht bewähren. Dabei können sowohl die beacht-

200 Dazu eingehend Schorkopf Überstaatlichkeit (Fn. 18), 136ff. mwN.

${ }^{201} \mathrm{Zur}$ Zulässigkeit von Auslandseinsätzen der Bundeswehr gestützt auf Art. 24 Abs. 2 GG BVerfGE 90, 286 (345ff.).

202 Vgl. aber I. Pernice in: H. Dreier (Hrsg.) Grundgesetz Kommentar, 2. Aufl. 2006, Art. 24 Rn. 66: keine Anwendung des Struktursicherungsgedankens auf Art. 24 Abs. 2 GG.

${ }^{203} \mathrm{Zu}$ der völkerrechtlichen Diskussion um die Gewährleistung ausreichenden Rechtsschutzes im Rahmen von Mandatseinsätzen vgl. Lorenz Territorialer Anwendungsbereich (Fn. 193), 222 ff.

${ }^{204}$ EuG, Rs. T-306/01, Yusuf, Slg. 2005 Seite II-03533; Rs. C-315/01, Kadi, Slg. 2005 Seite II-03649.

${ }^{205}$ Kritisch gegenüber der Entscheidung des Europäischen Gerichts erster Instanz L. Harings EuZW 2005, 705; C. Ohler EuR 2006, 848 (849f.); M. Payandeh ZaöRV 66 (2006), 41 (54ff.); K. Schmalenbach JZ 2006, 349 (352f.); B. Fassbender AöR 132 (2007), 257 (274ff.); Schorkopf Überstaatlichkeit (Fn. 18), 286ff.; S. Hörmann EuR 2007, 120; Röben Außenverfassungsrecht (Fn. 8), 493; grundsätzlich zustimmend $M$. Kotzur EuGRZ 2006, 19 (25f.); S. Steinbarth ZEuS 2006, 269 (285); A. v. Arnauld AVR 44 (2006), 201 (213 ff.); verbunden mit der Forderung nach Verbesserung des Rechtsschutzes der Vereinten Nationen C. Tomuschat, CMLRev. 43 (2006), 537 (551).

206 Anders als jüngst durch den Supreme Court der USA vorausgessetzt, El-Masri v. United States, No. 06-1613, 76 U.S.L.W. 3186, kennt das deutsche Recht keinen Staatsgeheimnisvorbehalt für die Rechtfertigung von Grundrechtseingriffen, s. etwa VG Berlin, InfAusIR, 1991, 167; dazu G. Biehler, Auswärtige Gewalt, 2005, 177, 331. 
lichen Anstrengungen des Europäischen Gerichts erster Instanz, den Sicherheitsrat an das zwingende Völkerrecht zu binden, als auch die Einführung ${ }^{207}$ und Weiterentwicklung ${ }^{208}$ von De-Listing-Verfahren durch die Vereinten Nationen als Beleg für einen durch die nur lose Kopplung ermöglichten Dialog zwischen den Ebenen gelesen werden - auch wenn dessen Ergebnisse bislang noch unzureichend ausfallen. Indem das Verfassungsrecht auf seinen rechtsstaatlichen Standards insistiert, kann es unter Umständen auch im Widerspruch zu völkerrechtlichen Verpflichtungen - einen positiven Beitrag zur Globalisierung leisten.

${ }^{207}$ Guidelines of the 1267 Committee for the Conduct of It's Work, v. 7. 11. 2002 i.d.F. v. 29. 11. 2006, Abschn. 8 (a).

208 Einführung des Focal-Point-Verfahrens durch die Resolution 1730 v. 19. 12. 2006, die es Betroffenen ermöglicht, sich unmittelbar - nicht nur über seinen Heimat- oder Aufenthaltsstaat - mit einem Antrag auf Entfernung aus der Liste an die Vereinten Nationen zu wenden. 
Leitsätze des 2. Berichterstatters über:

\section{Das Verfassungsrecht vor den Herausforderungen der Globalisierung}

\section{A. Globalisierung}

1. Die Globalisierung hat eine Reihe faktischer und regulativer Phänomene hervorgebracht, die das nationale Verfassungsrecht provinziell erscheinen lassen.

2. $\mathrm{Zu}$ diesen Phänomenen gehören u.a. die Möglichkeit, der nationalen Rechts- und Verfassungsordnung auszuweichen, internationale Regulierungen privater und intergouvernementaler Akteure sowie internationaler Organisationen und Funktionssysteme.

3. Diese Entwicklungen fordern zentrale Strukturelemente der Verfassung wie die Souveränität, das Demokratieprinzip, das gewaltenteilige Verhältnis zwischen Parlament und Regierung und den Grundrechtsschutz heraus.

\section{B. Souveränität}

4. Art. 20 Abs. 2 S. 1 GG liegt ein relativ anspruchsloser, aber rechtlich beschreibbarer Begriff der innerstaatlichen Souveränität zu Grunde. Er fordert für die Ausübung von Hoheitsgewalt eine Rückführbarkeit auf Wahlen und Abstimmungen des Volkes.

5. Die globalisierungsbedingten faktischen Möglichkeiten, der nationalen Rechts- und Verfassungsordnung auszuweichen, tangieren den verfassungsrechtlichen Ableitungszusammenhang nicht.

6. Sowohl für auf völkerrechtlichen Verträgen beruhende als auch für intergouvernementale und private Regulierungen muss der Ableitungszusammenhang durch eine Übernahme der internationalen Normsetzungen in das nationale Recht hergestellt werden.

7. Dies gilt auch für scheinbar autonome Regulierungen internationaler Funktionssysteme etwa durch die Lex Mercatoria. Sie sind sowohl nach ihrem dogmatischen Selbstverständnis als auch faktisch von der nationalen Rechtsordnung abhängig. 
8. Im Sinn eines Ableitungszusammenhangs verzichtet das Grundgesetz in der Globalisierung "nicht auf die in dem letzten Wort liegende Souveränität" (BVerfGE 111, 307/319).

9. Souveränität bedeutet nicht faktische Entscheidungsfreiheit gegenüber Globalisierungsprozessen. Ihre Funktion liegt in der nur losen Kopplung von nationalem Recht und internationalen Regulierungen.

10. Die Souveränität ermöglicht so die akkommodierende Wahrung nationaler Eigenheiten und Differenzen.

11. Damit dient die Souveränität auch der internationalen Kooperation. Sie ermöglicht ein zwar asymmetrisches, aber dialogisches Verhältnis zwischen der nationalen Rechts- und Verfassungsordnung und den internationalen Akteuren.

\section{Demokratie}

12. Vor dem Hintergrund der identitärdemokratischen Tradition der deutschen Staatsrechtslehre ist die Wahrnehmung der Globalisierung in der Perspektive eines demokratischen Defizits nahe liegend und verbreitet.

13. Der Defizitperspektive entsprechen drei Strategien im Umgang mit der Globalisierung: nationale Gegensteuerung, Demokratisierung der internationalen Ebene, Substitution demokratischer durch technokratische Legitimation.

14. Alle drei Strategien lassen keine ausreichende Kompensation des wahrgenommenen Defizits erwarten.

15. Eine andere Perspektive eröffnet ein kontextbezogenes realistisches Demokratieverständnis. In ihr erscheinen die Globalisierungsprozesse nicht notwendig demokratisch defizitär.

16. Der Realismus dieses Demokratieverständnisses rückt einerseits die durch die internationale Kooperation gesteigerte Handlungsfähigkeit und die damit gesteigerten Partizipationschancen der nationalen Akteure in den Mittelpunkt, anderseits die durch die Internationalität limitierten nationalen Einflussmöglichkeiten.

17. Hinsichtlich der normativen Elemente dieses Demokratieverständnisses lässt sich zeigen, dass die erforderliche Partizipation, Verantwortlichkeit und Responsivität sowie der Gemeinwohlbezug in internationalen Kooperationen gewährleistet werden können. 


\section{Gewaltenteilung}

18. Durch die internationalen Kooperationen verschiebt sich die gewaltenteilige Balance zwischen Legislative und Exekutive zugunsten der Regierung.

19. Aus demokratie- und verfassungstheoretischer Perspektive ist eine stärkere Einbindung des Parlaments in die internationalen Kooperationen erstrebenswert. Durch die Beteiligung des Parlaments wird gesellschaftliche Öffentlichkeit hergestellt. Dies stärkt die demokratische Verantwortlichkeit und Responsivität.

20. Aufgrund des regelmäßigen Gleichklangs von Parlamentsmehrheit und Regierung ist die Beteiligung des Bundestags als solche wichtiger als einzelne Entscheidungsrechte. Bereits die Beteiligung bietet die. Grundlage für öfentliche Auseinandersetzungen zwischen Regierungsmehrheit und Opposition, die die demokratische Verantwortlichkeit für internationale Kooperationen stärken.

21. Ein Muster für eine ausreichende Beteiligung sichernde Regelung kann in Art. 23 Abs. 2 und 3 GG gesehen werden.

22. Die Beteiligung an der kooperativen supranationalen Rechtssetzung weist dem Bundestag eine veränderte Rolle zu. Er muss insoweit sein Selbstverständnis von einem Hauptakteur auf das eines Akteurs unter vielen umstellen.

23. Ein Wertungswiderspruch der Verfassung liegt darin, dass der Bundestag beim auswärtigen Handeln der Europäischen Union in dem Verfahren nach Art. 23 Abs. 2 und 3 GG beteiligt werden muss, während für das auswärtige Handeln der eigenen Regierung nur geringere Beteiligungsrechte bestehen.

24. De constitutione ferenda sollte das in Art. 23 Abs. 2 und 3 GG angelegte Beteiligungssystem allgemein auf internationale Kooperationen erstreckt und die Delegationsmöglichkeit des Art. 45 S. 2 GG zur Steigerung der Leistungsfähigkeit des Bundestags insoweit auf die Fachausschüsse ausgedehnt werden.

25. De constitutione lata ergibt sich das für die Beteiligung des Bundestags besonders wichtige Recht auf umfassende und frühestmögliche Information im gegenständlichen Anwendungsbereich von Art. 59 Abs. $2 S .1 G G$, zu dem auch die Entwicklungen in internationalen Organisationen gehören, bereits aus dem geltenden Verfassungsrecht.

26. Der Transparenz, Effektivierung und Konkretisierung des Informationsrechts sowie seinem Interorgancharakter entspräche es, ein Verfahrensreglement in einer Interorganvereinbarung zwischen Bundestag und Bundesregierung festzuhalten.

27. Die umfassendere Einbindung des Bundestags in internationale Regulierungsprozesse würde seine neue internationalisierte Rolle stärken und 
die Entwicklung eines entsprechenden institutionellen Selbstverständnisses unterstützen.

\section{E. Grundrechte}

28. Die nur lose Kopplung von nationalem Recht und internationalen Regulierungen eröffnet die verfassungsrechtliche Möglichkeit, die Grundrechte in den Prozess der Globalisierung einzubringen.

29. In den vielgestaltigen Konstellationen, in denen deutsche Hoheitsgewalt mit ausländischen oder internationalen Kontexten in Berührung kommt, ist sie aufgrund von Art. I Abs. $3 \mathrm{GG}$ grundsätzlich in vollem Umfang an die Grundrechte gebunden.

30. Aus der offenen Staatlichkeit des Grundgesetzes ergibt sich keine Reduktion des Grundrechtsschutzes auf einen international anerkannten Mindeststandard im Falle eines Internationalisierungsbezugs.

31. Bei der Anwendung der Grundrechte in internationalen Kontexten sind jedoch die besonderen faktischen Verhältnisse und die beschränkten rechtlichen Handlungsoptionen in Rechnung zu stellen. Zudem können globalisierungsspezifische Politikziele Grundrechtseingriffe rechtfertigen.

32. Modifikationen des grundrechtlichen Maßstabs ergeben sich nur im Rahmen der Übertragung von Hoheitsrechten und sind dort durch die mit Art. 23 und 24 GG verbundene Kompetenz zur Verfassungsänderung legitimiert.

33. Dass auch der auf ein systematisches Versagen gerichtete Grundrechtsschutz im Rahmen von Art. 23 und 24 GG verfehlt werden kann, zeigen die Listing-Verfahren des Sicherheitsrats der Vereinten Nationen.

34. Indem das Verfassungsrecht auf seine rechtsstaatlichen Standards insistiert, kann es - unter Umständen auch im Widerspruch zu völkerrechtlichen Verpflichtungen - einen positiven Beitrag zur Globalisierung leisten. 


\section{Aussprache und Schlussworte}

\section{Das Verfassungsrecht vor den Herausforderungen der Globalisierung}

Schneider, H.-P.: Ich hätte als weder Völker- noch Europarrechtler nicht gewagt, die Aussprache zu eröffnen, wenn mich der Herr Vorsitzende nicht darum gebeten hätte. Vielleicht hängt das mit dem Thema des Beitrags zusammen, den ich beisteuern möchte. Zunächst herzlichen Dank an die Referenten. Ich glaube, dass es Ihnen beiden sehr gut gelungen ist, zuerst die Außenperspektive des Problems der Globalisierung darzustellen und dann die Innenansicht. Einen Punkt habe ich allerdings vermisst. Sie haben natürlich mit einem gewissen Recht das Schwergewicht auf Bedrohung durch den internationalen Terrorismus gelegt und den Sicherheitsaspekt in den Vordergrund gerückt. Ich meine aber: Die eigentliche "Achillesferse" des demokratischen Verfassungsstaats sind die internationalen Finanzmärkte, wenn man das realistisch sieht. Die Souveränität der Staaten wird weniger durch den weltweiten Terrorismus bedroht (gegen den kann man sich ja noch national oder vielleicht auch mit Hilfe internationaler Vereinbarungen zu Wehr setzen), als durch die Finanzmärkte, für die ein Ordnungsrahmen auch nicht entfernt in Sicht ist. Daher habe ich an Sie die Frage, wie dieses viel bedrohlichere Globalisierungsrisiko eigentlich beherrscht werden kann? Wir wissen, dass alle Finanzministerien heute in ihren Kreditabteilungen über spezielle Referate für Devisen- und Wertpapiergeschäfte verfügen, die auf den Finanzmärkten aktiv sind - nicht nur die Landesbanken, sondern eben auch die Finanzministerien. Wir haben gerade erfahren, dass eine Landesbank wegen verlustreicher Geschäfte mit amerikanischen Immobilienkrediten praktisch konkursreif war, eine andere Bank mit Mehrheitsbeteiligung des Bundes fast bankrott. Hinzu kommen noch riesige Staatsfonds in Indien und in China, die praktisch auf einen Schlag unsere gesamte Wirtschaft aufkaufen könnten - mit kaum auszudenkenden Konsequenzen für die Arbeitsmärkte und die Sozialpolitik. Die eigentliche Gefahr, der die Verfassungsstaaten infolge der Globalisierung ausgesetzt sind, liegt daher in der Bedrohung des sozialen Friedens und der inneren Stabilität durch die internationalen Finanzmärkte. Da muss uns etwas einfallen. Ein kleiner Beitrag dazu mag der Versuch der Föderalismuskommission II sein, im nationalen Rahmen 
die Staatsverschuldung abbauen zu helfen, d.h. ein Schuldenregime zu etablieren mit nachhaltiger Entschuldung, Konsolidierung und Sanierung der Haushalte von Bund und Ländern. Das ist sicher ein richtiger, wichtiger nationaler Schritt; aber wir müssen auch zu internationalen Regelungen kommen. In diesem Zusammenhang stellt sich für mich eine weitere Frage: Wer kontrolliert eigentlich die Rating-Agenturen, die ja von ungeheurer Bedeutung sind für die Einschätzung der Bonität einzelner Staaten und den entsprechenden Zinssatz für Staatskredite? Das sind so ein paar offene Fragen, die mich beschleichen, wenn ich mir morgens die Dollarkurse ansehe und sie mit dem in eine gedankliche Beziehung bringe, was man herkömmlich noch Souveränität nennt.

Albers: Ich habe eine kurze Frage an Ralf Poscher. Du hast ein sehr geschlossenes Bild von der nationalen Verfassung gezeichnet, dies mit der Kernthese, dass sich viele Streitpunkte beruhigend harmonisch auflösten. Kann man aber die von Dir beschriebenen Fragen und Konstellationen überhaupt im Rückgriff allein auf das nationale Verfassungsrecht beurteilen? Liegt das zentrale Problem nicht gerade darin, dass mittlerweile unsicher geworden ist, nach welchem Maßstab auf welcher Ebene etwaige Kollisionen aufzulösen sind? Stellt sich beispielsweise das Verhältnis zwischen Völkerrecht und nationalem Recht aus völkerrechtlicher Sicht oder in internationalen Kontexten nicht zumindest partiell anders dar als aus Perspektive des Verfassungsrechts? Die Görgülü-Entscheidung hat mit ihren Ausführungen, das Grundgesetz verzichte nicht auf die in dem letzten Wort der deutschen Verfassung liegende Souveränität, im Ausland immerhin Irritationen, Widerspruch oder sogar Empörung ausgelöst. Und man kann sie für richtig halten, aber man muss doch zumindest sehen, dass eine Reihe schwieriger Probleme infolge der in einem Mehrebenensystem strukturbedingten Unsicherheiten über die Maßstäbe entsteht, nach denen streitige Konstellationen zu beurteilen sind, und dass man deswegen nicht allein auf das Verfassungsrecht blicken kann.

Häberle: Ich habe drei Fragen, und zwar nur deshalb, weil ich seit 53 Jahren ein Dilettant in Sachen Völkerrecht bin und heute von den bestechenden Referaten viel lernen konnte. Erstens: Was heißt „Globalisierung“, hat die Globalisierung ein Ethos und wenn ja welches? Sind es nur empirische Entwicklungen (Weltmarkt, planetarische Kommunikation, Weltöffentlichkeit) oder spielen Gemeinwohlaspekte, sozialer Fortschritt, Umweltschutz, Gerechtigkeitselemente, Menschenrechte, kulturelle Vielfalt eine Rolle?. - Zweitens: Was ist das Neue an der Globalisierung? Der Ausdruck selbst ist ja noch nicht so alt, vielleicht aber 
die Sache? Der Sprachwissenschaftler J. Trabant hat kürzlich sogar von „Globalesisch“ als Sprache geschrieben. Vergegenwärtigen wir uns einige Klassikertexte, die vor langer Zeit fast alles vorweg genommen haben. Shakespeare: „Die ganze Welt ist Bühne“; Goethe: „Weltliteratur"; Kant: „weltbürgerliche Absicht“; F. Schiller: „Was ich als Bürger dieser Welt gedacht“. Also gab es schon längst vor der „Globalisierung“ Weltbilder, Weltreligionen, Weltbetrachtungen, von Europa aus die Kolonialisierung anderer Erdteile. Bereits bei den alten Griechen finden sich einschlägige Zitate, etwa im Hellenismus. Was ist aber das Besondere und das Neue - das „Veloziferische“, ein Goethe-Zitat - was ist das Neue an dem auch durch das Internet bewirkten Phänomen der Globalisierung?. - Drittens: Sollte man nicht noch stärker im Sinne der Textstufenanalyse die einzelnen Verfassungen miteinander vergleichen? Im Ansatz hat dies wohl Herr Nolte getan. Es finden sich reiche textliche Belege für das, was man "nationales Weltverfassungsrecht" im Kleinen nennen könnte - so wie es "nationales Europaverfassungsrecht" gibt. Ich nenne einige Beispiele: (Welt-)Friedensklauseln in vielen neueren Verfassungen, Kooperations- und Öffnungsklauseln, humanitäre Klauseln bis hinein in die vermeintlich kleinen totalrevidierten Schweizer Kantonsverfassungen, es finden sich national viele universale Menschenrechtsgarantien. Damit schließt sich der Kreis meiner drei Fragen zum Anfang hin - all dies im Lichte der erwähnten Klassiker.

Ruffert: Ich hätte eine Frage an Sie, Herr Poscher, und zwar zum Inhalt Ihres Souveränitätsbegriffs und zu seiner Funktion. Ich habe das so verstanden, dass die Souveränität den Nationalstaaten eine Art „Rückfallposition" gibt, damit sie bestimmte Werte im Globalisierungsprozess zu sichern in der Lage sind. Braucht man dafür die Souveränität oder ist diese Sicherungsfunktion nicht in den Werten selbst enthalten (Demokratie, Grundrechte, Sozialstaat)? Hintergrund der Frage ist, dass die Souveränität in der völkerrechtlichen Diskussion, wenn ich das richtig sehe, seit einiger Zeit anders verstanden wird, nämlich als Ausdruck für das Potential, sich an der internationalen Kooperation zu beteiligen. Diesen Aspekt habe ich wiederum in Ihren Ausführungen zum Demokratieprinzip gefunden. Meine Frage ist also, wie man die Dinge begrifflich und konzeptionell auseinander halten kann.

Oppermann: Man muss zunächst dem Vorstand ein Lob aussprechen, dass er die Außenseite unseres Themas heute Nachmittag zu Wort gebracht hat. Sonst wäre die ganze Thematik unvollständig geblieben. Die beiden Referate waren in ihrer intelligenten Abstraktionshöhe beinahe unangreifbar. Daher lediglich zwei zustimmende Bemerkungen. 
Herr Poscher, ich fand es gut, dass Sie den Souveränitätsbegriff in das Zentrum Ihres Referates gestellt haben. Ich stimme Ihnen auch zu, dass der Souveränitätsbegriff unentbehrlich geblieben ist, wie etwa in der Entscheidung im 111. Band. Man sollte aber gleichzeitig betonen, dass die Souveränität in der heutigen Realität der Globalisierung/Europäisierung eine relative geworden ist. Steinberger hat einmal zur Souveränitätsfrage in der EU die schöne Formulierung gebraucht, sie befinde sich zwischen der Europäischen Union und den Nationalstaaten ,in der Schwebe“. Auf jeden Fall ist die nationale Souveränität durch die moderne internationale Entwicklung in Mitleidenschaft gezogen worden, obwohl man sie angeblich nicht teilen kann. In Ausnahmezuständen mag sie im Sinne des berühmten Wortes von Carl Schmitt noch in Erscheinung treten. Aber sie spielt in der Staatenpraxis längst nicht mehr ihre frühere Rolle.

Meine zweite Bemerkung gilt der international/europäischen Rechtsprechung des Bundesverfassungsgerichts. Sie spiegelt diesen Souveränitätswandel gut wider. Die Entscheidung zu den Auslandseinsätzen der Bundeswehr halte ich - im Gegensatz zu Ihnen, Herr Meyer - für eine der besten des Bundesverfassungsgerichts. Sie hat eine große politische Kontroverse so aufgelöst, dass diese Frage durch die Einschaltung des Parlaments gänzlich unumstritten geworden ist. Das hat ein wenig mit Parlamentssouveränität zu tun. Das war keine „Entthronung“, sondern eine glückliche Anpassung der Verfassungsrechtsprechung an die Wirklichkeit.

Die europäische Rechtsprechung aus Karlsruhe stellt sich als ein dauerndes Auf und $\mathrm{Ab}$ dar. In ihr spiegelt sich die erwähnte Ambivalenz heutiger Souveränität. „Solange I“ war eine Fehlentscheidung ohne Verständnis für den Integrationsprozeß. „Solange II" zollte anschließend dder „Europafreundlichkeit“ des Grundgesetzes den nötigen Respekt, mit einer etwas „knurrenden“ Bestätigung in „Maastricht“ 1993. „Maas-

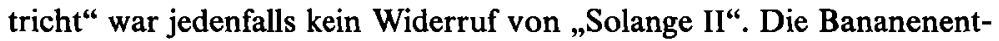
scheidung akzentuierte anschließend wiederum im Ergebnis die Belange der Supranationalität, während „Europäischer Haftbefehl“" zuletzt erneut stärker die nationale Karte ausspielte. Vor einem „Krieg“ mit dem Europäischen Gerichtshof ist das Bundesverfassungsgericht immer wieder zurückgeschreckt. Anders ausgedrückt: Karlsruhe behält sich eine letzte Souveränitätsreserve vor, erkennt aber gleichzeitig die souveränitätsmindernden Notwendigkeiten der Europäisierung an. Eine solche Souveränitätsreserve ist vielicht nicht unklug, wenn man die Unwägbarkeiten des weiteren Integrationsprozesses - jetzt in Gestalt des Reformvertrages - ins Auge fasst. 
Oeter: Ausgangspunkt meines kurzen Einwurfes ist die These 10 von Herrn Poscher, die mit der Frage der Souveränität beginnt. Souveränität ermögliche die akkomodierende Wahrung nationaler Eigenheiten und Differenzen. Gegen den Satz als solchen hätte ich gar keine Einwände, aber mit diesem Satz gehen erhebliche Gefahren einher, denn die Bestimmung der nationalen Eigenheiten und Differenzen muss - und ich glaube darauf hat Georg Nolte zu Recht hingewiesen - in einem dialektischen Prozess geschehen. Also das nationale Eigene muss sich auch immer wieder rückbeziehen auf das Universale, sonst gerät man zu leicht in die Gefahr, infolge von Kränkungsreflexen in Übersprungshandlungen zu geraten. Herr Poscher hat ja selbst den Begriff der narzistischen Kränkung bemüht im Blick auf den Bundestag, also des Wechsels des Parlaments in die Nebenrolle. Man kann im Blick auf heute morgen im Grunde auch eine narzistische Kränkung rekonstruieren. Der Befund, den uns Herr Volkmann vorgeführt hat - wenn man so will des Kaisers neue Kleider der bundesrepublikanischen Staatsrechtsdogmatik - beinhaltet im Kern ja auch eine narzistische Kränkung - der normative Allmachtsanspruch, der in der Entgrenzung der verfassungsrechtlichen Argumentation, in die Übernahme der politischen Wirklichkeit mündet. Die politische Wirklichkeit übernimmt hier den normativen Anspruch. Ein ähnliches Problem stellt sich bei uns hier, in dem Feld über das wir heute diskutieren, natürlich auch. Die Vorstellung der normativen Steuerung von Globalisierung, oder auch nur der rechtlichen Reaktionen auf Globalisierung, aus den Setzungen der deutschen Staatsrechtslehre, funktioniert evident nicht. Man kann daraus natürlich jetzt unterschiedliche Schlussfolgerungen ziehen. Eine falsche Schlussfolgerung wäre sicherlich, zu sagen, wir beharren einfach auf dem Anderssein, sei es auch nur historisch gewachsen; es ist anders, weil historisch gewachsen, deswegen muss es so bleiben, oder - so vielleicht sogar noch schlimmer im Sinne von Herrn Volkmann heute morgen - so ist der Zeitgeist. Wir erliegen dem Zeitgeist natürlich nicht bewusst. Wir beharren einfach nur darauf, und insofern möchte ich nachhaltig noch einmal auf die Pointe des Vortrages von Georg Nolte verweisen, die auch in seiner Schlussthese noch einmal aufscheint, dass sich nämlich diese Bestimmung des normativen Propriums einer Verfassungsordnung im Grunde in einem dialektischen Prozess rückbeziehen muss auf die Völkerrechtsordnung, auf die globale Ordnung, und auch in einem Prozess der Rechtsvergleichung sich Rechenschaft darüber ablegen muss, was eigentlich in diesem Prozess Bestand haben sollte. Und das ist vielleicht doch so historisch akzidentell, dass wir es nicht überhöhen sollten zu Teilen der Identität, die auf „koste was es wolle“ verteidigt werden müsse. Das kann man sich auch im Blick auf die Grundrechtsfrage, die in dem Schlussteil von 
Herrn Poschers Referat eine Rolle gespielt hat, fragen: Ist vielleicht der Weg, den das Europäische Gericht erster Instanz mit seinem sehr zurückgenommenen ,Jus cogens'-Konstrukt bestritten hat, ist das nicht vielleicht ein sehr intelligenter Weg des Umgangs mit der Problematik, sehr viel intelligenter als weit überhöhte Forderungen der unbedingten Wahrung als vorgegeben gesehener normativer Standards.

Hofmann, R.: Zunächst wollte ich, wie auch die anderen Vorredner, den beiden Referenten gratulieren und Zustimmung äußern zur Grundthese, dass die Globalisierung in der Tat bedingt, dass sich das Verfassungsrecht sehr viel mehr mit internationalen Entscheidungen, mit fremden Rechten beschäftigt als bisher. Zustimmung auch zu der Aussage, dass die Notwendigkeit einer - wie Herr Poscher es genannt hat, wenn ich es recht erinnere - „dialogischen Kooperation“ bestehe. Grundsätzliche Zustimmung auch zu der Aussage, dass die Grundrechtsbindung aus Art. 1 Abs. 3 GG bei solchen Sachverhalten mit Auslandsberührung bleibt. Jetzt aber mangelnde Zustimmung - Herr Poscher, das wird Sie nicht überraschen - zu Ihrer Aussage, dass sich aus Art. 1 Abs. 3 GG nicht die Notwendigkeit ergibt, bei solchen Sachverhalten eine Reduktion des Inhalts der Grundrechtsbindung anzunehmen. Ich habe das einmal versucht zu begründen, will darauf hier aber nicht näher eingehen, aber doch betonen, dass ich meine, dass die Entscheidung des Grundgesetzgebers für die Offenheit des Grundgesetzes bedingt, dass man bei Sachverhalten mit Auslandsberührung bereit ist, den Inhalt der Grundrechte anzupassen. Frage: Wo liegt die Grenze? Da, glaube ich, kann man immer noch aus der Solange II-Formel einiges ableiten: Nämlich, ,im Wesentlichen vergleichbar“. Und dann kommt es natürlich darauf an, was man versteht unter dem Begriff ,im Wesentlichen“. Insofern, meine ich, lässt sich vertreten, dass damit gemeint ist, was im nationalen Recht die Wesensgehaltsgarantie wäre, und ich glaube, es lässt sich begründen, dass das, was wir bei einzelnen Grundrechten als Wesensgehaltsgarantie verstehen, dem entspricht, was das Völkerrecht als einen Mindeststandard bezeichnet. Letzter Punkt und da möchte ich jetzt eine Frage an Georg Nolte richten, obwohl ich im Großen und Ganzen mit seinem Referat sehr einverstanden bin, und das ist der Punkt, ob man aus Art. 24 Abs. 2 GG wirklich ableiten kann, dass man gegenüber dem Sicherheitsrat der VN im Grunde mehr an Grundrechtseingriffen akzeptiert als gegenüber der EG bzw. EU. Das meine ich nicht. Ich glaube, auch da, also gegenüber dem Sicherheitsrat, müsste die Bindung an das "Wesentliche" bestehen, und wenn der VNSicherheitsrat im Einzelfall bei diesen Listingverfahren Grundrechte oder Standards verletzt, die sowohl dem völkerrechtlichen Mindeststan- 
dard wie unserer Wesensgehaltsgarantie entsprechen, dann, so meine ich, sind auch unsere Gerichte aufgerufen, dem entgegenzutreten - und das kann - und das schließt im Grunde an das an, was Herr Oppermann gesagt hat - und sollte man so tun, wie es das Bundesverfassungsgericht gegenüber dem EuGH getan hat: Nicht die „Tür zuknallen“, sondern sagen: „Es gibt Grenzen, die wir noch akzeptieren können. Danach folgen wir euch aber nicht mehr. Hier jedoch ist die Grenze vielleicht gerade noch nicht erreicht". Es mag einem deutschen Gericht erhebliche „Bauchschmerzen“ bereiten, eine solche Aussage zu machen. Sie ist aber wegen der gebotenen internationalen Kooperation mit diesen $\mathrm{Ge}-$ richten und Entscheidungsträgern, glaube ich, notwendig.

Jochum, G.: Ich habe eine Frage zu Herrn Noltes These 16. Wenn ich das richtig verstanden habe, sollen die nationalen Gerichte andere Rechtsordnungen gegenseitig berücksichtigen und dadurch Konflikte vermeiden. Also ich weiß nicht genau, ob das möglicherweise nicht Richter, Verfassungsrichter überfordert. Ich kann natürlich nachvollziehen, dass man die Rechtsordnungen berücksichtigt an die man gebunden ist, also beispielsweise EMRK oder EG-Vertrag, aber hinsichtlich anderer Verfassungen, wie z.B. der der USA, hätte ich doch große Bedenken. Und zwar deswegen, weil diese Verfassungsordnungen sich von unserer doch sehr stark unterscheiden. Beispiel: In den USA gibt es keine Garantie der Menschenwürde, weswegen es in der Rechtsprechung des Supreme Courts auch kein Problem war, die Sklaverei zu rechtfertigen. Die jüngsten Entscheidungen des Supreme Courts zu Guantanamo zeigen ja auch, das dort ein Mindeststandard zumindest nicht das ist, was vom Referenten gefordert wird. Dort wird im Grunde genommen nur habeas corpus eingeklagt. Ich weiß nicht, ob diese Art von Vergleichen letztlich nicht dazu führt, dass letztlich der nationale ordre publique aufgegeben werden soll und zu so einer Art. internationalem odre publique führen soll was dann in der Folge die Frage stellt, was denn diese internationale ordre publique eigentlich heißen soll? Ist das sozusagen der Minimumstandard von Grundrechten, der irgendwann in der Verfassung der Vereinigten Staaten von 1789 definiert worden ist als kleinster gemeinsamer Nenner oder in der internationalen Erklärung der Menschenrechte oder in der europäischen Menschenrechtskonvention. Das wäre einfach mal die Frage, woher nimmt man dann eigentlich diese internationalen Regelungen, die dann als gemeinsamer ordre publique - wenn das überhaupt Ihre Forderung ist - herhalten sollen?

Bausback: Ich möchte mich beschränken auf eine Nachfrage zum Referat von Herrn Nolte, das mich - wie das Referat von Herrn Poscher - 
begeistert hat. Meine Nachfrage bezieht sich auf These 8. Herr Nolte, Sie sehen in dem Rechtsprechungsdialog ein Mittel zur Verhinderung eines menschenrechtsfeindlichen race to the bottom und zur Vermeidung von Verschiebungen im Gewaltenteilungsgefüge. Wirkt dieser Rechtsprechungsdialog, der ja schon in ihrer These 6 angesprochen wird, naturgesetzlich in dieser menschenrechtsfreundlichen Richtung, oder könnte es auch einmal sein, dass er sich im Sinne einer Verstärkung eines race to the bottom bewegt?

Ich vermute, dass es eine quasi naturgesetzliche Festlegung der Wirkungen des Dialogs in menschenrechtsfreundlicher Richtung gibt und hoffe insoweit, von Ihnen Zustimmung und ggf. einen Beleg für meine diesbezügliche Annahme zu erhalten. Wenn es eine solche Determinierung des angesprochenen Dialogs in eine menschenrechtsfreundliche Richtung über die Strukturen der freiheitlichen Staaten und die Schutzmechanismen des internationalen Menschenrechtsschutzes geben sollte, dann wäre es nicht nur gerechtfertigt, von einem Rechtsprechungsdialog zu sprechen, sondern darüber hinausgehend von einer sich immer weiter entwickelnden Menschenrechtsdialektik.

Und als kurze Anmerkung zum Schluss: Eine solche menschenrechtsfreundliche Wirkung des freiheitlichen Staaten wäre auch ein Beleg dafür, dass die Rolle des Staates an sich heute zwar gewandelt ist, aber weder bedeutungslos geworden ist, noch bedeutungsloser wird.

Paulus: Vielen Dank den beiden Referenten für ihre sehr anregenden Referate. Ich kann der Versuchung nicht ganz widerstehen, kurz etwas zur Souveränität zu sagen. Für das Völkerrecht stellt die Souveränität das Gegenteil zur völkerrechtlichen Bindung dar. Wo keine Völkerrechtsbindung besteht, da sind die Staaten frei, das zu tun, was sie wollen. Es gibt auch eine Souveränität innerhalb des Völkerrechts, die eine Vermutung zu Gunsten der Staatenbefugnis darstellt, aber die Vermutung ist so vielfältig durchbrochen, dass es schwierig ist, sie in dieser allgemeinen Form aufrecht zu erhalten. Aber das nur am Rande. Was mir in beiden Referaten etwas zu kurz kam, sind die Menschenrechtsstandards des allgemeinen Völkerrechts, die mit der EMRK praktisch deckungsgleich sind und zum Teil noch über diese hinausgehen. International liegt das Problem selbstverständlich bei der Durchsetzung. Aber ich glaube schon, dass man, bevor man einen Widerspruch zwischen dem nationalen oder europäischen Recht einerseits und dem Völkerrecht andererseits konstruiert, versuchen sollte, die Schätze, die im völkerrechtlichen Menschenrechtsschutz liegen, erst einmal zu heben. Die Befugnisse des Sicherheitsrates sind begrenzt und müssen begrenzt sein, weil sich sonst die Staaten ihrer Souveränität in einem völlig un- 
verantwortlichen Maße begeben hätten. Wenn der Sicherheitsrat darüber hinausgeht, dann können ihm durchaus Grenzen gezogen werden. Art. 25 der Charta der Vereinten Nationen sieht nur die rechtmäßigen Beschlüsse, die Beschlüsse des Sicherheitsrates im Rahmen seiner Befugnisse, als verbindlich an. Hier wäre also durchaus Spielraum für eine Solange-Rechtsprechung, nicht nur im Rahmen des Jus cogens-Standards, sondern im Rahmen der Charta der Vereinten Nationen selbst, die in Art. 1 die Menschenrechte zu ihren Zielen zählt, die wiederum für den Sicherheitsrat laut Art. 24 und 25 der Charta verbindlich sind. Eine letzte Frage richtet sich an Herrn Nolte. Ich hatte Sie am Ende im Punkt 11 so verstanden, dass Sie das humanitäre Völkerrecht als Kompetenztitel beim Auslandseinsatz heranziehen wollen. Ich habe da große Zweifel. Das humanitäre Völkerrecht begrenzt die Tätigkeit des Staates im Krieg, räumt ihm aber in der Regel keine zusätzlichen Befugnisse zum Einsatz von Waffengewalt ein.

Murswiek: Mit der Durchdringung von Innen- und Außenpolitik, wie sie angesprochen worden ist von Herrn Nolte, mit dem Einwirken insbesondere des Sicherheitsrats in das Innere der Staatenwelt, nimmt die Charta der Vereinten Nationen immer mehr auch den Charakter einer Weltverfassung an. Der Sicherheitsrat funktioniert immer mehr als Exekutivorgan einer Weltinnenpolitik oder einer Weltpolizei, und daraus resultieren natürlich auch Verfassungsfragen im Hinblick auf den Rechtsschutz, insbesondere den Grundrechtsschutz, wie sie in beiden Referaten angeklungen sind. Ich kann Herrn Nolte im wesentlichen zustimmen in dem, was er dazu gesagt hat, insbesondere dazu, dass man beim Grundrechtsschutz die Besonderheiten der Außenpolitik berücksichtigen muss, andererseits aber den völkerrechtlichen Mindeststandard auf jeden Fall wahren sollte. Ich möchte jetzt auf eine andere Ebene der Problematik hinweisen, die nicht angesprochen wurde in den Referaten, nämlich eben diese Ebene der Charta als Weltverfassung. Wenn man sich das so vorstellt, kann und muss man sich fragen, welche Funktion in verfassungsrechtlichen Kategorien der Sicherheitsrat dort einnimmt, besonders im Vergleich mit Regierungen von Verfassungsstaaten. Versteht man unter einer Diktatur ein Regime, das normativ nicht beschränkt ist, nicht konstitutionell eingehegt durch Gewaltenteilung und gerichtliche Kontrolle, dann kann man die Macht des Sicherheitsrats als Diktaturgewalt begreifen. Der Sicherheitsrat formuliert die Voraussetzungen seiner Freiheitseinschränkungen von Fall zu Fall selbst, und er unterwirft sich keiner Gerichtsbarkeit. Das mag akzeptabel gewesen sein, solange es bei der Ausübung des Sanktionsregimes um den Ausnahmefall der Verhinderung eines Krieges ging. Aber wir erleben 
zurzeit eine Veralltäglichung der entsprechenden Befugnisse, nachdem die Kautelen, die im Art. 39 vorhanden sind, Bedrohung oder Bruch des Friedens, internationale Sicherheit, Weltfrieden, aufgeweicht worden sind und somit die Befugnisse des Sicherheitsrats ganz andere Anwendungsbereiche gefunden haben. Im Grunde genommen haben wir es jetzt mit einer nicht mehr beschränkten Generalklausel zu tun, ohne dass es irgendeine Form gerichtlicher Kontrolle gibt, so dass meines Erachtens die Frage auf die Agenda der internationalen Politik, aber auch der Staats- und Völkerrechtswissenschaft gehört, ob hier nicht eine sachangemessene Konstitutionalisierung, wie sie auch Herr Poscher angesprochen hat, erforderlich ist.

Mayer: Ich möchte zwei Punkte ansprechen. Eine erste Frage betrifft die Globalisierung und das Sicherheitsrecht im Hinblick auf die tatsächlichen oder empfundenen Bedrohungen, wie Georg Nolte uns das nahegebracht hat. Die Frage richtet sich aber auch an Ralf Poscher, der mit der Globalisierung keine Reduktion des Grundrechtsschutzes hinnehmen möchte. Mir scheint, dass unter dem Aspekt des Sicherheitsrechtes die Herausforderung an das Verfassungsrecht in der Globalisierung zu allererst sein könnte, sicher zu stellen, dass Verfassungsrecht überhaupt relevant bleibt. Das sage ich vor dem Hintergrund gegenwärtiger Diskussionen hier in Deutschland mit zum Teil sehr eigenartigen und weit reichenden Vorschlägen, und dies obgleich man in Europa - jedenfalls in Deutschland - noch gar keine Attentate mit hunderten oder tausenden von Toten gehabt hat. Hier stehen uns die amerikanischen Erfahrungen mahnend vor Augen. Amerikanische Kollegen, ich möchte hier Bruce Ackerman nennen, empfehlen uns, rechtzeitig nachzudenken, weil sich unter dem Eindruck von hunderten oder tausenden von Toten sehr schlecht nachdenken lässt. Und in diesem Sinne möchte ich eine Frage stellen, es ist eine offene Frage. Reicht eigentlich unser innerstaatliches, unser nationales Notstandsrecht aus? Funktioniert unser nationales Notstandsrecht, und zwar im Sinne maximaler Freiheitsgewähr, in Anbetracht neuartiger Bedrohungslagen? Der zweite Punkt betrifft die Mitwirkung des Deutschen Bundestages. Das hat Ralf Poscher angesprochen. Er hat vorgeschlagen, dass es ein Mehr an Information des Deutschen Bundestages geben muss, und meine Frage dazu ist: Reicht das aus? Blickt man nämlich in den Bereich der europäischen Integration - und dieses Beispiel ist ja auch genannt worden -, so zeigt sich dort, dass es lediglich mit einem Mehr an Information nicht wirklich getan ist. Der Deutsche Bundestag hat nicht ohne weiteres die Ressourcen diese Informationen zu verarbeiten. Es entsteht ein Verarbeitungsproblem, für dessen Lösung eine adäquate Logistik erst aufgebaut werden 
muss. Ein Weiteres kommt hinzu: Im Bereich der europäischen Integration hat der Deutsche Bundestag sich neuerdings ein Büro in Brüssel eingerichtet. Es scheint demnach so zu sein, dass man mit der Information alleine nicht wirklich weit kommt. Man muss vor Ort dabei sein. Würde man dann nicht konsequenterweise überlegen müssen, ob der Deutsche Bundestag nicht auch beispielsweise in der deutschen Vertretung bei der NATO oder bei der WTO in irgendeiner Form repräsentiert sein sollte? Hier würde sich freilich sofort die Frage anschließen, was es eigentlich für unsere Vorstellung von Gewaltenteilung bedeutet, wenn wir den Deutschen Bundestag in dieser Art und Weise in die europäischen Angelegenheiten und in die auswärtige Gewalt mit einbinden.

Puttler: Aus der Fülle der Probleme, die uns beide Referenten in beeindruckender Weise dargelegt haben, möchte ich nur auf einen Aspekt eingehen, nämlich den des Grundrechtsschutzes gegen die so genannten "smart sanctions" des UN-Sicherheitsrates. Hierbei geht es um die Frage, wie die Grundrechte der Personen garantiert werden können, deren Namen in die schwarzen Listen des UN-Sicherheitsrates aufgenommen worden sind.

Herr Kollege Nolte hat in diesem Zusammenhang von einem Rechtsprechungsdialog $z$ wischen internationalen und nationalen Spruchkörpern gesprochen Bei der Frage des Grundrechtsschutzes für Personen, denen aufgrund der Sanktionen des Sicherheitsrates der Zugang zu ihrem Vermögen verweigert wird, wird es zu einem Dialog beispielsweise zwischen dem Bundesverfassungsgericht auf deutscher Seite und einem internationalen Spruchkörper auf der anderen Seite aber nicht kommen können. Zum einen gibt es keinen internationalen Spruchkörper, der für einen Dialog zur Verfügung stünde. Zwar überprüfen dem Sicherheitsrat zugeordnete Sanktionsausschüsse die Namenslisten und können auch einen Namen von einer schwarzen Liste wieder streichen. Voraussetzungen und Verfahren eines solchen „delisting" sind jedoch völlig intransparent. Sanktionsausschüsse sind keine unabhängigen Gerichte. Sie sind nationalen Stellen keinerlei Rechenschaft schuldig und werden daher kaum mit nationalen Gerichten in einen Dialog eintreten wollen.

Auf der anderen Seite wird das Bundesverfassungsgericht auch deshalb keinen unmittelbaren Dialog aufnehmen können, weil die Bundesrepublik Deutschland gar nicht mehr zur Umsetzung solcher Resolutionen des Sicherheitsrats befugt ist. Im Bereich derartiger außenpolitisch motivierter Handelssanktionen werden die Europäische Union und die Europäische Gemeinschaft auf der Grundlage der Art. 301 und 308 EGVertrag tätig. EU und EG setzen die Resolutionen des Sicherheitsrates lediglich im Interesse der nach der UN-Charta verpflichteten Mitglied- 
staaten um, da diese ihre Kompetenzen in diesem Bereich auf europäische Institutionen abgegeben haben.

Wie soll in einem solchen System Grundrechtsschutz für gelistete Personen hergestellt werden? Art. 23 Abs. 1 GG verlangt, dass die Bundesrepublik Deutschland sich nur an einer Europäischen Union beteiligt, die einen dem Grundgesetz im wesentlichen vergleichbaren Grundrechtsschutz gewährleistet. Ich wüsste gerne, ob ich Herrn Nolte so verstehen darf, dass er aus deutscher Sicht von den europäischen Institutionen und Gerichten die Einhaltung zweier unterschiedlicher Standards verlangt: bei originärer europäischer Rechtsetzung einen dem Grundgesetz im wesentlichen vergleichbaren Grundrechtsschutz und bei der Umsetzung von Sicherheitsratsresolutionen einen geringeren Standard? Herr Nolte bezeichnete letzteren als völkerrechtlichen Mindeststandard. Ein solcher Mindeststandard dürfte allerdings deutlich unter den grundrechtlichen Wertvorstellungen des Grundgesetzes liegen. Ich denke da nur an das Eigentumsrecht, das die „smart sanctions“ des Sicherheitsrates verletzen könnten. Das Eigentumsrecht kann keine „Weltgeltung“ beanspruchen, findet es sich doch allenfalls in regional geltenden völkerrechtlichen Verträgen. Im Völkergewohnheitsrecht wird es nicht garantiert. Schon gar nicht handelt es sich beim Eigentumsrecht um ius cogens - auch wenn das Gericht Erster Instanz in seiner Rechtsprechung zu den Sanktionsumsetzungen mit dem Begriff des ius cogens sehr großzügig umgegangen ist. Wenn ich Herrn Kollegen Poscher folge und fordere, dass wegen Art. 23 Abs. 1 GG die Bundesrepublik Deutschland in jedem Fall von europäischen Institutionen einen mit dem deutschen Grundgesetz im wesentlichen vergleichbaren Grundrechtsschutz verlangt, müsste Deutschland gegebenenfalls auf einen Völkerrechtsbruch durch EU und EG dringen, damit wir die Gebote unserer Verfassung einhalten können. Da wir von den rudimentären Menschenrechtsgarantien des Völkergewohnheitsrechts jedenfalls keinen auch nur annähernd grundgesetzähnlichen Grundrechtsschutz erhoffen können, dürften wir in manchen Fällen von "smart sanctions" nur die Wahl zwischen Verfassungsverletzung und Völkerrechtsbruch haben.

Streinz: Herr Nolte, Sie haben treffsicher eine besonders brisante Herausforderung der Globalisierung herausgegriffen, nämlich die so genannten gezielten Sanktionen der Vereinten Nationen, und dabei auch einen interessanten Ansatz entwickelt zur Lösung des Problems, das aus aktuellem Anlass ja vielfältig diskutiert wird, ohne dass hier bislang eine letztlich befriedigende Lösung gefunden wurde, was ja auch die These 33 von Herrn Poscher zeigt. Wenn ich das richtig verstehe, könnte dies ein Fall für Solange II werden, wobei ich die Frage habe, ob das gegebenen- 
falls tatsächlich aufgegriffen würde. Vielleicht bleibt hier letztlich eine gewisse Aporie, wie auch in dem möglichen potentiellen Konflikt zwischen Bundesverfassungsgericht und EuGH. Allerdings: Wir müssen ja praktische Lösungen finden. Ihr Ansatz ist hier wie dort, wenn nicht zur Lösung, so doch zur Entschärfung des Problems, ein Rechtsprechungsdialog, von dem sie sich einiges versprechen, wie ihre These 8 zeigt. In ihrer positiven Intention mit einem gewissen Optimismus. Aber Optimismus braucht man als Völkerrechtler, sicherlich als Jurist allgemein, wie heute Vormittag gesagt wurde. Wir müssen an die gestaltende Kraft des Rechts glauben, auch wenn dies manchmal schwer fällt. Richtig ist sicher, dass ein universell akzeptierter Standard anzustreben ist, weil nur der im völkerrechtlichen und weltweiten Rahmen eine Chance auf Verwirklichung hat. Gleichwohl sehe ich hier einige Probleme. Das eine ist die Relativierung des Standards, was eben auch angesprochen wurde. In der Tat berechtigt das Grundgesetz nach der Rechtssprechung des Bundesverfassungsgerichts zu gewissen Relativierungen, und Art. 23 spricht nicht ohne Grund von im wesentlichen vergleichbarem Grundrechtsschutz, von demokratischen, rechtsstaatlichen etc. Grundsätzen, und das Bundesverfassungsgericht hat im Maastricht- Urteil dies ja hinsichtlich des Prinzips der Demokratie schön ausgeführt. Relativierungen sind generell erforderlich in Fällen mit Auslandsberührung, wobei hier systemimmanent wohl sicher mit dem faktischen Ansatz von Herm Poscher einiges gemacht werden kann. Meine Frage ist: Wie steht es mit der Menschenwürde? Eignet sich die für Relativierungen? Wir haben ja auch in Deutschland Probleme damit, ob sie unantastbar ist oder auch nur war. Bestehen hier unterschiedliche Austestungsmöglichkeiten oder - um es nicht so negativ zu formulieren - Konkretisierungen im Kontext? Ist es anders, wenn dies auf nationaler Ebene erfolgt, als wenn dies auf europäischer Ebene geschieht? Hierzu sagt der Europäische Gerichtshof ja im Omega-Urteil, dass die Mitgliedstaaten gewisse Konkretisierungsspielräume haben. Wie ist dies auf universeller Ebene? Also im Anschluss an die Frage von Frau Puttler: Was ist hier der völkerrechtliche Mindeststandard? Das EuG hat auf das ius cogens rekurriert, war dann aber der Ansicht, dass Rechtsschutz nicht unbedingt geboten sei. Das beruhigt mich nicht gerade. Jetzt haben Sie als eine Möglichkeit gesehen, dass unbestimmte oder konstruktiv wirkende Drohungen mit Nichtumsetzung gegebenenfalls wirken könnten, offenbar also auch von nationalen Gerichten, wenn diese gegebenenfalls bei Vollzugsmaßnahmen angerufen werden. Das Bundesverfassungsgericht hat das ja im Urteil zum europäischen Haftbefehl auch angesprochen, wahrscheinlich in Verkennung der völkerrechtlichen Verpflichtung. Aber es wäre gegebenenfalls auch ein Widerspruch zur völkerrecht- 
lichen Verpflichtung, wenn man sagt, dass der verfassungsrechtlich unbedingt gebotene Maßstab entgegensteht. Meine Frage ist: Wird das wirklich beeindrucken? Wird der Solange II-Vorbehalt hier wirklich noch ernst genommen und wie ernst ist dann die Betonung der in dem letzten Wort liegenden Souveränität, um These 8 von Herrn Poscher aufzugreifen, in der Praxis zu nehmen?

Gersdorf: Böse Zungen behaupten, dass es einer Onlinedurchsuchung durch deutsche Sicherheitsbehörden nicht bedürfe. Die weltweite Vernetzung der nationalen Sicherheitsbehörden ermöglichte es den nationalen Sicherheitsstellen, jederzeit an die relevanten Informationen heranzukommen. Es sei nicht erforderlich, dass ein Bundestrojaner - so wird die für Onlinedurchsuchungen erforderliche Software genannt - in einen Computer in Deutschland eingenistet wird. Die Onlinedurchsuchung könne auch durch israelische, pakistanische, US-amerikanische oder britische Sicherheitsbehörden durchgeführt werden. Und die Informationen könnten dann im weltweiten Informationssystem der Sicherheitsbehörden an die relevanten Stellen gelangen. Niemand weiß genau, wer der Urheber ist, und niemand weiß genau, wer was veranlasst hat, aber alle Sicherheitsbehörden sind entsprechend informiert. Es gibt zu dieser internationalen Zusammenarbeit der Sicherheitsbehörden keinerlei Alternative. Aber, Herr Nolte, ist der verfassungsrechtlich verbürgte Grundrechtsschutz angesichts dieser weltumspannenden $\mathrm{Zu}$ sammenarbeit der Sicherheitsbehörden noch hinreichend gewährleistet? Diese Frage bezieht sich nicht nur auf Grundrechtseingriffe durch die deutsche Staatsgewalt, sondern ebenso auf Grundrechtseingriffe durch ausländische Staatsgewalt. Ich möchte noch einen weiteren Punkt ansprechen. Herr Schneider hatte eingangs darauf schon Bezug genommen. Globalisierung heißt zwar nicht nur, aber doch in erster Linie Globalisierung der Kapitalströme. Im Zuge der Globalisierung können ausländische Staatsunternehmen - nicht nur ausländische Investoren inländische Schlüsselindustrien besetzen. Sie können sich in inländische Unternehmen einkaufen oder diese zur Gänze aufkaufen, die beispielsweise Telekommunikations-, Energieversorgungs- oder Eisenbahnnetze betreiben. Wie reagiert der Verfassungsstaat auf diese Fragen der Globalisierung? Kann, soll oder muss der Gesetzgeber auf diese Gefahren reagieren? Was sagt das Verfassungsrecht zu dieser wichtigen Frage der aktuellen Tagespolitik?

Ress: Was wir als einen wesentlichen Effekt der Globalisierung beobachten, ist ein Rückgang des Rechtsschutzes. Wir haben beim Europäischen Gerichtshof für Menschenrechte gewisse Ansätze, die mit der 
Bosporus-Entscheidung kamen, welche eine Vermutung für die Rechtmäßigkeit des Handelns der europäischen Organe eingeführt hat. Wir haben jetzt durch ein Obiter dictum im Behrami-Fall eine völlige Ausklammerung der Aktion des Sicherheitsrates vom Rechtsschutz des Straßburger Gerichtshofes. Wie weit soll das gehen? Sie haben, Herr Nolte, meiner Ansicht nach völlig zu recht auf die Probleme der nachfolgenden Kontrolle von Sicherheitsratsbeschlüssen, das ein allgemeines Problem der Kontrolle von Akten internationaler Organisationen ist, in Ihren Thesen 5 und 6 hingewiesen. Was ist die Alternative, wenn es solche Kontrollen nicht gibt? Würden die Gerichte unseres Staates oder anderer Staaten unter Umständen diese Fragen als Vorfragen nicht dennoch überprüfen? Ich erinnere nur: auch bei uns sind viele völkerrechtliche Fragen als Vorfrage aufgeworfen worden. In der Bankovich-Entscheidung stand als Vorfrage die Völkerrechtmäßigkeit des gesamten NATO-Einatzes im Kosovo zur Frage. Wie weit geht diese Überprüfung als Vorfrage? Im Grunde ist, was Sie hier vertreten, eine Vorfragenprüfungsreduzierung. Ich habe eine gewisse Sympathie für die These 34 von Herrn Poscher, der versucht hat, wenn ich das recht sehe, doch noch einen gewissen Rest von Rechtskontrolle zu sichern, da er schreibt, indem das Verfassungsrecht auf seine rechtsstaatlichen Standards insistiert, kann es unter Umständen auch im Widerspruch zu völkerrechtlichen Verpflichtungen einen positiven Beitrag zur Globalisierung leisten. Wie weit können wir uns, und das ist meine Frage, aus verfassungsrechtlichen Gründen einen Widerspruch zu völkerrechtlichen Verpflichtungen leisten? Und wie würde sich das auswirken? Wir kennen die Literaturäußerungen von Herrn Tomuschat und anderen zur Frage, ob der Sicherheitsrat legibus solutus ist. Ich glaube, wir stehen hier an einem wirklichen Scheidewege, da die internationale Gemeinschaft bisher nicht in der Lage war, über den IGH ein Kontrollsystem für derartige Akte internationaler Organisationen zu installieren. Und wenn Einzelpersonen erst einmal auf solch einer Liste stehen, die in einem obskuren Verfahren zustande kommt, sind deren Grundrechte dann absolet.

Kotzur: Die Referate und die Diskussionen haben, so meine ich, gezeigt, dass sich Globalisierung kaum definieren, sondern eher aus ihren Phänomenen heraus begreifen lässt. Und zu diesen Phänomenen scheint mir das Spannungsfeld zwischen Identitätswahrung und neuen Identitätszuschreibungen zu gehören. Die nationalen Gerichte, insbesondere die nationalen Verfassungsgerichte, aber auch die Gerichte regionaler bzw. supranationaler Verantwortungsgemeinschaften wie der EGMR, der EuGH oder das EuG sind für „Identitätswahrung“ durch Rechtspre- 
chung zuständig. Sie können aber auch, und das deutet Herr Nolte an, neue Identitätszuschreibungen leisten, gerade was die Grundrechte angeht. Diese Identitätszuschreibungen erfolgen durch wechselseitige Rezeption, durch einen tatsächlichen Dialog. Er ermöglicht Wechselwirkungen zwischen der nationalen und der internationalen Ebene. Grundrechtsstandards werden zwischen den jeweiligen Grundrechtsräumen „hin und her transportiert“, nationale werden internationalisiert, internationale in die nationalen Rechtsordnungen implementiert. Auf diese Weise wird, was vorher schon verfassungsstaatliche Textreserve war, was in den nationalen Verfassungen steckt, staatenübergreifend aktualisiert bzw. konkretisiert In dieser kooperativen Verwirklichung der nationalen, regionalen und internationalen Grundrechtsstandards durch die Zusammenarbeit der entscheidungszuständigen Gerichte liegt eine große Chance für die Konstitutionalisierung des Völkerrechts, die Herr Murswiek angesprochen hat. Hier können die in Verantwortung genommenen nationalen und regionalen Gerichte letztlich auch den Sicherheitsrat ein Stück weit bändigen, „zähmen“, konstitutionell einhegen. Sie sollten - darüber wird man trefflich streiten können - das vielleicht etwas deutlicher tun als das EuG in der Yusuf-Entscheidung. Durch solches Miteinander kann „Weltrecht“ entstehen, ohne dass es dazu eines Weltstaates bedürfte oder wir uns gar vor dem letztverbindlichen Richterwort eines Weltgerichts fürchten müssten.

Uerpmann-Wittzack: Ich möchte auf Fragen der Gewaltenbalance eingehen, die Sie, Herr Poscher, angesprochen haben. Sie hatten gefordert, dass der Deutsche Bundestag in internationalen Angelegenheiten stärker beteiligt wird, und Sie haben Art. 23 mit seinen Absätzen 2 und 3 GG als Vorbild gepriesen. Ich frage mich, ob der Bundestag mit einer solchen Aufgabe nicht schlichtweg überfordert ist. Franz Mayer hat das auch schon kritisch angemerkt. Soweit ich sehe, ist das einzige Parlament der Welt, das effektiv die Aushandlung völkerrechtlicher Verträge begleitet, der US-Kongress. Allerdings verfügt er über einen entsprechenden Unterbau an Mitarbeitern, der ihn in die Lage versetzt, derart komplexe Vorgänge zu begleiten. Sieht man sich Art. 23 GG in der Praxis an, so scheint mir der Einfluss des Bundesrates in Angelegenheiten der Europäischen Union wesentlich stärker zu sein als der des Bundestages. Dabei hat der Bundesrat mit den hinter ihm stehenden Ländern die große Ministerialbürokratie der Länder zur Verfügung, wiederum mit Personal, das in der Lage ist, Vorgänge in Brüssel tatsächlich in der ganzen Breite zu verfolgen. Will man den Bundestag in diesem Bereich stärken, wäre vielleicht vordringlich, dass sich der Bundestag mit einem Europäischen Dienst und, wenn man Ihnen, Herr 
Poscher, folgt, mit einem Internationalen Dienst ausstattet. Dann könnte er sich mit wissenschaftlichen Referenten in genügender Anzahl den Sachverstand und den Überblick verschaffen, um bestehende und vielleicht noch hinzuzufügende Beteiligungsrechte tatsächlich wahrzunehmen.

Weib: Eine Frage an Herrn Poscher zunächst wegen ihrer These 23, ein Wertungswiderspruch bestünde darin, dass der Bundestag in Fragen des auswärtigen Handelns der EU in dem Verfahren nach Art. 23 GG stärker beteiligt werden müsse als wenn die eigene Regierung außenpolitisch handele. Diesen Wertungswiderspruch kann ich nicht erkennen, da der Bundestag im Bereich des Handelns der eigenen Regierung sehr viel stärkere, unmittelbare Kontrollrechte hat. Als Stichworte mögen genügen: Untersuchungsausschüsse, Elektionsfunktion bis hin zum konstruktiven Misstrauensvotum.

Eine Frage an Herrn Nolte. Wenn ich Sie recht verstanden habe, dann läuft Ihr Ansatz darauf hinaus, und das wird in Ihrer letzten These 19 deutlich, dass Rechtsvergleichung und völkerrechtliche Analyse, also etwa das Bemühen eines deutschen Verfassungsgerichts, seine Entscheidung in Respektierung oder zumindest beträchtlicher Erwägung völkerrechtlicher Rechtssituationen zu fällen, letztlich $\mathrm{zu}$ neuen Legitimationsschichten für nationale verfassungsgerichtliche Jurisprudenz heranwachsen. Was die völkerrechtliche Analyse angeht, können wir das verfassungsrechtlich gut einordnen wegen Art. 23 und 24 GG und der Völkerrechtsfreundlichkeit des Grundgesetzes. Ich frage mich aber, wie es mit der Rechtsvergleichung aussieht. Dort haben wir nicht solche unmittelbaren verfassungsrechtlichen Ankerpunkte, um Rechtsvergleichung als Argumentationsmöglichkeit für eine Entscheidungsfindung durch das Bundesverfassungsgericht einzuführen. Und daran knüpfe ich die nächste Frage an. Ist nicht diese Vorstellung des Rechtsdialoges zwischen verschiedenen internationalen und nationalen Gerichten und Verfassungsgerichten vielleicht eine sehr kontinentaleuropäische Vorstellung? Wie würde der US Supreme Court sich verhalten? Wenn man sich erinnert, was im Fall La Grand passiert ist, nämlich dass der Supreme Court die Vollstreckung einer Todesstrafe nicht einstellt, obgleich der IGH etwas anderes anmahnt, dann denke ich doch, dass der Supreme Court auf solch einen Rechtsdialog zum Völkerrecht und auf rechtsvergleichende Argumente etwa aus Entscheidungen des Bundesverfassungsgerichts, keinen Wert legt. Ich fürchte das wäre vielleicht in Großbritannien ähnlich zu sehen. Insoweit frage ich mich zumindest, ob Ihr Konzept wirklich global geeignet wäre? 
Häberle: Erlauben Sie diesen Spontanbeitrag. Mein Vorredner hat möglicherweise Recht in Bezug auf den US Supreme Court. Ich überblicke ein wenig die Judikatur der lateinamerikanischen Verfassungsgerichte. Es ist ganz erstaunlich, wie das peruanische Verfassungsgericht, der mexikanische Supreme Court und weitere lateinamerikanische Verfassungsgerichte, etwa in Brasilien, sich immer wieder beim deutschen Bundesverfassungsgericht und bei deutschen Wissenschaftlern Rat holen und deren Paradigmen schöpferisch rezipieren.

Masing: Ich möchte den Aspekt Souveränität und Demokratie im Referat von Herrn Poscher aufgreifen. Ihnen ging es, wenn ich recht verstanden habe, um eine Klein- und Abarbeitung der Legitimationsprobleme unter der Zielsetzung, Frieden mit einer ohnehin unaufhaltbaren Entwicklung zu schließen. Sie treten hierbei einer Überforderung und Überladung von Verfassungsprinzipien entgegen, die unter den Bedingungen der Internationalisierung nur enttäuscht werden können. Innerstaatlich haben mich diese Ausführungen über weite Teile auch sehr überzeugt. Sie haben dogmatisch stringent einiges an Klarheit geschaffen. Allerdings scheinen mir die Änderungen der Legitimationsstrukturen, die mit der Globalisierung verbunden sind, doch weiterzugehen und mit dieser Blickrichtung noch nicht ganz erfasst zu sein. Anders gewendet: Mir scheint Ihre Antwort letztlich zu äußerlich. Und obwohl Sie die Tür für die Internationalisierung eher öffnen wollen, sehe ich die Gefahr, dass man sich mit dieser Perspektive zu sehr auf eine nationalstaatliche Perspektive zurückzieht und sich mit dieser zufrieden gibt.

Reduziert heißt Ihre These: Souveränität und Legitimität haben primär eine nationalstaatliche Dimension, und diese verhindert nicht, dass wir international zusammenarbeiten und uns selbst binden. Im überstaatlichen Kontext ist evident, dass wir nur einen begrenzten Aktionsfreiraum haben und uns auf die internationalen Kräfteverhältnisse und Verhandlungssituationen einlassen müssen. Dem widerspricht weder die Idee der Souveränität noch der Demokratie. Das ist - zunächst gesehen - richtig. Allerdings verlieren wir, glaube ich, angesichts des wachsenden Ausmaßes der Internationalisierung damit doch die Wurzeln des Demokratieprinzips. Denn die Wurzeln der Demokratie liegen in der Idee der Selbstbestimmung auf der Grundlage von Gleichheit und damit insbesondere auch in der Idee der Gesetzgebung, d.h. der Setzung von Normen in Bezug auf ein kollektiv definiertes gemeines Wohl und auf gemeinsame Interessen - im Gegensatz zu einem bloßen Aushandeln von partikularen Interessen wie zwischen Ständen, alten Landschaften oder ähnlichem. Wenn die Normerzeugung demgegenüber, wie es heute zunehmend der Fall ist, internationalisiert wird und vom Gesundheits- 
über das Energierecht zu immer weiteren Fragen der Regulierung auf internationale Gremien übergeht, wenn de facto die Normensetzung also immer weiter in die Verhandlungsmasse eines internationalen do ut des gerät, müssen wir uns doch fragen, woher sich Legitimität dann in einem substantiellen Sinne herleitet. Das Problem beginnt damit, dass es so der Normsetzung oft schon an Zurechenbarkeit fehlt. Es ist unklar, wer aus welchem Grunde für die Gestaltung welcher Normen verantwortlich ist - wie gerade die allein durch Durchsetzungsmacht konstituierte Basel 2-Gruppe verdeutlicht. Entsprechend fehlt es an jeder Transparenz - in exemplarischer Weise deutlich, wenn sich Regulierungsgruppen informell treffen und entscheidenden Standards vorfestlegen, nach denen innerstaatlich dann reguliert wird. Überhaupt fehlt es an einem kollektiven Diskurs darüber, was das Gemeinsame denn sein soll, es mangelt an einer Entscheidung, die in Bezug auf das Ganze getroffen wird - und zwar sowohl in Bezug auf die übernationale, als auch in Bezug auf die nationale Ebene. Hierüber gerät dann schließlich aber auch die Grundlegung der Herrschaft in der Idee der Gleichheit und Freiheit in Gefahr. All dieses kann man, denke ich, nicht dadurch ersetzen, daß man analoge Strukturen zu Art. 23 Abs. 2 und 3 GG schafft. Diese sind doch nur traurige Hilfskrücken. Wenn wir uns gerade Art. 23 Abs. 2 und $3 \mathrm{GG}$ näher ansehen - ich erinnere nur an den europäischen Haftbefehl (und es gibt neue Dissertationen, die das in allgemeinerer Weise bestätigen) - so zeigt sich schnell, dass das Parlament mit dieser Form von Einbindung im Grunde völlig überfordert ist. Die Vorschriften des Art. 23 Abs. 2 und 3 GG sind strukturell unzureichend und funktionieren in der Praxis kaum.

Kurz zusammengefasst: Mir scheint es wichtig, dass wir Demokratie als mehr als eine Technik verstehen. Es geht hier um eine substantielle Idee von Legitimation, und wir sollten auch in einem internationalen Kontext versuchen, die Substanz dieser Idee zu retten, sie neu zu konstruieren oder vielleicht notwendigenfalls - horibile dictu - auch zu ersetzen. Jedenfalls scheint es mir dafür nicht ausreichend, und das nur ein letzter Satz zu Herrn Nolte, auf ein pragmatisches Managing der verschiedenen Gerichtsbarkeiten zu verweisen und die Flucht in eine Kasuistik anzutreten. Wir brauchen eine Rechtsidee - und den Stachel, diese zu suchen, dürfen wir uns nicht ziehen lassen.

Poscher: Zunächst zu der Frage der internationalen Finanzmärkte: Das ist ein Themenfeld, wo sich zeigt, dass die internationalen Kooperationen eben nicht nur zu Souveränitätsbeschränkungen führen, sondern dass es Fragen gibt, die man nur international lösen kann. Auf der nationalen Ebene allein wird man das Problem der Finanzmärkte nicht 
lösen können. Deshalb wird man unter dem Druck der Verhältnisse unter Umständen zu einer internationalen Regelung kommen, oder man wird die entsprechenden Krisen in Kauf nehmen müssen. Aber das Themenfeld zeigt, wie Handlungsoptionen des Nationalstaats erst durch die Internationalisierung entstehen, denn allein national können wir das Phänomen nicht regeln. Dass auf der internationalen Ebene immer wieder Fortschritte gemacht werden, lässt sich an vielen Bereichen ablesen etwa bei der Regulierung des Internet, wo man jetzt internationale Standards entwickelt, die versuchen, das Problem aufgedrängter Nachrichten zu bewältigen. Solche Prozesse müssten auch in Gang kommen, um Probleme der Finanzmärkte zu adressieren. Nur auf dieser Ebene werden sie sich lösen lassen.

Der nächste Punkt, die Souveränitätsfrage, war ja ein Punkt, zu dem ganz viele Fragen und Anregungen kamen. Dies ist in der Tat kompliziert, und zwar deshalb kompliziert, weil man ganz verschiedene Ebenen auseinander halten muss. Die beiden Ebenen, die ich versucht habe bei der Souveränitätsfrage zu trennen, sind zunächst einmal die normative und die faktische. Dann wird das Ganze dadurch verkompliziert, dass wir es nicht nur mit einer Ordnung zu tun haben, sondern mit einem Rechtspluralismus. Wir haben mehrere Rechtssysteme, für die jeweils die Frage nach Normativität und Faktizität zu untersuchen ist. Ich habe versucht, die zurzeit vorliegende Konstellation dadurch zu erklären, dass wir verschiedene Ordnungen haben, die unter Umständen jede für sich einen Vorrang- und Souveränitätsanspruch erheben. Das Völkerrecht verlangt, dass es durchgesetzt wird. Es kennt keine Klausel, die besagt, dass das nationale Recht im Zweifel vorgeht, wenn es sich um Verfassungsrecht handelt. Aber ebenso kennt das Verfassungsrecht auch keine Formel, die dem Völkerrecht den unbedingten Vorrang einräumt. Normativ können diese Ordnungen in einen Konflikt treten, und es gibt keine übergreifende Ordnung, die diesen Konflikt auflösen könnte. Deshalb werden sich die Probleme nur im Faktischen lösen. Was ich versucht habe aufzuzeigen, war, welche Funktion - das ist dann wieder eine faktische Beschreibung - diese normative Konfliktlage hat. Eine Funktion liegt darin, dass so ein Dialog zwischen den Ebenen ermöglicht wird, dass so Anregungen in beide Richtungen fließen können. Wenn wir das aufgeben würden, wenn wir die eine Ordnung der anderen Ordnung vollständig unterordnen würden, wenn diese Unterordnung der einen unter die andere mit in die normative Selbstbeschreibung aufgenommen würde, dann würde sich diese Konstellation auflösen, dann hätten wir harmonische Verhältnisse. Dann würden wir uns die Frage gar nicht stellen, wie wir verfassungsrechtlich mit den Sicherheitsresolutionen umzugehen haben, sondern wenn es den absoluten Vorrang der Völkerrechts- 
ordnung auch nach der eigenen Verfassungsordnung gäbe, dann hätte sich das Problem damit gelöst, dass der Sicherheitsrat die Frage entschieden hat. Aber so ist die Konstellation nicht. Insofern stimmt die Beschreibung, nach der die Souveränität in der Schwebe hängt, weil wir die nationale Souveränität und den Vorranganspruch, den das Völkerrecht erhebt, auseinander halten müssen. Das bedeutet in letzter Konsequenz, dass es jedenfalls verfassungsrechtlich zulässig ist, das Völkerrecht zu brechen, um Verfassungsbestimmungen in internationalen Kooperationen durchzusetzen. Dagegen spricht nicht die Verfassung, wohl aber das Völkerrecht. Der entscheidende Effekt dieser Konstellation liegt jedoch nicht darin, dass das Völkerrecht ständig gebrochen werden darf, sondern darin, dass diese Möglichkeit auf der völkerrechtlichen und auf der internationalen Ebene antezipiert wird und dort bestimmte Reaktionen auslösen kann. Ich hatte ja versucht, jedenfalls drei Beispiele aufzuzeigen, an denen man sehen kann, wie sich dies auswirkt.

Die Trennung der Ebenen ist auch der Grund, warum ich skeptisch gegenüber Strategien wäre, die Ebenen ineinander zu verschieben, indem man versucht - das war ja auch eine Anregung, die aus Ihrem Kreis kam -, im nationalen Verfassungsrecht das Völkerrecht zu rekonstruieren, um doch noch etwas aus dem Völkerrecht rauszuholen, was die Spannung erträglicher machte. Dies ist auch die Tendenz des Europäischen Gerichts erster Instanz, das sich aufschwingt, dem Sicherheitsrat zu erklären, was im Völkerrecht zum ius cogens zählt. Demgegenüber würde ich auch für das Bundesverfassungsgericht empfehlen, keine völkerrechtlichen Maßstäbe zur Kontrolle von Maßnahmen des Sicherheitsrats heranzuziehen, sondern bei den eigenen Maßstäben zu bleiben und zu schauen, ob diese Maßstäbe in der Völkerrechtsordnung berücksichtigt werden oder nicht.

Die zweite Frage, die ja auch mehrfach kam, war die Frage, wie es mit dem Bundestag steht. Ist es nicht viel zu optimistisch, über den Weg des Art. 23 GG, der sich praktisch noch nicht so beeindruckend entwickelt hat, noch mehr erreichen zu wollen? Ich denke in der Tat, dass dies eine Herausforderung ist. Doch die Frage der Organadäquanz von Aufgaben ist eine Gleichung mit zwei Variablen. Wenn man dem Bundestag jetzt die Aufgabe zumutet, auch auf der internationalen Ebene präsent zu sein und internationale Prozesse mitzugestalten, dann müssen seine Mittel und Ressourcen entsprechend erweitert werden, so dass er diese neuen Aufgaben organadäquat wahrnehmen kann - und wenn man sie so ausweiten muss wie im Fall des amerikanischen Senats. Der Bundestag hat dies übrigens im Ansatz auch schon getan. Nach der Einführung von Art. 23 GG n.F. hat man etwa die Anzahl der Mitarbeiter in den Fraktionen erhöht. Darüber hinaus werden weitere institutionelle Ver- 
änderungen im Bundestag nötig sein, wenn er seine Internationalisierungsaufgaben adäquat wahrnehmen soll, um auch noch auf diesem Gebiet die Prozesse politisch zu filtern und die nötige politische Aufmerksamkeit bereitzuhalten. Dies ist eine institutionelle Aufgabe für den Bundestag, die man dadurch befördern kann, dass man ihm noch mehr solcher Aufgaben überträgt, damit er sich stärker institutionell bewusst wird, welche Anforderungen an ihn gestellt werden. Eine weitere Aufgabe wird ja auf jeden Fall auf ihn zukommen, nämlich die Überwachung des Subsidiaritätsprinzips. Die Tendenz, dass der Bundestag stärker in internationale Kooperationen eingebunden wird, wird also ohnehin weiter voranschreiten.

Der Wertungswiderspruch, - das sei sofort eingeräumt - das ist auf dem Thesenpapier ein bisschen scharf formuliert. Ich würde vielleicht genauer von einer Wertungsunebenheit sprechen. Aber immerhin ist es kurios, dass der Bundestag, wenn die EU - und sei es nur im Rahmen der zweiten oder dritten Säule - einen völkerrechtlichen Vertrag abschließt, entsprechend über die Vorlagen informiert werden muss, während er, wenn derselbe Vertrag durch die eigene Regierung abgeschlossen wird, nach dem geltenden Reglement nicht in gleicher Weise Kenntnis erlangen muss.

Zum Schluss noch eine Anmerkung zu der Demokratiefrage. In der Tat, man kann sich fragen, leistet das noch die Substanz der Demokratie? Der Hauptgedanke war, dass man jedenfalls zurzeit die demokratische Legitimation wesentlich aus dem nationalen Kontext speisen muss. Man kann dann versuchen, durch institutionelle Anpassungen dafür $\mathrm{zu}$ sorgen, dass die demokratisch vorausgesetzten Mechanismen auch bei Internationalisierungsthemen funktionieren und dass auch insoweit eine politische Aufmerksamkeit und Wachsamkeit gewährleistet ist. Dazu gehören auch Ansätze zu Öffentlichkeitsbeteiligungen von Nichtregierungsorganisationen auf der internationalen Ebene, die in die nationalen Räume zurückwirken und insoweit einen Beitrag zur demokratischen Legitimation leisten können. Ansonsten gehört zur Beschäftigung mit der Demokratisierung der Globalisierungsphänomene aber auch die Einsicht, dass man nur beschränkten Einfluss hat, wenn man sich an internationalen Regulierungen beteiligt. Dass man nicht omnipotent über die Ergebnisse bestimmen kann, sondern im Zweifel nur etwas Besseres bekommt als die beste nationalstaatliche Regelung, die im Alleingang vorgenommen werden könnte - dieses Faktum muss man auch demokratietheoretisch anerkennen.

Nolte, G.: Ich möchte mich für Ihre Beiträge herzlich bedanken. Ich hatte schärfere Einwände gegen meine Grundthese zu den Listingver- 
fahren des Sicherheitsrates befürchtet. Aber lassen Sie mich zunächst allgemein anfangen: Warum habe ich den Aspekt Sicherheitsrecht herausgegriffen und nicht das, woran man vielleicht auch denken könnte, nämlich die internationalen Finanzströme? Nun, die Freiheit der Finanzströme ist als verfassungsrechtliche Fragen jedenfalls rechtlich nicht so greifbar und ich dachte, ich sollte Ihnen etwas Greifbares präsentieren. - Herr Gersdorf, dass man im Bereich Onlinedurchsuchung Schutz gegenüber ausländischer Staatsgewalt braucht, mag grundsätzlich richtig sein, aber hier stoßen wir gerade auf das Phänomen, auf das ich aufmerksam machen wollte. Wir dürfen es mit der Schutzpflichtdimension bei der Grundrechtsinterpretation nicht übertreiben, sonst stoßen wir an Sinngrenzen. Ich fürchte, unser Verfassungsrecht kann uns vor solchen Gefahren nicht schützen. - Was ist eigentlich neu an der Globalisierung? Vieles daran ist nicht neu und das, was wir heute als Globalisierung bezeichnen, kann man auch als Intensivierung oder vielleicht als Wiederaufnahme eines Prozesses ansehen, der schon in der zweiten Hälfte des 19. Jahrhunderts besonders stark empfunden wurde. Ich stimme Ihnen völlig zu, Herr Häberle, die Menschenrechte sind nicht nur Völkerrecht, sondern auch nationales Verfassungsrecht. Und sie kommen nicht nur aus einer nationalen Verfassung, sondern aus vielen nationalen Verfassungen. Deshalb sehe ich diese scharfe Trennung zwischen Völkerrecht und Rechtsvergleichung gar nicht. Die Urteile, die ich verglichen habe, betreffen ja zumeist die Interpretation des Völkerrechts. So ging es in den Entscheidungen des House of Lords oder des US Supreme Court, über die ich gesprochen habe, wesentlich um die Interpretation von Völkerrecht aus englischer, amerikanischer Sicht. - Ich bin sehr zuversichtlich, Herr Jochum, dass man sich im Wege der Rechtsvergleichung nicht auf einen US-amerikanisch geprägten Mindeststandard einigen wird. Vielmehr denke ich, wie es auch Herr Häberle andeutet, dass die Vereinigten Staaten von Amerika in Bezug auf viele verfassungsrechtliche Fragen die große Ausnahme in der Welt und gerade nicht der Maßstab sind. Der Rest der Welt steht in einem viel intensiveren Dialog und gegenseitigen Rezeptionsprozessen. - Herr Bausback, es ist natürlich eine sehr berechtigte Frage, ob dieser Rechtsprechungsdialog immer zu einer menschenrechtsfreundlichen Interpretation führt. Das ist in der Tat nicht garantiert. Es ist aber unsere beste Hoffnung. Denn die Gerichte sind Institutionen, die ein institutionelles Eigeninteresse daran haben, die Grundrechte zu bewahren und zu schützen. Und ich wüsste nicht, welche bessere Chance besteht, als auf das Ethos der Richter zu vertrauen, das wir ihnen vielleicht auch an den Universitäten beibringen können. Ich habe - wie Ihnen vielleicht aufgefallen ist - nicht von Weltverfas- 
sung gesprochen, nicht von Diktatur, nicht von Souveränität. Ich habe die großen Begriffe vermieden. Und ich glaube, die großen Begriffe sollten hier im Grundrechtsbereich auch vermieden werden. Auf grundrechtlichen Mindeststandards kann man unabhängig davon bestehen, ob sich ein politisches Gebilde als Staat versteht, als Teil einer europäischen Verfassung, als Element einer Weltverfassung oder als Knoten in einem Netzwerk. Am wichtigsten ist das richtige und möglichst international kompatible Grundrechtsverständnis. - Der völkerrechtliche Mindeststandard, auf den ich mich in Hinblick auf die Problematik der VN-Listen beziehe, ist, wie Herr Paulus richtig andeutet, nicht so niedrig wie der Begriff Mindeststandard nahelegt. Es gibt etwa inzwischen auch Judikate des Internationalen Strafgerichtshofs für Jugoslawien, in denen der Begriff des ius cogens bzw. der völkerrechtliche Mindeststandard in einer Weise ausgefüllt wird, der auch anspruchsvollere nationale Verfassungsrechtler durchaus Respekt entgegenbringen müssten. Ich habe auch nichts dazu gesagt, ob bestimmte Maßnahmen oder Aspekte der jetzigen Sicherheitsratsregime diesem Mindeststandard entsprechen oder nicht. Ich habe vielmehr versucht, eine methodische Grundorientierung zu entwickeln, die - ich gebe es $\mathrm{zu}$ - auch aus strategischen Gründen ein Plädoyer für Kasuistik und Pragmatik enthält. Hier gibt es ein System kommunizierender Röhren. Der Sicherheitsrat ist nicht ein blinder Diktator, sondern in ihm sitzen mindestens fünf Regierungen, die ein sehr starkes Interesse daran haben, dass dieses Instrument auch in Zukunft noch funktioniert. Es ist aber auch gemeinsames Interesse der Menschheit, dass dieses System funktioniert und nicht infolge eines Schocks über ungewöhnliche Maßnahmen mit breit formulierten Einwänden grundsätzlich blockiert wird. Ich vertraue darauf - und ich glaube auch, dass das Grundgesetz aufgrund seiner Bezugnahme auf das VN-System darauf vertraut -, dass sich der Sicherheitsrat in Interaktion mit den Staaten und sonstigen Beteiligten an den in vergleichbaren Situationen anwendbaren Mindeststandards orientieren wird. In diese Richtung kann er gebracht werden, wenn Maßnahmen stark einzelfallbezogen auf ihre evidente Zulässigkeit oder Unzulässigkeit hin geprüft werden. Dann müssen manche große Fragen nicht unbedingt sofort gestellt und gelöst werden bzw. sie können sich durch Reform auf anderer Ebene erledigen. Mein Plädoyer für Kasuistik rührt auch daher, dass wir manchmal dazu neigen, zu schnell zu verallgemeinern. Wir neigen dazu, grundsätzliche Maßstäbe für den Sicherheitsrat formulieren zu wollen, ohne die genauen Konstellationen vor Auge zu haben, die sich ergeben können. - Das System der Vereinten Nationen ist fragiler als das System der Europäischen Union, weil es bei seiner Anwendung weniger auf einer evidenten gemeinsamen Interessengrundlage beruht. Dieses Sys- 
tem ist aber wertvoll und es ist notwendig, dass es sich durch Dialogprozesse integriert und weiterentwickelt. - Herr Masing, Kasuistik kann in manchen historischen und sachlichen Konstellationen das Richtige und in manch anderen das Falsche sein. Vielleicht sind wir in Bezug auf die Entwicklung des Sicherheitsrates in einer im Ansatz ähnlichen Situation wie es die Bundesrepublik in den sechziger Jahren gegenüber der europäischen Wirtschaftsgemeinschaft war. Damals wurden bestimmte grundsätzliche und überraschende Positionen zum ersten Mal auf europäischer Ebene formuliert, dann hat aber eben auch ein gegenseitiger Koordinierungsprozess stattgefunden. Dieser Koordinierungsprozess ist im Bereich der Sicherheit sehr viel schwieriger als im Bereich der Wirtschaft. Sicherheit ist weniger leicht regionalisierbar. Weltweit gibt es in Hinblick auf Sicherheit aber sehr unterschiedliche Maßstäbe. Wenn wir die Sicherheit haben wollen, müssen wir diese anderen Maßstäbe zumindest berücksichtigen. Wie ein Mindestniveau rechtlich genau zu konstruieren ist, darüber kann man nachdenken. Ich habe mich dabei auf ius cogens und auf allgemeine Rechtsgrundsätze konzentriert. Ich habe nicht, wie Herr Paulus das vorschlägt, auf die in Art. 25 der VNSatzung enthaltenen allgemeinen Kompetenzen des Sicherheitsrates rekurriert. Hier besteht meines Erachtens die Gefahr, dass die gemeinsamen Maßstäbe leichter verloren gehen als wenn wir uns auf die weltweit anerkannten Grundrechte und auf den gemeinsamen menschenrechtlichen Mindeststandard beziehen. 